University of Louisville

ThinkIR: The University of Louisville's Institutional Repository

Electronic Theses and Dissertations

$12-2006$

\title{
A programmable mask for direct write lithography.
}

Kunal Pharas 1979-

University of Louisville

Follow this and additional works at: https://ir.library.louisville.edu/etd

\section{Recommended Citation}

Pharas, Kunal 1979-, "A programmable mask for direct write lithography." (2006). Electronic Theses and Dissertations. Paper 1128.

https://doi.org/10.18297/etd/1128

This Master's Thesis is brought to you for free and open access by ThinkIR: The University of Louisville's Institutional Repository. It has been accepted for inclusion in Electronic Theses and Dissertations by an authorized administrator of ThinkIR: The University of Louisville's Institutional Repository. This title appears here courtesy of the author, who has retained all other copyrights. For more information, please contact thinkir@louisville.edu. 


\title{
A PROGRAMMABLE MASK FOR DIRECT WRITE LITHOGRAPHY
}

\author{
By \\ Kunal Pharas \\ B.E. (Electrical Engineering) \\ Engineering College Bilaspur, C.G., India. \\ August, 2002
}

\begin{abstract}
A Thesis
Submitted to the Faculty of the

Graduate School of the University of Louisville

in Partial Fulfillment of the Requirements

for the Degree of

Master of Science

Department of Electrical Engineering

University of Louisville

Louisville, Kentucky
\end{abstract}

December 2006 
Kunal Pharas

A Thesis Approved on

November 29, 2006

By the following Thesis Committee:

Shamus McNamara, Ph.D., Thesis Director

Kevin M Walsh, Ph.D.

Sergio B Mendes, Ph.D. 


\section{ACKNOWLEDGEMENTS}

I would like to express my gratitude to my advisor, Dr. Shamus McNamara, for his perennial support and inspiration that went into this thesis without which I would not have been able to achieve this task. I would also like to thank the technical assistance and support of Mark Crain, the cleanroom manager, as well as my colleague, Chakravarthy Yamarthy, a PhD student. I would also like to thank the staff of the cleanroom for helping me out with new instruments. Additional thanks go to the director of the cleanroom, Dr. Walsh, who provided me with such a great environment to work with in the cleanroom which has one of the best facilities as a school cleanroom in the nation.

Last but not the least I wish to thank my parents who raised me, always supported me and loved me throughout my life. 


\section{ABSTRACT \\ A PROGRAMMABLE MASK FOR DIRECT WRITE LITHOGRAPHY \\ Kunal Pharas \\ November 29, 2006}

Lithographic processes for printing device structures on integrated circuits plays a major role in the semiconductor industry. This project aims at designing and fabricating a programmable mask for a direct write lithography system which can achieve higher throughput at a reasonable cost for the semiconductor industry in the future. The device has apertures of different sizes which can be used as programmable masks by opening and closing the shutters over them. The shutters are actuated by electrostatic comb drive actuators which are microfabricated nickel structures electroplated on copper over a sacrificial layer and are released later by a sacrificial etch. The high aspect ratio apertures are etched through the wafer using deep reactive ion etching (DRIE) stopping at the oxide layer. The optical image of the developed photoresist that was exposed through the apertures resembles almost identical feature size and linewidth measurement of the pattern exposed. Future developments regarding the optimization of micromechanics and optics have also been discussed. 


\section{TABLE OF CONTENTS}

Page

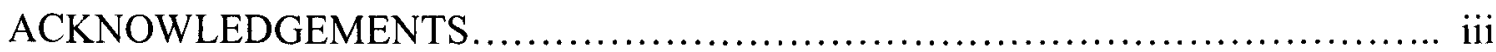

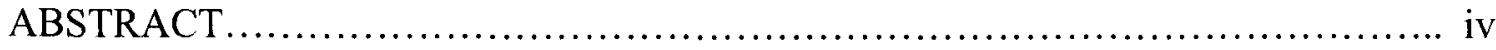

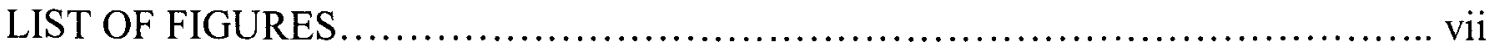

\section{CHAPTER}

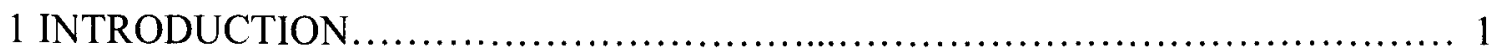

1.1 Methods of Direct Write Lithography.............................................. 1

1.1.1 Electron Beam Lithography............................. 2

1.1 .2 Ion-Beam Lithography.......................................... 2

1.1.3 Laser Beam Lithography................................. 4

1.1.4 Scanning Probe Lithography............................... 4

1.2 Previous Implementations of Optical DWL......................... 6

1.2.1 MIT's Zone Plate Array.................................... 6

1.2.2 Direct Write Lithography Through a Programmable Phase Modulating Spatial Light Modulator......................... 7

$1.3 \quad$ Shutters....................................................... 9

1.3.1 Texas Instrument's Deformable Mirror Device................... 9

1.3.2 Micro Shutters of NASA........................................... 10

1.3.3 Micromachined Motor.................................... 12

1.4 Implementation of Direct Write Lithography........................ 12

1.4.1 Optical Shutter............................................. 13

1.4.2 Fabrication of Programmable Mask......................... 14

1.4.3 Potential of DWL.................................................... 14

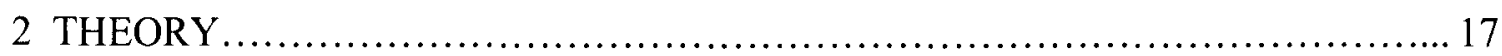

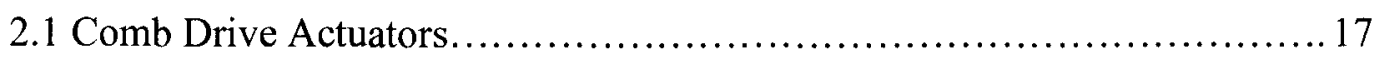

2.1.1 Analysis and Design of the Comb Drive.................................. 18

2.2 Electrostatic Cantilever Actuator................................ 25

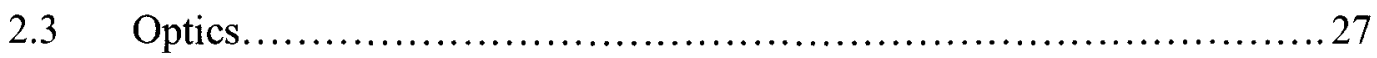

3 FABRICATION PROCESS .............................................. 29

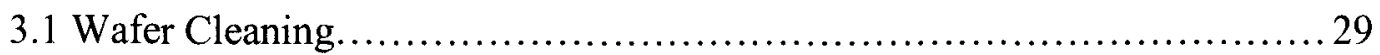

3.2 Wafer Doping ................................................... 30 


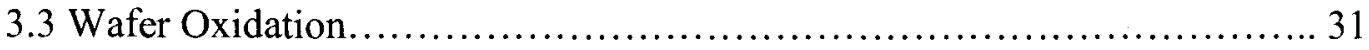

3.4 Contact Mask........................................................... 32

3.5 Aluminum Sputtering................................................ 33

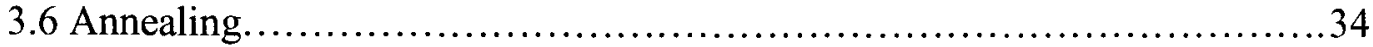

3.7 Image Reversal........................................................... 34

3.8 Chrome Layer......................................................... 36

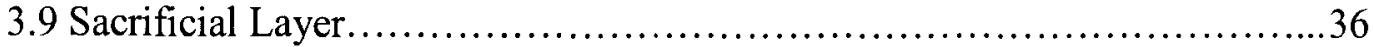

3.10 Seed Layer.............................................................. 37

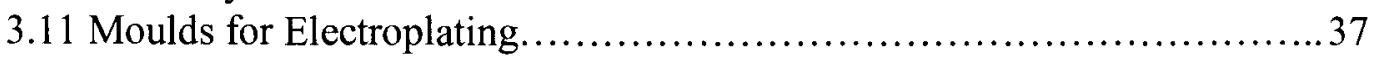

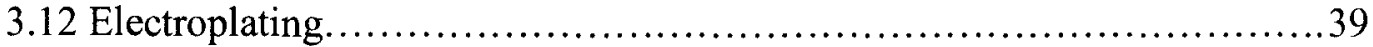

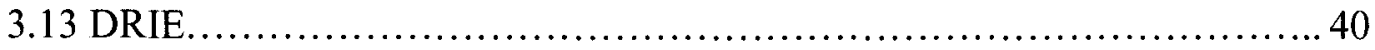

3.14 Etching of Sacrificial Layer............................................. 42

4. RESULTS........................................................................... 43

4.1 Contact Resistance Measurements.................................... 43

4.2 Resistivity of the Deposited Film..................................... 46

4.3 Test Structures to Measure Stress......................................... 47

4.4 Fabrication Results................................................... 49

4.4.1 Thick Photoresist as Electroplating Mould.......................49

4.4.2 Electroplated Nickel Structures................................51

4.4.3 DRIE of Apertures........................................53

4.4.4 Sacrificial Layer Etching..................................... 54

4.5 Test Results for Comb Actuators......................................... 57

4.6 Optical Image of Exposed Apertures................................. 57

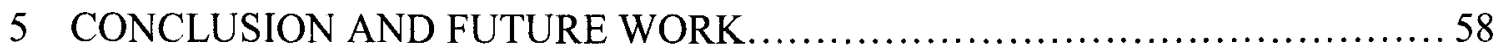

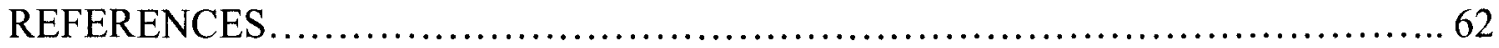

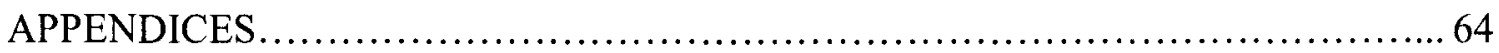

A : FABRICATION OUTLINE ..................................................64

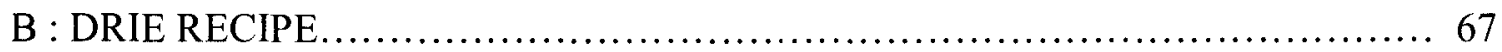

C : L-EDIT DESIGN FOR EACH MASKING LAYER............................. 68

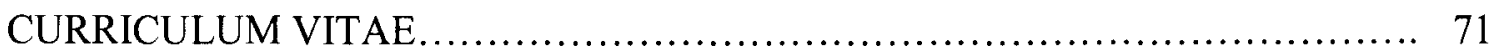




\section{LIST OF FIGURES}

1.1 Diagram Illustrating Principle of Ion Beam Lithography .........................

1.2 (a) Schematic of the micromachined scanning thermal microscopy probe, and (b) SEM of the 8-probe array surface micromachined from polyimide on a $\mathrm{Si}$ substrate. Scanning Probe Lithography.... .5

$1.3(a, b)$ Lines of $500 \mathrm{~nm}$ width written by patterning successive dots with $200 \mathrm{~nm}$ spacing ( $1 \mathrm{~s}$ heating per dot) can be seen after partial development of the photoresist. (c,d) Parallel lithography is demonstrated where two adjacent probes in the 8 probe array simultaneously generate the same pattern. Patterns Obtained with Scanning Probe Lithography......................................... 5

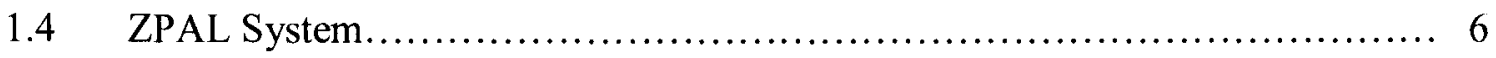

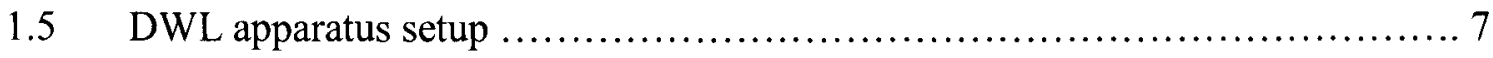

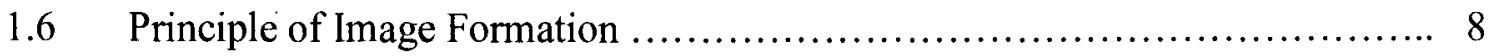

1.7 i) Optical Cross Connect formed by tilting mirrors ii) SEM images of DMD micromirror array at different stages of fabrication ........................ 10

1.8 i) Mechanical and electrostatic actuated shutter ii) Magnetic and electrostatic actuated shutter

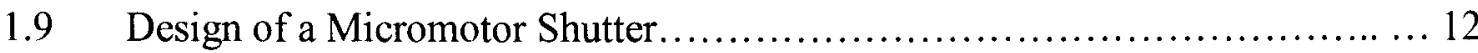

1.10 i)Schematic of the Programmable DWL ii) Cross Section of Programmable Mask.....................................................................13

2.1 Schematic of Comb Fingers. Above: Top view of one set of combs. Below: Cross-sectional view of combs, showing that the fixed combs are thicker than the moving combs. ....................................................... 18

$2.2 \quad$ Parallel Plate Capacitor................................................... 20

2.3 Folded Flexure Spring a) Top view b) Cross sectional view.................. 21

$2.4 \quad$ Equivalent Spring System............................................... 22 
2.5 Layout Showing Comb Drive Dimensions when a) the shutter is open b) the shutter is closed.

2.6 Graph Showing Displacement of Comb Actuator as a Function of Applied Voltage.

2.7 Cantilever Beam Actuator............................................. 25

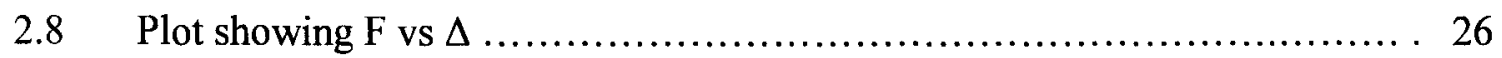

2.9 Cantilever Beam Configurations................................... 27

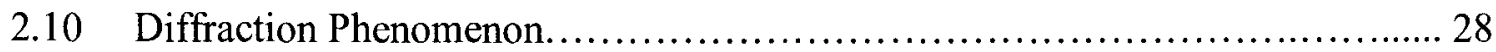

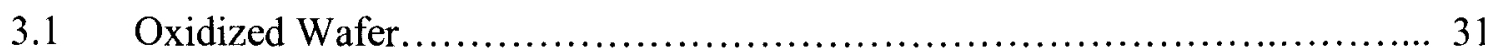

Contact Windows on Oxide......................................... 32

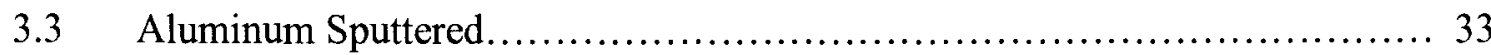

Aluminum just on the pads.......................................... 34

Positive Photoresist Reaction.................................................. 35

3.6 Reaction during Reversal Bake..........................................

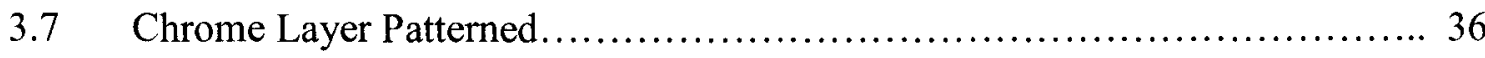

$3.8 \quad$ Sacrificial Layer Patterned.......................................... 36

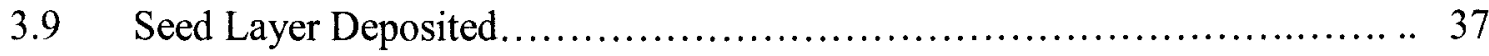

3.10 Moulds Formed for Electroplating................................... 37

3.11 Nickel Electroplated over Copper.................................. 39

3.12 Hole Etched Through Wafer with DRIE.............................. 40

3.13 Sacrificial Layer Etched to Free the Structure.......................... 42

4.1 Schematic showing the current path between contact pads on the silicon substrate. There is a contact resistance per unit area $\left(R_{c}\right)$ between the pad and the substrate, and the substance has some resistance to it $\left(R_{1}\right) \ldots \ldots \ldots \ldots \ldots \ldots \ldots \ldots \ldots \ldots, 43$

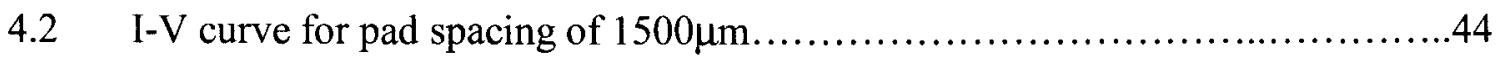




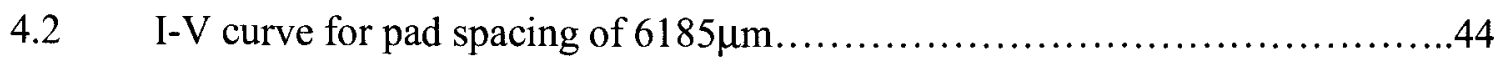

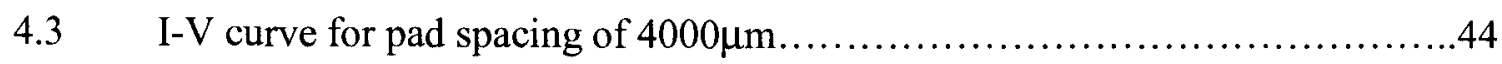

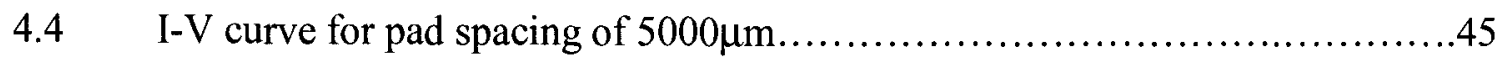

4.5 Test Structure Used to Measure the Contact Resistance..................... 45

4.6 Van Der Pauw Structure a)on Mask b)on Wafer........................... 46

4.7 Stress test structures for measuring strain in electroplated nickel, the left diagram is from the mask and the right one is from the wafer.........................44

4.8 The spacing between the moulds of the comb fingers has a thin layer of photoresist layer remaining on the substrate................................50

4.9 AZP4903 mould as seen under the SEM. The walls are almost vertical with a little slope of about 5 degrees. The photoresist is only half developed..........50

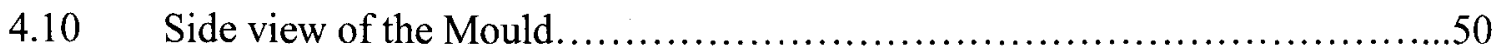

4.11 A Picture of Four Comb Drive Dies taken with a Microcamera...............51

4.12 A Detailed Picture of a Comb Drive............................................51

4.13 SEM Picture of the Comb Fingers Suspended in Air with the Seed Layer at the base ....................................................................... 52

4.15 Top view of the Combs under SEM..................................52

4.16 Picture showing Good Fabrication result. The Fingers Maintain their

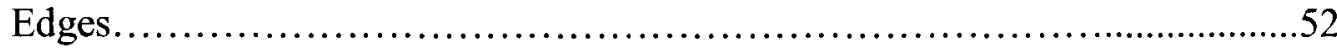

4.17 Top view of the $15 \mu \mathrm{m}$ Aperture when Illuminated from the Top and Bottom Sides Simultaneously. This Image was taken using a 20x Objective............53

4.18 Optical Images of the Light Transmitted Through the Programmable Mask at Various Resolutions..............................................................53

4.19 SEM picture of Alignment marks after Etching in Plasma Asher. Square hole is through wafer Etch. Missing letters of "UofL" shows Poor Adhesion of Nickel to Susbtrate. .54 
4.20. SEM picture of the Comb Fingers after Etching in Plasma Asher. Free Combs are touching the Fixed fingers showing Incomplete Etch and Poor Adhesion....................................................................55

4.21 SEM picture of the Shutter showing the DRIE hole in the wafer after Etching in Plasma Asher. The shutter is $20 \mu \mathrm{m}$ wide. The DRIE hole did not go through the Substrate. .55

4.22 SEM picture of the Anchor with Springs after Etching in Plasma Asher. . .56

4.23 SEM picture of the Cantilever Beam Actuator along with the DRIE hole after Etching in Plasma Asher. .56

4.24 Optical Image of Developed Photoresist that was Exposed through the a) $15 \mu \mathrm{m}$ Aperture at 1000x resolution; b) $15 \mu \mathrm{m}$ Aperture at 500x resolution .57

5.1 A schematic of a Direct Write Lithographic system using an Array of Optical elements. The Micro-Lens array at the top Collects the light, and the micro-lens array at the bottom Focuses the Light onto the Silicon Wafer .60 


\section{CHAPTER 1 INTRODUCTION}

This research work tries to bring out the salient features of optical direct write lithography. Direct write lithography is the direct contact of the light beam on the wafer without going through a mask. As Moore's law marches the semiconductor industry toward smaller and smaller feature sizes, the optical lithography requirements get harder to meet. The smaller feature sizes apply to the photomasks used in optical lithography, and thus the costs of photomasks is rapidly increasing which greatly increases the complexity of producing the photomasks and thus the cost of manufacturing the photomasks. A photomask set for a modern microprocessor costs in excess of a million dollars! [2].

With a sufficiently high volume, the high photomask cost can be amortized to a small cost per unit produced. This works well for high-volume applications, such as microprocessors and memory chips, but it makes the unit cost astronomical for small production volumes, prototyping runs, and research. Interest in direct write lithography has grown to reduce costs of mask making and time to market for fast prototyping and low volume production of ASICs (Application Specific Integrated Circuits).

\subsection{Methods of Direct Write Lithography}

There are several methods of Direct Write Lithography. They include E-Beam, Ion Beam, Laser Beam and Scanning Probe Lithography. 


\subsubsection{Electron Beam Lithography}

A beam of electrons is rastered across the sample in a manner analogous to a CRT screen. E-beam lithography can be performed using a modified scanning electron microscope. This method has precise control of the energy and dose delivered to a resist coated wafer, Electron beams are deflected and modulated with speed and precision by electrostatic and magnetic fields, and imaging of electrons forms a small point of less than $100 \mathrm{~A}$ as opposed to a spot of $5000 \mathrm{~A}$ for light. Two distinct ways stand out in the use of scanning electron beams for lithography, i.e., direct writing on a resist coated substrate or using electrons to create a mask whose pattern can subsequently be transferred onto a wafer.

The major advantages of e-beam lithography is the ability to register accurately over small areas of a wafer, lower defect densities, and a large depth of focus due to the lack of intermediate masks [22].

The disadvantages include the fact that resolution is affected by scattering of the e-beam inside the resist substrate and by back scattering from the substrate exposing the resist over a greater area than the beam spot size. Another disadvantage is that a more complex apparatus is required, and the exposure speed is relatively slower compared to other methods. As a result, the use of electron beam lithography has been limited to mask making and direct writing on wafers for specialized applications [22].

\subsubsection{Ion Beam Lithography}

Ion beam lithography takes place by flood exposure with $\mathrm{H}^{+}, \mathrm{He}^{2+}$, or $\mathrm{Ar}^{+}$through a mask of $\mathrm{Au}$ on a silicon membrane. It mainly consists of point-by-point exposures with 
a scanning source of liquid gallium metal [22]. A jet-like protrusion of liquid metal forms at the source tip under the influence of an electrical field. The gallium-gallium bonds are broken under the influence of the extraction field and are uniformly ionized without droplet or cluster formation (Fig 1.1). Ions chemically react with substrate, allowing a greater variety of surface modifications such as patterned doping. The resolution of ion beam lithography is better than that for electrons because the secondary electrons produced by an ion-beam are of lower energy and have a short diffusion range so that hardly any back scattering occurs. Also, the ion beam spot size has the smallest possible size, smaller than UV, X-ray, or electron beam spots. The ion mass (typically hydrogen) is much larger than that of an electron, and thus its de Broglie wavelength is significantly smaller. The primary drawback is that the beam intensity of an ion beam system is much

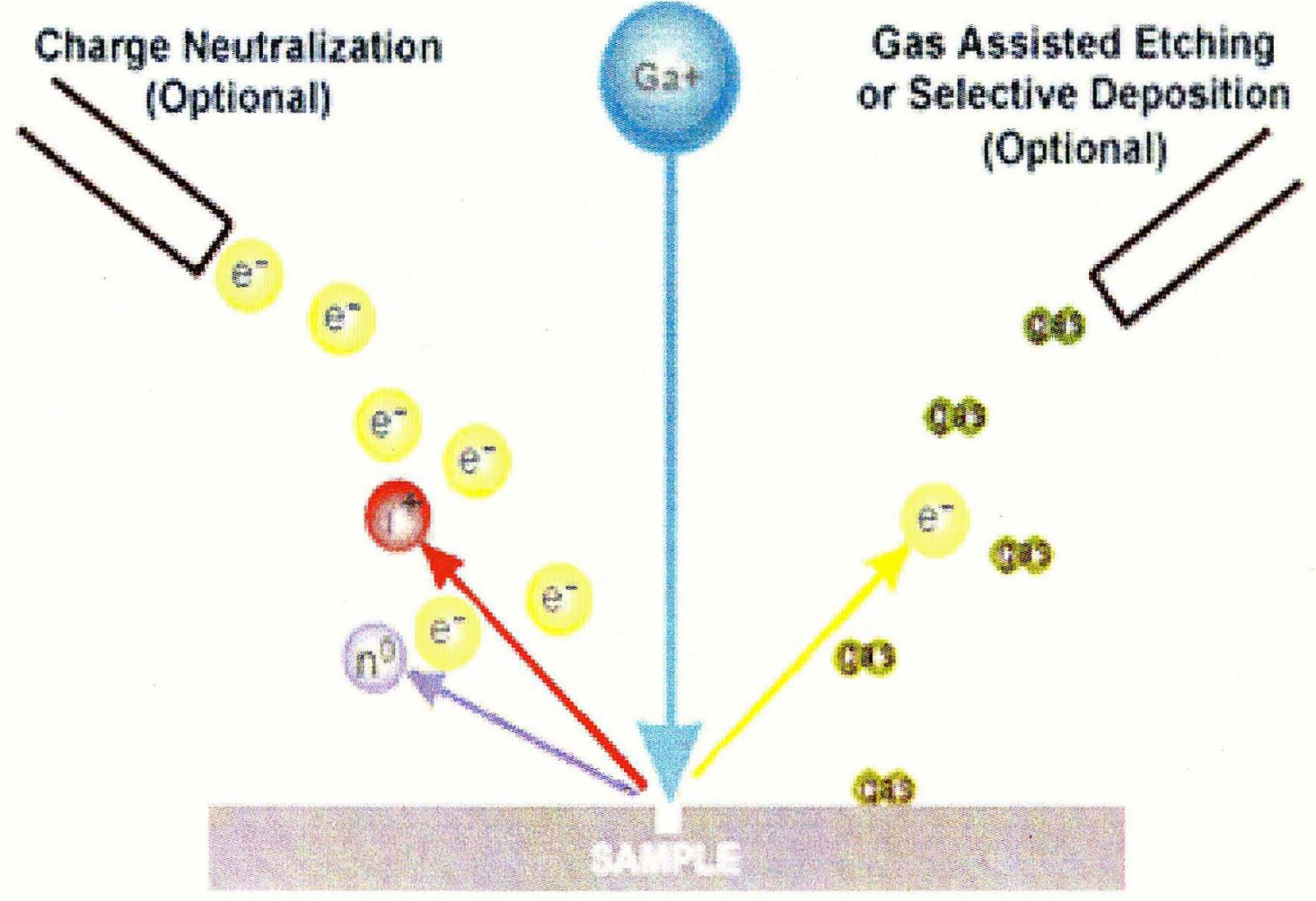

Fig 1.1 Diagram Illustrating Principle of Ion Beam Lithography. 
lower than what can be generated for electron beams, and thus the throughput is significantly lower than for e-beam lithography [22].

\subsubsection{Laser Beam Lithography}

Laser beam lithography is a method used for creating photomasks that competes with e-beam lithography. E-beam lithography has generally been the method of choice for generating the smallest feature sizes, but the laser-beam lithography technique is a strong contender, with a similar market size as electron-beam equipment. The advantages of a laser-beam system include a lower cost and use of an optical photoresist. There have been no significant developments for using multiple laser-beams because a large lens is required in the proximity of the photomask or wafer, making it difficult to accommodate multiple laser beams.

\subsubsection{Scanning Probe Lithography}

Scanning probe lithography (SPL) is an emerging area of research in which the scanning tunneling microscope (STM) or the atomic force microscope (AFM) is used to pattern nanometer-scale features. This utilizes a scanning probe tip that either chemically modifies the surface of a wafer or deposits a thin layer of a protective polymer on the surface of a wafer, i.e., dip-pen lithography. This direct-write technique offers highresolution patterning capabilities for a number of molecular and biomolecular 'inks' on a variety of substrates, such as metals, semiconductors, and monolayer functionalized surfaces. Chemical modifications can occur by anodic oxidation of silicon or thermallyinduced polymer cross-linking. These techniques suffer from low throughput as the scanrate is extremely slow compared to e-beam rastering. Scanning probe lithography also 
suffers from low etch-resistance because the protective layer is very thin. Attempts have been made to increase the throughput by increasing the number of probes acting in parallel, but obtaining independent control of the probes has proven difficult. Thus far, only a few probes operating in parallel have been demonstrated. The only massively parallel demonstration to date is the IBM Millipede project, wherein a large number of probes are used for data storage.

a)
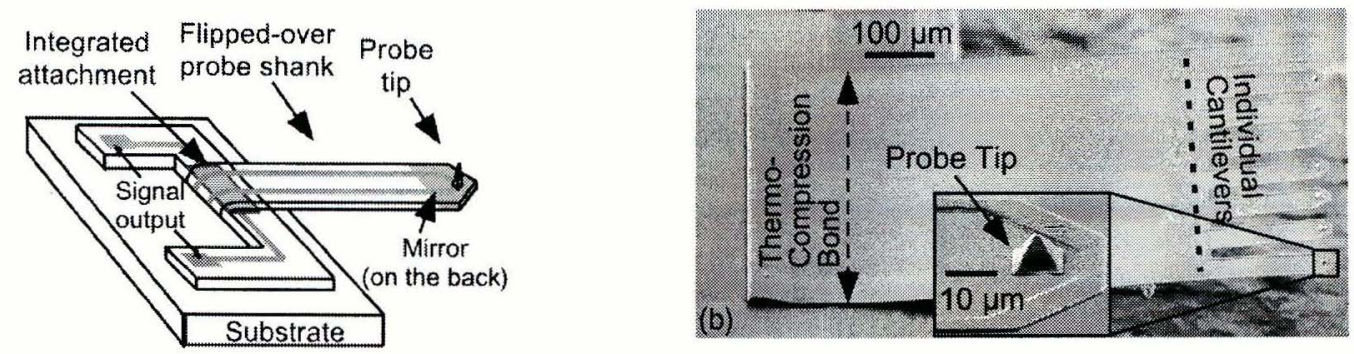

Fig. 1.2: (a) Schematic of the micromachined scanning thermal microscopy probe, and (b) SEM of the 8-probe array surface micromachined from polyimide on a Si substrate. Thin film resistors integrated on the tip of the cantilevers allow the individual probes in the array to be heated independently of one another [17].
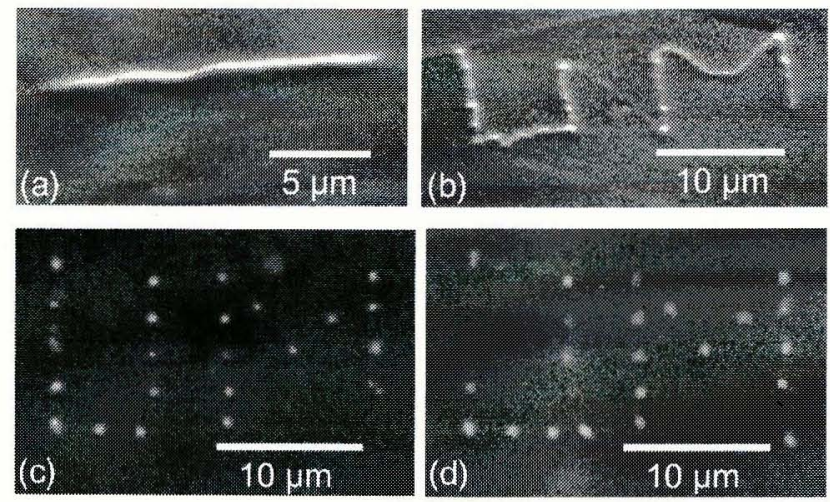

Fig. 1.3: $(a, b)$ Lines of $500 \mathrm{~nm}$ width written by patterning successive dots with $200 \mathrm{~nm}$ spacing ( $1 \mathrm{~s}$ heating per dot) can be seen after partial development of the photoresist. (c,d) Parallel lithography is demonstrated where two adjacent probes in the 8 probe array simultaneously generate the same pattern [17]. 


\subsection{Previous Implementations of Optical Direct Write Lithography (DWL)}

In the past the concept of DWL was implemented by a couple of research groups like ZPAL and High throughput Direct Write Lithography through a programmable phase modulating SLM (Spatial Light Modulator) as described in the following sections.

\subsubsection{MIT's zone plate array}

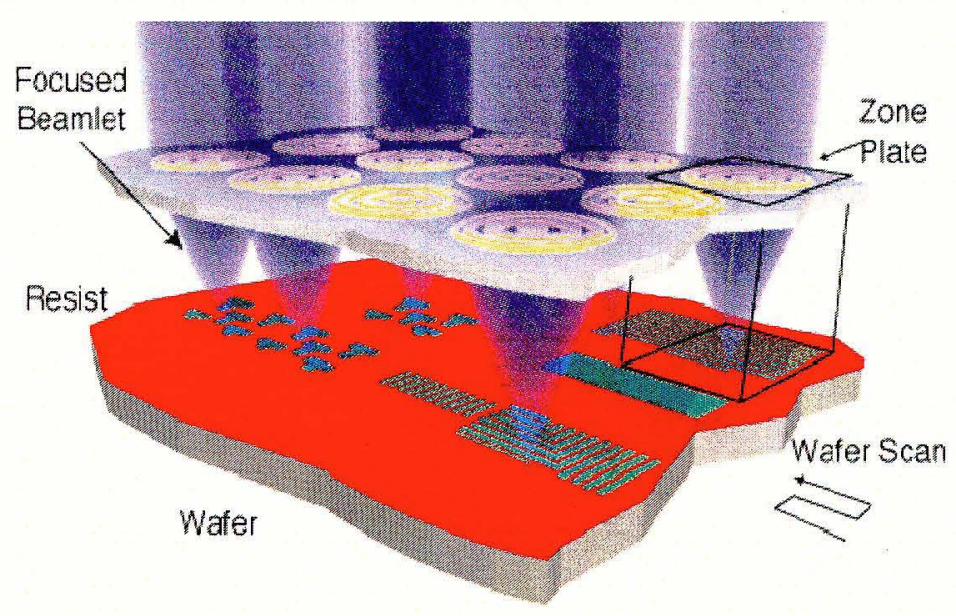

Fig 1.4 ZPAL System [16].

An array of hundreds of microfabricated diffractive optical elements (Fresnelzone-plate lenses) is used, each focusing a beam of light onto the substrate (Fig 1.4). A computer-controlled array of micromechanical elements turns the light to each lens on or off as the stage is scanned under the array, thereby printing the desired pattern in a dotmatrix fashion. No mask is required, enabling designers to rapidly change circuit designs. The ZPAL system consists of a light source, micromechanics, zone plate array and a moving stage. Each zone plate is made to write independently by one of the two methods: (1) by controlling their illumination with the help of micro mirrors which will tilt and reflect the beam of light on the substrate and (2) by using shutters which will electro- 
statically actuate to open or close to allow the incident radiation to pass through. The zone plate is made up of quartz substrate and it's a diffractive optical element of circular symmetry in which the local spatial period depends on the radius in such a way, that the first order diffracted radiation from any radius value crosses the axis at the same point, the focal length. The function of the stage is to raster scan the substrate over a zone plate unit cell to produce the desired patterns.

\subsubsection{Direct Write Lithography through a programmable phase modulating} spatial light modulator

Fig 1.5 DWL apparatus setup.

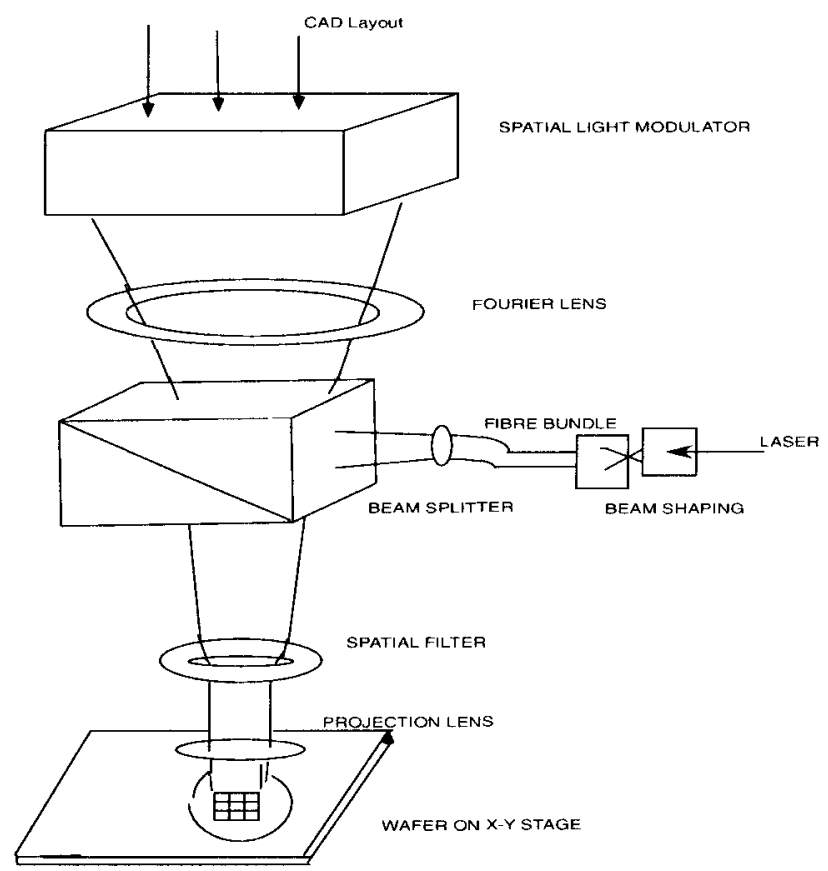

A programmable phase-modulating spatial light modulator is imaged onto the wafer using flash-on-the-fly-exposure by an excimer laser. The phase pattern on the reflective top layer of the modulator is transformed into an intensity-modulated image in the wafer plane by a demagnifying optical system with spatial filtering. Imaging is done during a single shot of an excimer laser light source while the $x-y$ stage carrying the wafer moves continuously. These individual images are stitched into a full wafer layout by triggering both the excimer laser and the data transfer to the SLM when the stage 
interferometer indicates the correct position for placement of the pattern. While the stage moves to the next image position, the next pattern is transferred to the SLM, then the laser pulse repeats the cycle and slowly the entire wafer area is patterned.

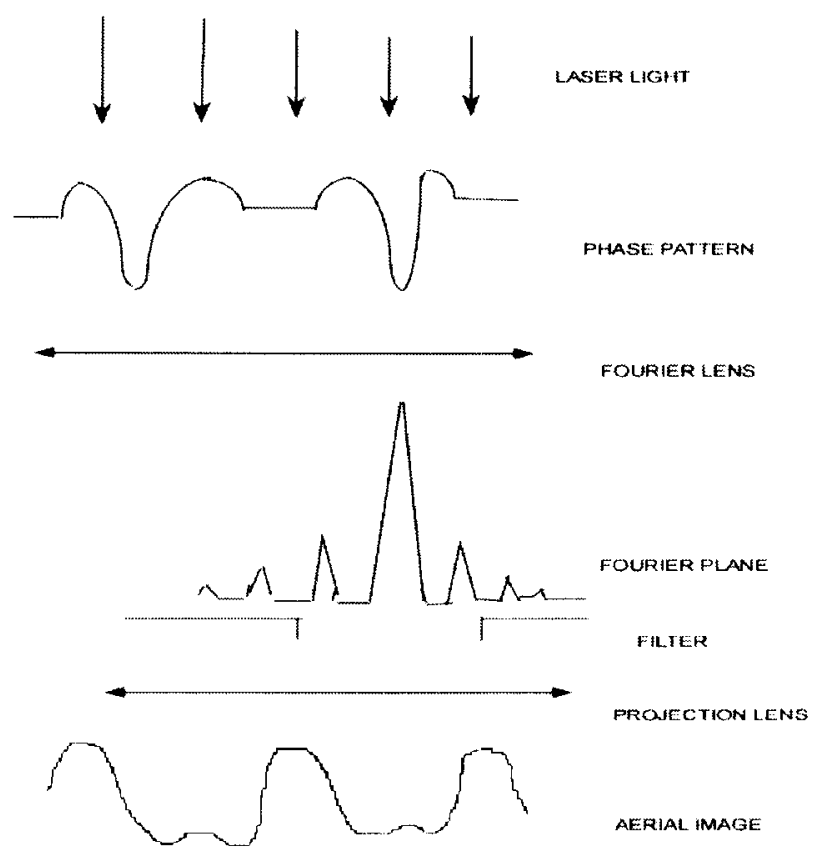

Fig 1.6 Principle of Image Formation [3].

The SLM consists of an array of rectangular electrodes with a reflective, deformable viscoeleastic layer on top. During operation, a uniform bias voltage is applied to the pixel electrodes and the mirror electrode. Upon applying a signal voltage of opposite polarity to neighboring pixel electrodes, the viscoeleastic layer deforms, generating a sinusoidal phase grating corresponding to the addressed pixels. The phase of the reflected light is modulated by the phase pattern on the SLM surface. The deformation amplitude is chosen so that practically all the light is diffracted into the first and higher orders, creating a dark area in the undiffracted light reflected by the 
modulator. The diffraction pattern corresponding to the SLM pattern is filtered by the aperture stop of the system, eliminating the high spatial frequency components due to phase grating. Thus the aerial image is formed by Fourier synthesis of the transmitted light, with dark areas where the modulator is deformed and bright areas where it is flat. The range of allowable NA and partial coherence $(\sigma)$ is given by the waveform equation [3]:

$$
\frac{K \lambda}{R}<\mathrm{NA}<\frac{\lambda}{d(1+\sigma)}
$$

Where $R$ is the desired resolution of the system, $d$ is the grating period of the phase grating of the SLM divided by the reduction ratio of the optics, $\lambda$ is the wavelength of the excimer laser and $\mathrm{K}$ is the usual factor parametrizing the quality of the lithographic process.

\subsection{Shutters}

Shutters are commonly used in MEMS optical devices to guide the ray of light propagating through a fiber or to filter the light before it enters an aperture. Some examples of the shutters implemented in the past include TI's DMD, Micro Shutters of NASA, Microrotor shutter. They are described in the following subsections.

\subsubsection{Texas Instrument's Deformable Mirror device (DMD)}

The Deformable Mirror Device is basically an array of mirrors which could tilt based on actuation to direct the light from incoming optical fibers onto the plane of outgoing fibers. Depending on the state of the micromirror the individual pixels will be on or off. During developments the major problem was the stiction problem where the 
mirrors actuate until pull-in and are stopped by the bumpers. These mirrors are now commonly used in video projection displays.

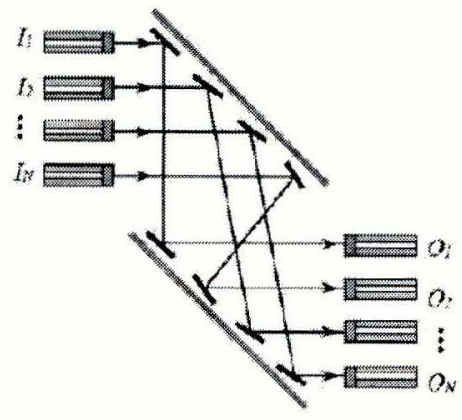

i)

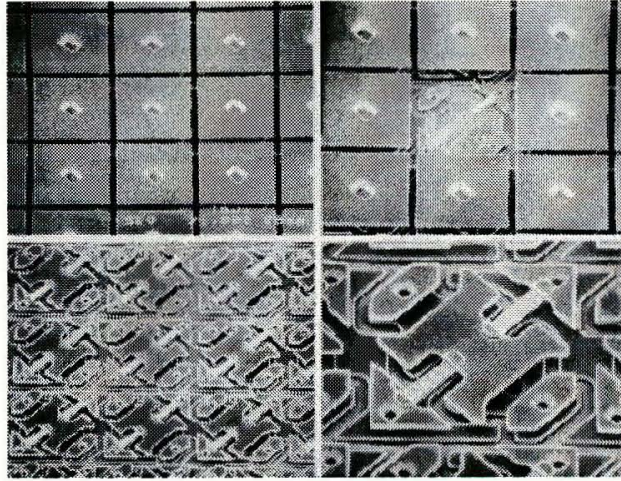

ii)

Fig 1.7 i) Optical Cross Connect formed by tilting mirrors ii) SEM images of DMD micromirror array at different stages of fabrication [13].

\subsubsection{Micro Shutters of NASA}

The shutters can open up to 90 degrees, are made of a silicon nitride membrane, and each individual shutter measures $100 \mu \mathrm{m} \times 100 \mu \mathrm{m}$ in cross section. The shutters are actuated either by a combination of mechanical and electrostatic force or by a combination of magnetic and electrostatic force. A CMOS circuit embedded in between the shutter frames serves as the circuit for programmable shutter selection for the first approach while a control of row and column electrodes fulfills the shutter selection for the second approach. 


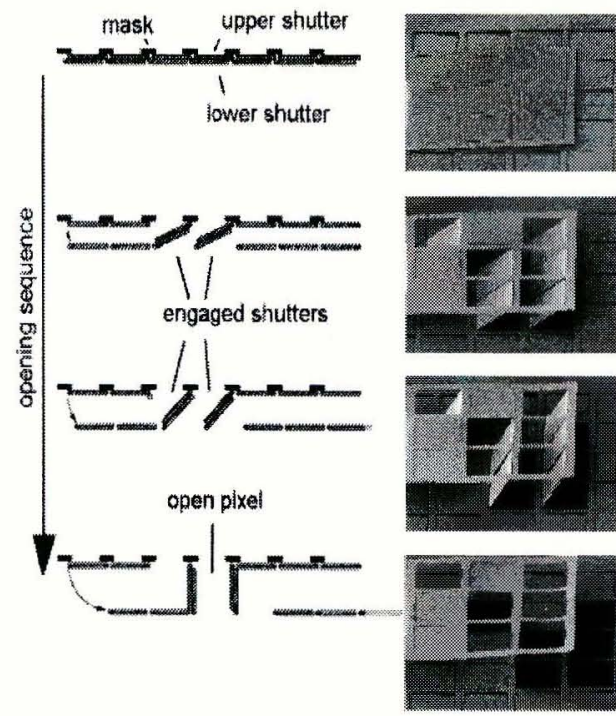

(i)

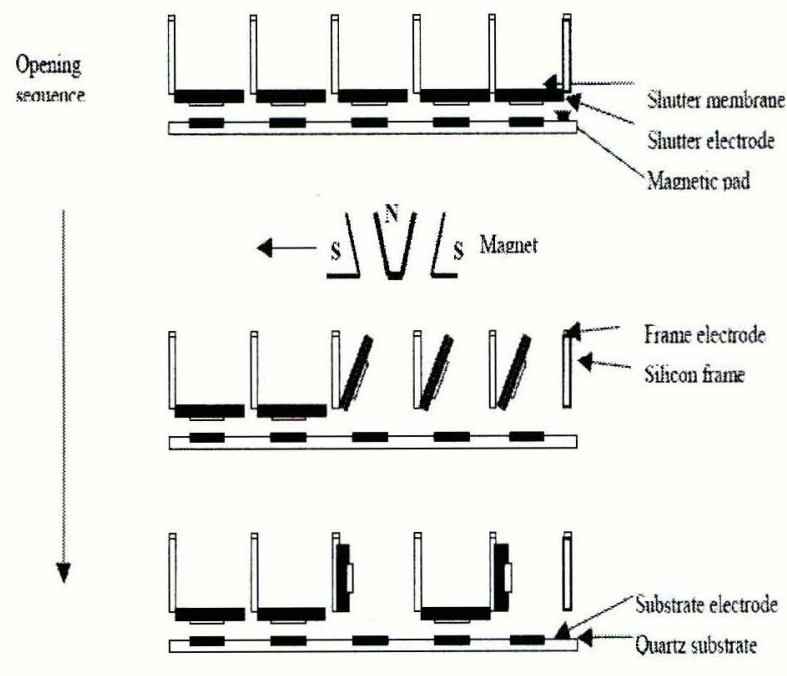

(ii)

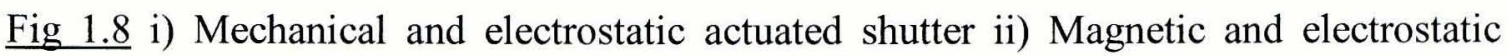
actuated shutter [15].

For the first approach an upper array and a lower array are aligned and brought in close contact. A voltage is applied to engage upper and lower shutters. A mechanical motion driven by precision controlled step motors directs the upper array moving against the lower array. The motion makes engaged shutter pixels open.

For the second approach a shutter array is fabricated with a magnetic pad on each shutter and an electrical electrode strip on each row. A second electrode on the shutter array is located on the backside of the frame. The shutter array is flipped over facing a substrate. The substrate is transparent with electrical electrode strips aligned with columns of the shutter array and perpendicular to electrode strips on shutter rows. Shutters are able to open 90 degree into shutter windows when a magnetic field is applied 
to the shutter array. The magnet moves in one direction so that the shutters open row by row. Applying a voltage between selected electrode rows on the shutter array and columns on the substrate addresses the holding for shutter close, while a voltage between selected electrode rows and the frame electrode fulfills the holding for shutter open.

\subsubsection{Micromachined Motor}

The shutter is made on the rotor of a micromachined motor whose diameter is around 800 microns and the rotor moves when electrostatically actuated by the surrounding stator, over the aperture on a silicon substrate.

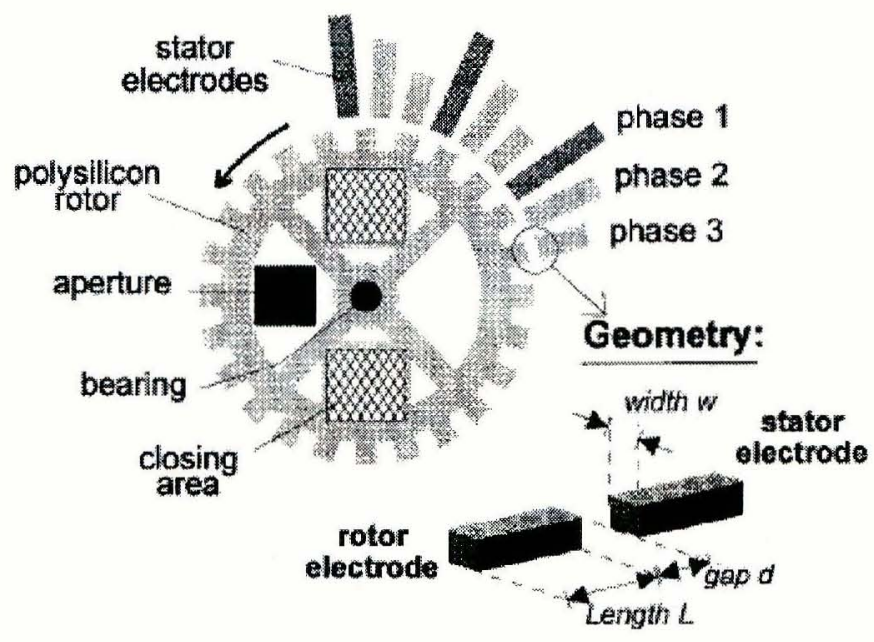

Fig 1.9 Design of a Micromotor Shutter [14].

\subsection{Implementation of Direct Write Lithography}

The traditional photomask is replaced with an addressable array of light modulating elements that are controlled in real time to produce the desired image (Fig1.10). The collimated light is incident upon the programmable mask, which was fabricated. The micro-optics on the programmable mask contains a shutter that can block 
the light when a pixel is supposed to be dark and can open to pass light through it when the pixel needs to be bright. The light source will be a normal traditional mercury lamp for i-line and g-line lithography. The substrate to be exposed will be placed under the shutter on a stage and the movement of many tiny shutters as they operate to block and allow light through them as per the design requirements will form a pattern on the photoresist coated substrate.

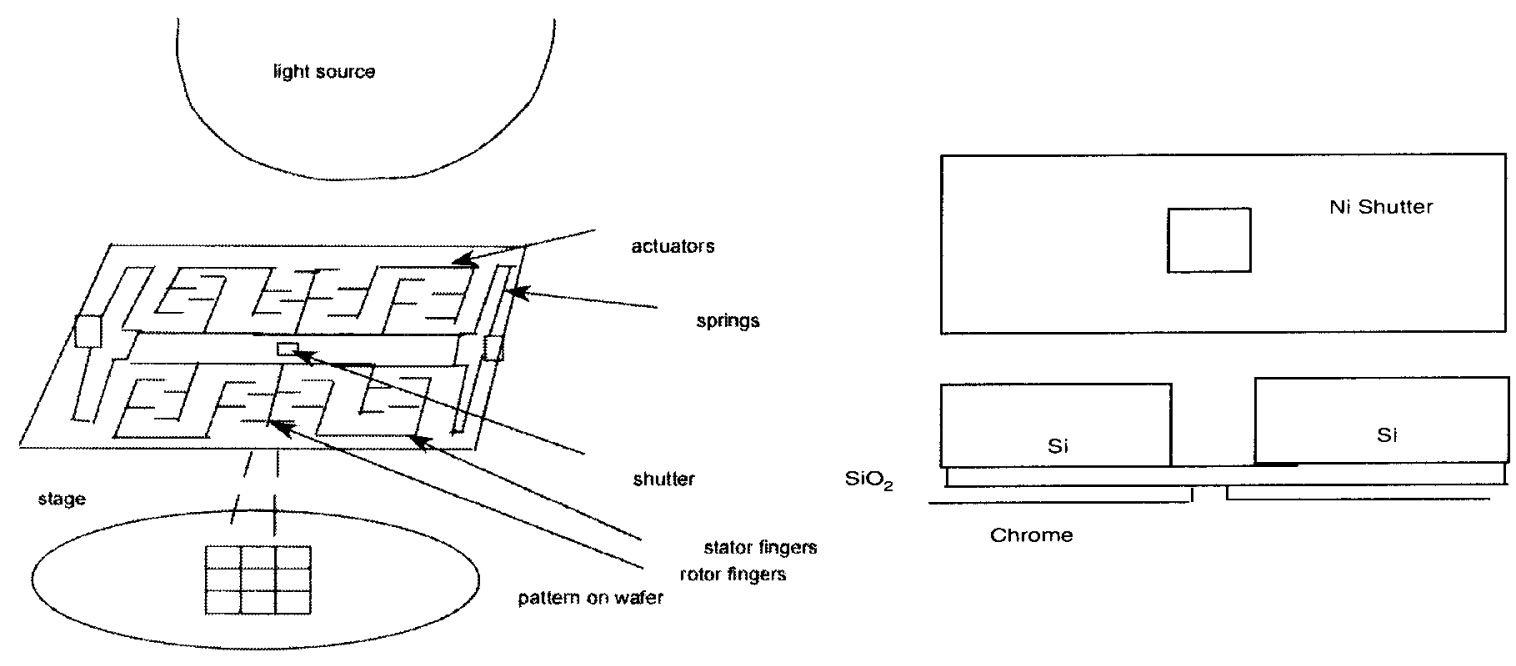

(i)

(ii)

Fig 1.10 (i) Schematic of the Programmable DWL (ii) Cross Section of Programmable Mask.

\subsubsection{Optical Shutter}

The shutter is a metal plate with an aperture and comb fingers attached to it. When a voltage is applied between the stator and rotor fingers there will be some capacitance acting between the stator and rotor fingers which will attract each other and thus actuate the fingers and in the process the shutter plate will move. With proper bias of voltage the shutter can move in both directions to open and close for light to pass through 
the hole in the wafer which will be acting as the base of the mask. Once the voltage is withdrawn the springs attached to the shutter will restore it to the original position. A more detailed analysis about the working principle is discussed in section 2.1 under theory. The bottom of the programmable mask contains a chromium aperture layer that acts as an imaging layer. Then, the image is focused on the substrate that is being exposed using conventional photolithography optics.

\subsubsection{Fabrication of Programmable Mask}

The fabrication part mainly consists of building the shutter on the wafer using the sacrificial layer approach in which once the comb fingers and shutter are formed by electroplating metal, the movable comb fingers along with the shutter will be released from the substrate using this approach and then using the boon of DRIE the entire wafer is etched to create the path for transmission of light. There are some cantilever structures as the shutters which will have less switching time and pitch size (the cantilever beam actuator has a pitch size of $1000 \mu \mathrm{m}$ compared to $4500 \mu \mathrm{m}$ pitch size of the comb drives), but their drawback is smaller displacement compared to the combs. To make the shutter efficient in converging the light and decreasing the exposure time microlenses will be used in the future work of the project. Also the programmable part of this project will be incorporated later when yield of devices per wafer is maximized.

\subsubsection{Potential of Direct Write Lithography}

The programmable mask can be fabricated on a 4" silicon wafer in the Lutz Micro-Nano Fabrication Cleanroom. Assuming an area of $70 \mathrm{~mm}$ x $70 \mathrm{~mm}$ (the maximum sized box that can fit on a 4" wafer), and a pixel size of $100 \mu \mathrm{m} \times 100 \mu \mathrm{m}$, the 
result is a $700 \times 700$ pixel array. The 4" $\times$ 4" photomask can be written with a resolution of $1 \mu \mathrm{m}$ in under 30 seconds using the chemicals and equipment available at the University of Louisville. This can be contrasted to the laser pattern generator (LPG) located in the Lutz Micro-Nano Fabrication Cleanroom. The LPG requires 50 hours to generate the same photomask.

Theoretically, the programmable mask can expose wafers at the same rate that wafers are exposed with a conventional mask aligner. The time required to expose a pixel is:

$t_{\text {pixel }}=\frac{A_{\text {pixel }}}{A_{\text {light }}} t^{\prime}$

where $t^{\prime}$ is the time required to expose the wafer with a conventional mask aligner, $A_{\text {pixel }}$ is the area of the pixel being imaged, and $A_{\text {light }}$ is the area of the light collection lens. The number of pixels in the array is:

$$
N_{\text {pixels }}=\frac{A_{\text {wafer }}}{A_{\text {light }}}
$$

where $A_{\text {wafer }}$ is the area of the wafer. The number of exposures required to expose the wafer is:

$$
N_{\text {exp }}=\frac{A_{\text {wafer }}}{A_{\text {pixel }} N_{\text {pixels }}}
$$

Eqs. (1.2)-(1.4), indicate that the total time to expose the wafer is:

$$
t_{\text {exp }}=N_{\text {exp }} t_{\text {pixel }}=t^{\prime}
$$


Thus, the theoretical time to expose a wafer using a programmable mask is the same amount of time required to expose the mask using a conventional mask aligner.

Achieving this result would revolutionize the IC (Integrated Circuit) industry.

The data transfer rate required to sustain a throughput of 120 wafers/hours for a $300 \mathrm{~mm}$ diameter wafer with $65 \mathrm{~nm}$ feature sizes (these are the current requirements for advanced manufacturing) is $70 \mathrm{~GB} / \mathrm{s}$. The IC industry is already comfortable with large data set sizes, as a mask file is in excess of a Terabyte in size, so handling this data flow is manageable. 


\section{CHAPTER 2}

\section{THEORY}

This chapter focuses on the physical and mathematical concepts applied in designing the microstructures. Actuation methods in MEMS that require displacements of more than $20 \mu \mathrm{m}$ are difficult to develop. Some common types of actuators include thermal actuators, scratch drives, mechanically-amplified deflections and the use of rotary motors and ratchets. However, the drawback with all these is that the response time is more than $20 \mathrm{~ms}$, and amplification of displacement usually comes at the cost of reduced force (Kenny, et al). MEMS actuators that can achieve fast response times are typically electrostatic actuators. They have a constant force over a large range of displacement.

Side instability limits the static displacement of comb drives. When the electrostatic force of attraction becomes greater than the spring restoring force in the lateral direction due to the increase in overlap area with increasing forward displacement, the teeth snap over sideways.

To obtain optimum displacement keeping in mind the size of the die and bending stress considerations stacks of six comb drives are integrated to actuate in parallel, for actuating each shutter.

There are two common types of electrostatic actuators a) the comb drive b) the parallel plate cantilever beam. 
These are low power and simple to fabricate actuators. The comb drive actuator was chosen for this work because of its larger range of actuation compared to the other.

\subsection{Comb drive Actuators}

Unlike the cantilever and to a large extent, the torsional actuators, the comb drive actuators can generate relatively large movements in the plane of the substrate. The fringe fields acting on a comb finger are approximated to be constant since the comb fingers are normally very long compared to the achieved displacement. Therefore, the electric field will effectively remain constant, ensuring a constant force on the comb finger for a given output voltage. In comb drives, the capacitance is varied by changing the overlap area, not the gap width, and since the capacitance is linearly related to area, the displacement will vary as the square of the applied voltage.

\subsubsection{Analysis and Design of the Comb Drive:}

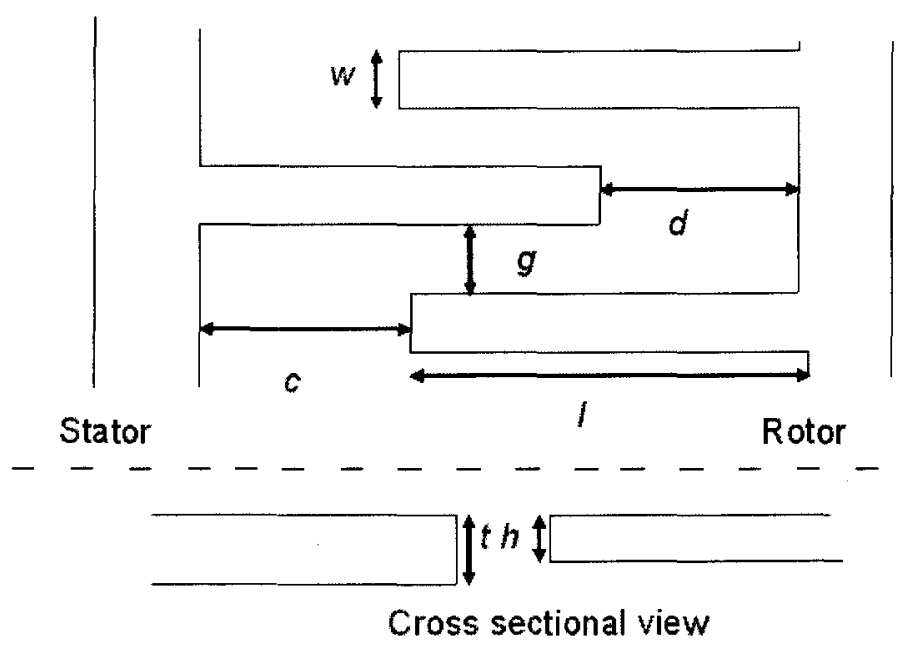

Fig 2.1 Schematic of Comb fingers. Above: Top view of one set of combs. Below: Crosssectional view of combs, showing that the fixed combs are thicker than the moving combs. 
In a comb drive there are two types of capacitances between the rotor and the stator, (a) the total capacitance between the stator and the rotor and (b) the capacitance which causes lateral force to be exerted onto the rotor. Field lines are always perpendicular to conducting surfaces and they never cross each other.

The electric field lines that provide a majority of the force for lateral displacement, in $\mathrm{x}$ direction are emitted from the sidewalls of the stator fingers, especially in the region where there is no finger overlap. Most of the cavity has constant, low electric field intensity, this ensures a near uniform force exerted on the rotor finger, regardless of displacement. The relationship between the electromotive force and electric field is given by:

$$
\mathrm{F}_{\mathrm{x}}=\frac{\varepsilon E_{x}^{2} A}{2}
$$

where $\varepsilon=$ permittivity of the medium

$$
A=\text { cross-sectional area of the plates }
$$

Apart from the lateral field, the $\mathrm{E}_{\mathrm{y}}$ fields are also important when $\mathrm{y}$-direction stability is a concern. If the stator and rotor are opposite in polarity, there will be an electrostatic attraction. When the y-direction displacement is skewed too far to either side the structure may collapse. The maximum potential difference which may be applied for out of balance forces is given by [9]:

$$
\mathrm{V}_{\max }<\frac{K y g^{3}}{2 \varepsilon h(1-d)^{1 / 2}}
$$

where $\mathrm{K}_{\mathrm{y}}$ is the spring constant of the rotor finger in the $\mathrm{y}$-direction.

The $\mathrm{z}$ direction $\mathrm{E}$ fields normal to the substrate are not symmetric. The top of the rotor finger will experience greater field strengths compared to the bottom. This is 
referred to as the levitation effect, since the fields will help suspend the comb fingers, preventing the structure from collapsing into the substrate. In general the $\mathrm{z}$ direction force is difficult to control since it is dependent on voltage which is subject to change. Of the parameters which influence this force, the thickness of the actuator fingers and the distance from the substrate are the two that are readily modified. Thus the mechanics of the structure must be designed such that the mechanical tension in the rotor suspension counter balances the $\mathrm{E}_{\mathrm{z}}$ field.

The force between the plates of a parallel plate capacitor

$$
\mathrm{F}_{\mathrm{p}}=\frac{\varepsilon A V^{2}}{2 d^{2}}
$$

where $\varepsilon$ is the permittivity of the medium between the plates, $A=$ wh is the plate area, $V$ is the voltage applied between the plates, $d$ is the initial gap.
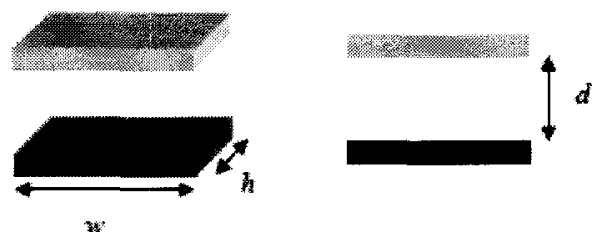

Fig 2.2 Parallel Plate Capacitor.

The electrostatic force of a vertical comb drive structure is [10]

$$
\mathrm{F}_{\mathrm{c}}=\frac{N \varepsilon h V^{2}}{g}
$$

where $\mathrm{N}$ is the number of comb pairs, $\varepsilon$ is the permittivity of the medium, $\mathrm{h}$ is the height of the comb teeth, $\mathrm{V}$ is the voltage applied to the two sets of comb teeth, and $\mathrm{g}$ is the gap between the comb teeth. 
This project concentrates on the voltage versus displacement characteristics of the comb drive. The spring force is

$$
\mathrm{F}_{\mathrm{s}}=\mathrm{K}_{\mathrm{z}} \mathrm{z}
$$

where $\mathrm{K}_{\mathrm{z}}$ is the spring constant in the $\mathrm{z}$ direction and $\mathrm{z}$ is the displacement.

Equating 2.4 and 2.5 ,

$$
\mathrm{Z}=\frac{N \varepsilon h V^{2}}{K_{z} g}
$$

Thus the factors which govern displacement versus voltage are $\mathrm{N}, \mathrm{h}, \mathrm{g}$ and $\mathrm{k}_{\mathrm{z}}$. Keeping in mind the factor $\mathrm{K}_{\mathrm{z}}$ a folded spring is designed which is as shown below.

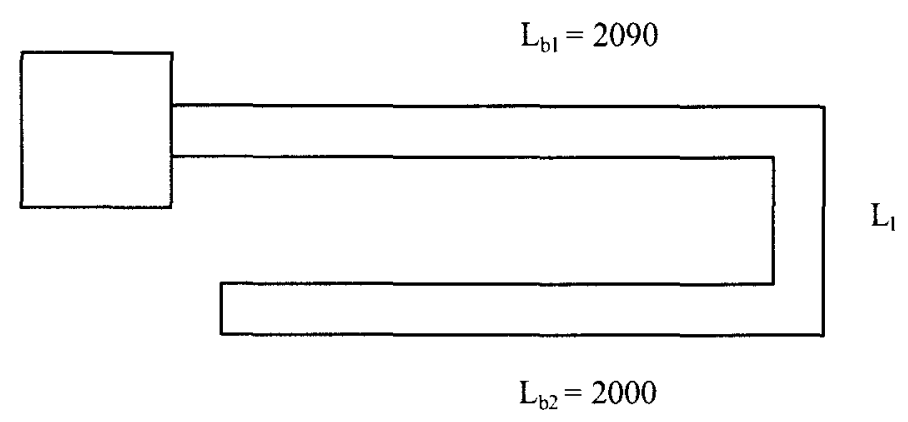

a)

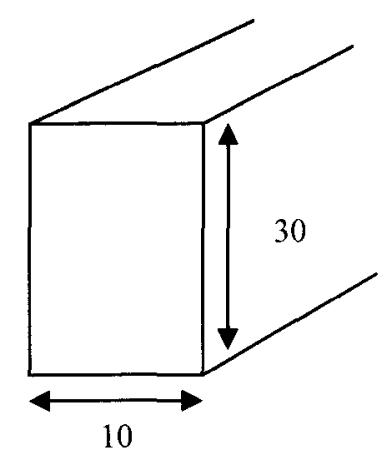

b)

Fig 2.3 Folded Flexure Spring a) Top view b) Cross sectional view. All dimensions are in $\mu \mathrm{m}$.

The springs are made up of folded beams (Fig 2.4). Each folded beam can be modeled as a cantilever beam based on the deflection of the beam which is $\mathrm{PL}^{3} /(3 \mathrm{EI})$ where $\mathrm{P}$ is the force applied, $\mathrm{L}$ is the beam length, $\mathrm{E}$ is the Young's modulus of the material and $\mathrm{I}=$ moment of inertia of the each spring along the perpendicular axis passing through its end.

The equivalent spring constant for each spring is $\mathrm{k} 1$ in series with $\mathrm{k} 2$ which is 


$$
\mathrm{K}=\frac{3 E I}{L_{b 1}^{3}+L_{b 2}{ }^{3}}
$$

where $L_{b 1}$ and $L_{b 2}$ are the spring lengths as defined in Fig 2.3

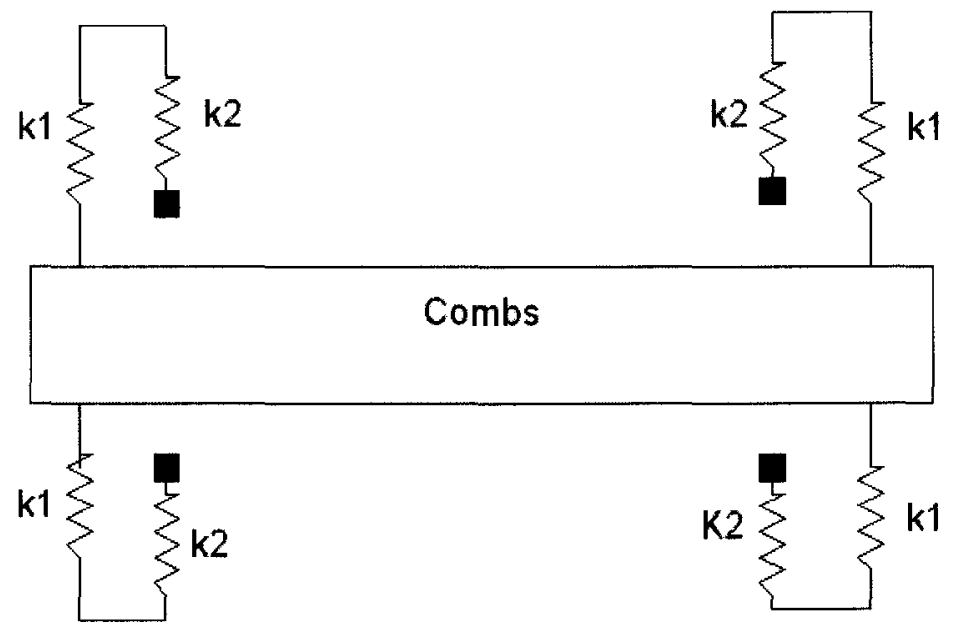

Fig 2.4 Equivalent Spring System.

Each of the four springs are in parallel and thus the net spring constant is

$$
\mathrm{K}_{\mathrm{z}}=4 * \frac{3 E I}{L_{b 1}{ }^{3}+L_{b 2}{ }^{3}}
$$

After inserting the moment of inertia Eq (2.8) becomes

$$
\mathrm{K}_{\mathrm{z}}=4^{*} \frac{E w^{3} h}{L_{b 1}{ }^{3}+L_{b 2}{ }^{3}}
$$

where $w=$ width of the spring

$$
\mathrm{h}=\text { height of the spring }
$$

and thus the displacement can be found combining $\mathrm{Eq}(2.9)$ and $\mathrm{Eq}(2.4)$ as

$$
\mathrm{z}=\frac{N \varepsilon V^{2}\left(L_{b 1}{ }^{3}+L_{b 2}{ }^{3}\right)}{4 E w^{3} g}
$$

The die size for each comb drive is $3.6 \mathrm{~mm}$ by $2 \mathrm{~mm}$. The width and height of the die is calculated based on the dimensions shown in Fig. 2.5. 
a)

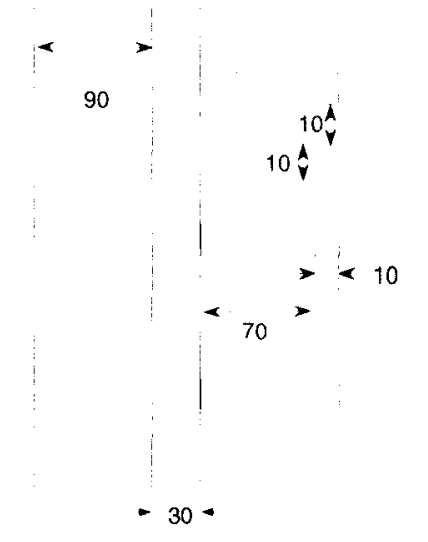

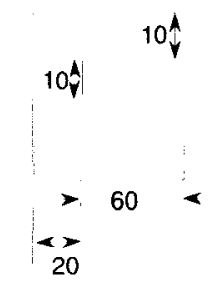

b)

Fig 2.5 Layout Showing Combdrive Dimensions when a) the shutter is open, and b) the shutter is closed.

The number of comb fingers and the lengths of the springs are chosen together to obtain a rectangular die without wasting space. Using spring lengths of $2090 \mu \mathrm{m}$ and $2000 \mu \mathrm{m}$, and 600 fingers, a layout is found that does not have empty space, and that provides a displacement of $25 \mu \mathrm{m}$ with 40 volts applied. The width of the fingers are chosen to be $10 \mu \mathrm{m}$ because the height of the nickel structures chosen is $30 \mu \mathrm{m}$ which will give an aspect ratio of 3:1 which is optimum for the thick photoresist used to form the moulds.

The model was tested analytically using the Young's modulus of nickel as 200GPa. The results are shown in Fig 2.5. Note that displacement over $100 \mu \mathrm{m}$ can be achieved. 


\section{Voltage vs Displacement}

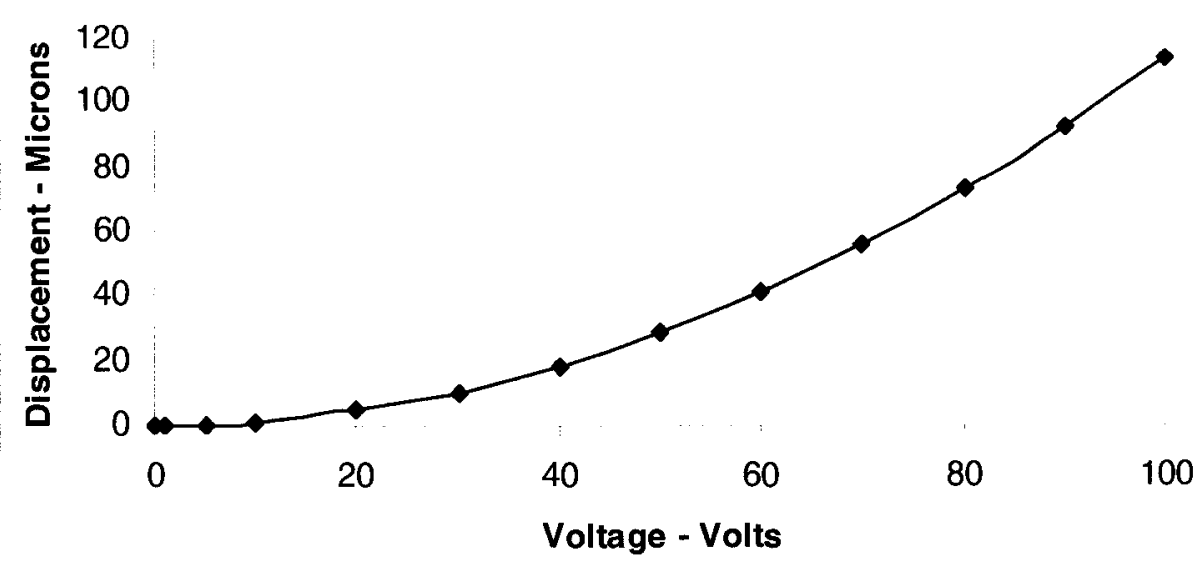

Fig 2.6 Graph Showing Displacement of Comb Actuator as a Function of Applied Voltage.

One important factor which controls the speed of the shutters is the resonant frequency of the comb drives

$$
f=\frac{1}{2 \pi} \sqrt{\frac{k}{m}}
$$

where $\mathrm{m}=$ total mass of the shutter and moving comb drive fingers

$$
\mathrm{k}=\text { spring constant of the comb drive }
$$

which simplifies to

$$
f=\frac{1}{2 \pi} \sqrt{\frac{k}{\rho h A}}
$$

where $\rho$ is density of electroplated nickel which is $8.9 \mathrm{gm} / \mathrm{cm}^{3}$
A is area of the movable metal layer which is $4.0412 \mathrm{E}+06(\mu \mathrm{m})^{2}$
$\mathrm{h}$ is height of actuator 
$\mathrm{k}$ is equivalent spring constant derived in (2.9)

After using these values the resonant frequency is $181.94 \mathrm{~Hz}$. This is acceptable for the current design but in the future when the microlenses are incorporated to increase the efficiency of incident light this frequency should be increased significantly for proper exposure.

\subsection{Electrostatic Cantilever Actuator}

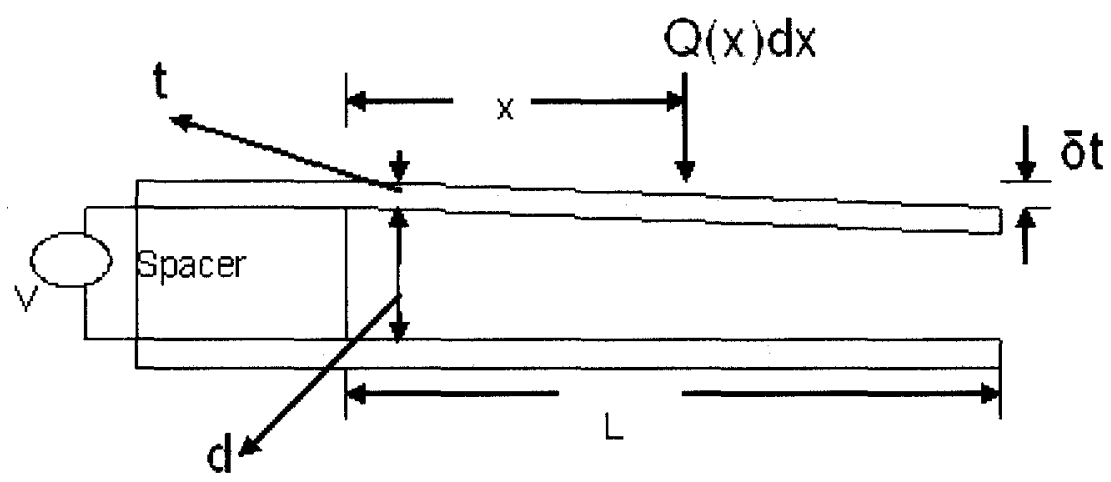

Fig 2.7 Cantilever Beam Actuator [18].

It is known that a concentrated load at a position, $x$, from the fixed end of a cantilever beam of width, $w$, results in a tip deflection, $\delta$, given by,

$$
\begin{array}{r}
\mathrm{d} \delta=\frac{x^{2}}{6 E I}(3 \mathrm{~L}-\mathrm{x}) \mathrm{wq}(\mathrm{x}) \mathrm{dx} \\
\mathrm{q}(\mathrm{x})=\frac{\varepsilon}{2}\left(\frac{V}{d-d(x)}\right)^{2}
\end{array}
$$

where $E=$ Young's modulus of the cantilever

$I=$ moment of inertia of the cantilever

$\mathrm{L}=$ beam length

$\mathrm{X}=$ distance of force (load) from the fixed end of the beam 
$\mathrm{d}=$ gap between cantilever and deflection electrode

The total tip deflection can be found by integrating Eq (2.11) from the fixed end $(x=0)$ to the tip of the beam $(x=L)$,

$$
\delta \mathrm{t}=\mathrm{w} \int \frac{(3 L-x)}{6 E I} \mathrm{x}^{2} \mathrm{q}(\mathrm{x}) \mathrm{dx}
$$

To make the solution of the integral possible, one can assume a square-law curvature of the beam at any point along its length,

$$
\delta(\mathrm{x}) \sim(\mathrm{x} / \mathrm{L})^{2} \delta \mathrm{t}
$$

Thus in turn yields a normalized load, F, required to produce a specified tip deflection,

$$
\mathrm{F}=\frac{\varepsilon w L^{4} V^{2}}{2 E I d^{3}}=4 \Delta^{2}\left(\frac{2}{3(1-\Delta)}-\frac{\tanh ^{-1} \sqrt{\Delta}}{\sqrt{\Delta}}-\frac{\ln (1-\Delta)}{3 \Delta}\right)^{-1}
$$

Where $\Delta$ is the deflection at the tip $(\delta \mathrm{T} / \mathrm{d})$.

Eq (2.16) shows for normalized load plotted versus normalized deflection shows that the relationship between tip deflection and applied voltage is nonlinear, and that once deflection exceeds a threshold voltage, the position of the tip is unstable, and the beam spontaneously deflects all the way down.

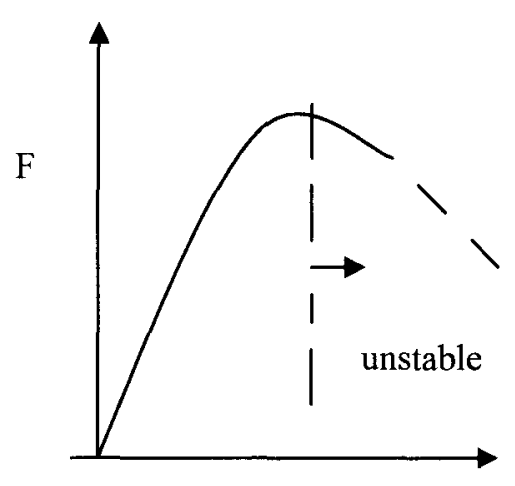

$\Delta$

Fig 2.8 Plot showing F vs $\Delta$. 
The cantilever has three modes of operation:

a) Floating mode: The cantilever does not touch the dielectric and the bending moment and shear force are zero at the free end.

b) Pinning mode: The free end of the cantilever is touching the dielectric but is free to pivot about the contact point. The deflection and bending moment are zero at the touching level.

c) Flat mode: A non- zero length of the beam is on the dielectric layer which increases with increase in voltage.

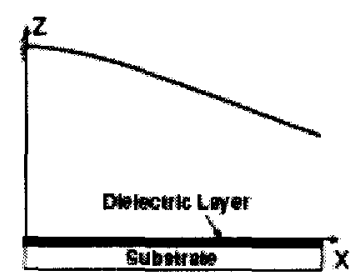

(a)

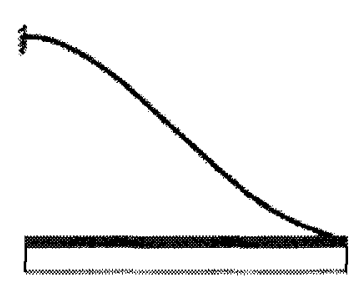

(b)

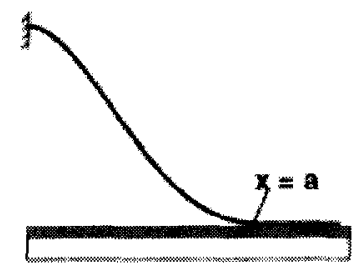

(c)

\section{Fig 2.9 Cantilever Beam Configurations.}

Pull in occurs when the floating configuration transitions to pinned configurations and with more voltage finally goes to flat mode.

\subsection{Optics}

Because the device made will be used for lithography a brief discussion about the optical science related to the same is presented. The physical behavior of light undergoes a drastic change when the optical components are comparable or smaller than the wavelength of light. At that point ray optics cannot be applied and wave related scattering and interference phenomena begin to dominate. Diffraction is the bending of light rays 
around sharp corners. Heissenberg's principle of uncertainty, states that light through a very well defined and small aperture (position) will have a less well-defined direction (momentum). Fresnel's number from the Fresnel's diffraction formula characterizes the spot size. For a light wave passing through an aperture and hitting a screen, the Fresnel number is defined as

$$
N_{F}=\frac{a^{2}}{L \lambda}
$$

where $\lambda$ iswavelength of light wave, $a$ is the characteristic size (e.g. radius) of the aperture, and $L$ is the distance of the screen from the aperture. [24].

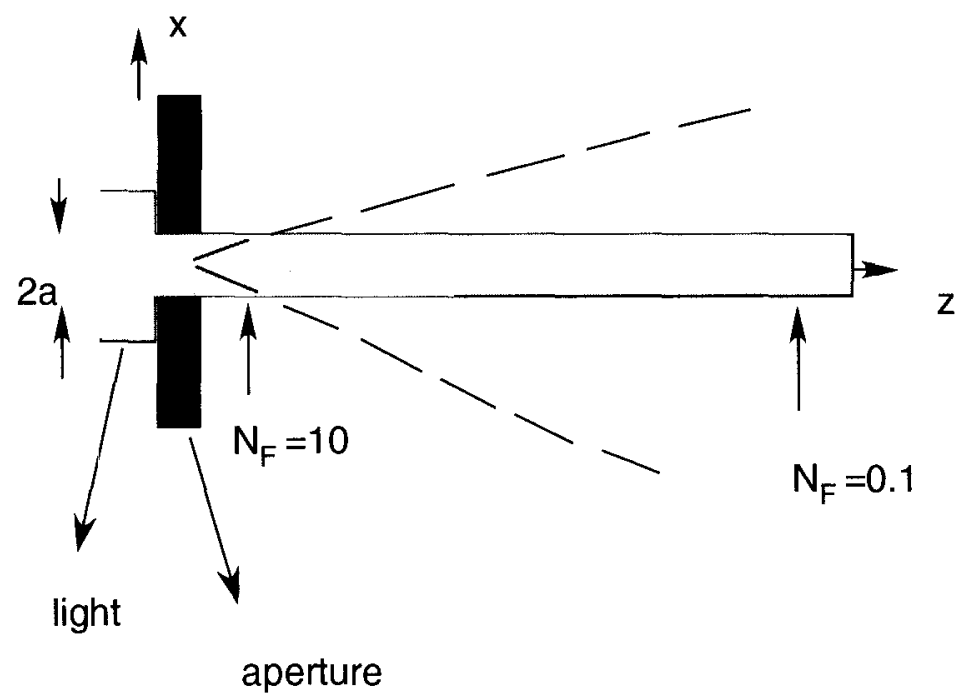

Fig 2.10 Diffraction Phenomenon.

In the system used here, the silicon will act as an aperture of size 15 microns (2a for this case), the wavelength of any of the following lines i.e, i-line ( $365 \mathrm{~nm})$, h-line $(405 \mathrm{~nm})$ or g-line $(436 \mathrm{~nm})$ will be used and since the mask will be used in contact lithography $\mathrm{L}$ is very small and therefore Fresnel number will be very high and thus the width of the Fraunhofer diffracted beam will be minimal. 


\section{CHAPTER 3}

\section{FABRICATION PROCESS}

This chapter contains the fabrication details for manufacturing the shutter system. The fabrication is a five mask process. A double side polished 300 micron thick silicon $<100>$ wafer is used.

\subsection{Wafer Cleaning}

A process developed in the 1960 s by Walter Kern is a two step process to remove organic and inorganic residues from silicon wafers. Hydrogen peroxide is used along with some base or acid. The first step is a base clean responsible for the removal of organic contaminants like photoresists. Its composition is a 5:5:1 solution of $\mathrm{H}_{2} \mathrm{O}$, hydrogen peroxide and ammonium hydroxide heated to $80 \mathrm{C}$. The wafers are submerged in the solution for 10 minutes. Once the cleaning process is complete wafers are rinsed under running DI water.

A 30 second 1:100 $\left(\mathrm{HF}: \mathrm{H}_{2} \mathrm{O}\right)$ will remove the oxide layer produced during the base clean. Also, it helps in removing the metallic contaminants.

The second step is the acid clean which uses a mixture of 5:1:1 water, hydrogen peroxide and hydrochloric acid at a temperature of $80 \mathrm{C}$. The wafers remain in the solution for 10 minutes and then they are rinsed off under running DI water. 


\subsection{Wafer Doping}

A Spin-on dopant $\left(\mathrm{PBF}_{6} \mathrm{MK}-37\right)$ is used to supply the $\mathrm{B}_{2} \mathrm{O}_{3}$ to the surface of wafer. Solid state diffusion is performed in two steps- predeposition and drive-in. A deposition process is controlled by several factors. One is diffusivity of the particular dopant. Diffusivity increases with temperature. Another factor is solid solubility of the dopant in the wafer material. It also increases with temperature. The deposition process requires three cycles. First cycle is loading which takes place in a nitrogen atmosphere. The second cycle is the actual doping cycle in which the diffusion is performed for 3 hours at $1100 \mathrm{C}$ with the gases set at a flow rate of $1.0 \mathrm{~L} /$ minute for nitrogen and $0.05 \mathrm{~L} /$ minute for oxygen, and third cycle is exit cycle which takes place in nitrogen atmosphere. During deposition a thin film of oxide can form on the exposed surface. This oxide is doped and can act as an unwanted source of dopant during the drive-in-oxidation step. Also, a deposition created oxide can be unetchable, causing incomplete etch in a subsequent masking process. The oxide is removed by a BOE (Buffer Oxide Etch). Now the drive-in diffusion is performed at $850 \mathrm{C}$ in $1.0 \mathrm{~L}$ /minute of oxygen for 15 minutes. It serves the following purpose:

The redistribution of the dopant deeper into the wafer. In the drive-in there is no dopant source. The heat alone drives the dopant atoms deeper and wider into the wafer. The surface concentration is reduced and distribution of atoms takes a new shape. After the drive in diffusion is done, the wafers are immersed in $\mathrm{BOE}$ for another 15 minutes to remove the unused boron layer as well as the boron oxide layer and the borosilicate glass layer. 


\subsection{Wafer Oxidation}

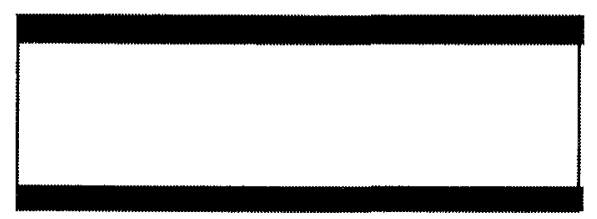

oxide

wafer

Fig 3.1 Oxidized Wafer.

The oxidation process is conducted to provide masking layer for the contact windows and on the bottom side to act as an etch stop for DRIE. The wafer is oxidized for a thickness of half a micron in a wet oxidation process at a temperature of $1050 \mathrm{C}$ for 45 minutes. The oxidation is performed with a Lindberg/Blue M 4", three zone furnace using high purity grade $\mathrm{N} 2, \mathrm{O} 2$ and a bubbler system. A gas flow rate of $1.0 \mathrm{~L} /$ minute of nitrogen is used to maintain a positive pressure within the furnace as it ramps up to the oxidation temperature at a ramp rate of $20 \mathrm{C}$ /minute. The gas is switched to oxygen at a flow rate of $1.0 \mathrm{~L} /$ minute around $600 \mathrm{C}$ and once the desired temperature is attained then the wafers placed on a wafer boat are pushed in at the rate of 12 inches/minute. The gas flow of the oxygen is passed through the bubbler, maintaining a temperature of $95 \mathrm{C}$ to perform the wet oxidation. After the dwell time, the nitrogen gas is switched back in and the wafers are slowly taken out of the furnace at the same rate in which they were introduced in the furnace and when the temperature drops down to $600 \mathrm{C}$ then the furnace is shut off. Then the oxide thickness is measured using the reflectometer. 


\subsection{Contact Mask}

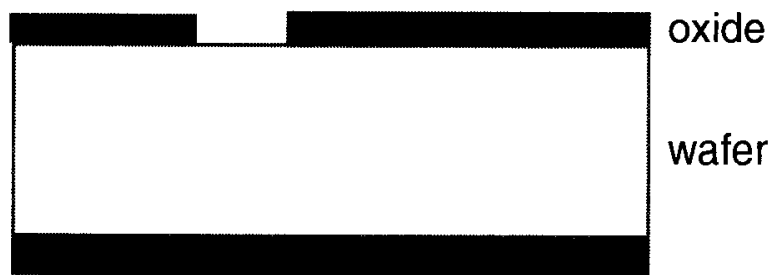

Fig 3.2 Contact Windows on Oxide.

Photolithography using the resist Shipley's S 1813 is done on the oxidized wafer with the contact mask for opening contacts for the nickel electroplated structures.

Transferring the image from the mask onto the wafer surface layer is an eight-step procedure [19]:

i) The wafer surface is cleaned and dried and placed on the spinner.

ii) The adhesive primer HMDS is spun on the wafer. The HMDS is spun onto the contact side of the wafer using a Solitec 5100 Spinner with a spread speed $500 \mathrm{rpm}$ for 2 seconds, and a spin speed of $4000 \mathrm{rpm}$ for 15 seconds.

iii) A thin layer of photoresist S-1813 is then spun on the surface at the same speed as that of the HMDS.

iv) Softbake is carried out for 75 seconds at $90 \mathrm{C}$ to partially evaporate the photoresist solvents.

v) Then the wafer is exposed to ultraviolet light (with a power density of $7 \mathrm{~mW} / \mathrm{cm}^{2}$ of $436 \mathrm{~nm}$ wavelength light) for 15.5 seconds in the Karl Suss mask aligner.

vi) The unpolymerized resist is removed in the developer solution of MF-319 by agitating the same for 45 seconds. Factors influencing the outcome are soft bake 
time and temperature, degree of exposure, developer concentration and time, temperature and method of developing.

vii) The wafer is hard baked for 90 seconds at $115 \mathrm{C}$ for additional evaporation of solvents and good adhesion of the resist to the wafer surface.

viii) The surface is inspected for alignment and defects under a microscope.

The developed wafer is etched in Buffered oxide etch (6:1:1) to remove the oxide layer at an etch rate of 0.1 micron per minute, with the backside protected by photoresist so as to keep the oxide. The wafer is agitated in the BOE until the contact pads become hydrophobic. Then the photoresist covering the wafer area without contacts as well as the backside was stripped off in acetone.

\subsection{Aluminum Sputtering}

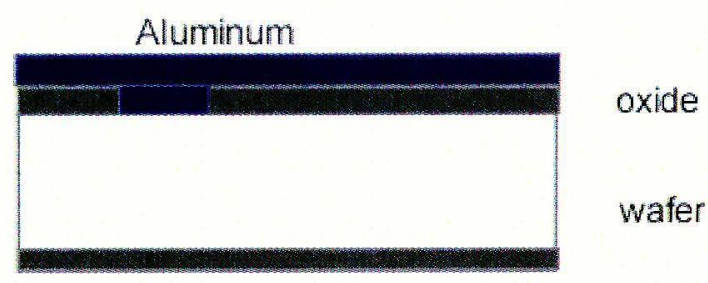

Fig 3.3 Aluminum Sputtered.

Aluminum is deposited on the contact windows by sputtering followed by image reversal. The sputtering is done on the DC side of the Technics series 4604 sputterer for 20 minutes at 200 Watts in static mode in an argon atmosphere of 20 mtorr to deposit a 0.7 um thick film. The aluminum target is an alloy of aluminum-silicon-copper ( $\mathrm{Al}$ $98.5 \%$, Si $1.0 \%$ and cu $0.5 \%)$. 


\subsection{Annealing}

Then the sputtered aluminum is annealed at $480 \mathrm{C}$ for 30 minutes in the trash furnace with $10 \% \mathrm{sccm}$ of argon gas, so that the aluminum adheres well to the silicon substrate. The aluminum alloy and silicon substrate are annealed so that the silicon from the wafer diffuses into the aluminum and minimizes the contact resistance between the two materials. The small component of silicon in the aluminum alloy controls the amount of silicon diffusion into the aluminum, limiting the migration of the aluminum into silicon substrate and thus restoring the crystal damage.

\subsection{Image Reversal}

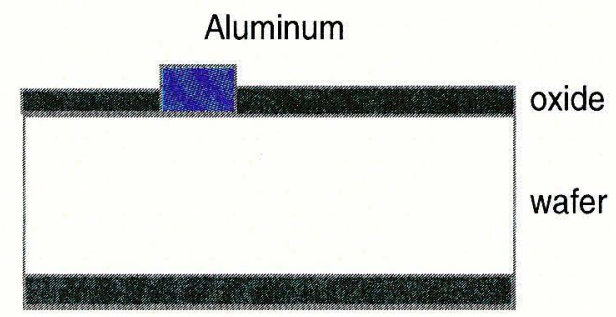

Fig 3.4 Aluminum just on the pads.

The wafer only needs aluminum on the aluminum pads and not on the entire wafer, so the wafer has to undergo image reversal. Image reversal helps in using a positive photoresist in place of a negative photoresist. Positive photoresist has the advantages of high contrast, good step coverage and high aspect ratios. Negative photoresists undergo a cross-linking reaction during exposure to ultra violet light, creating a differential solubility based on molecular weight. Contrast is limited with this reaction mechanism. Positive photoresists, on the other hand, undergo a reaction in which the photo-active compound (diazoketone) is changed from a dissolution inhibitor to a dissolution enhancer (carboxylic acid) [4]: 

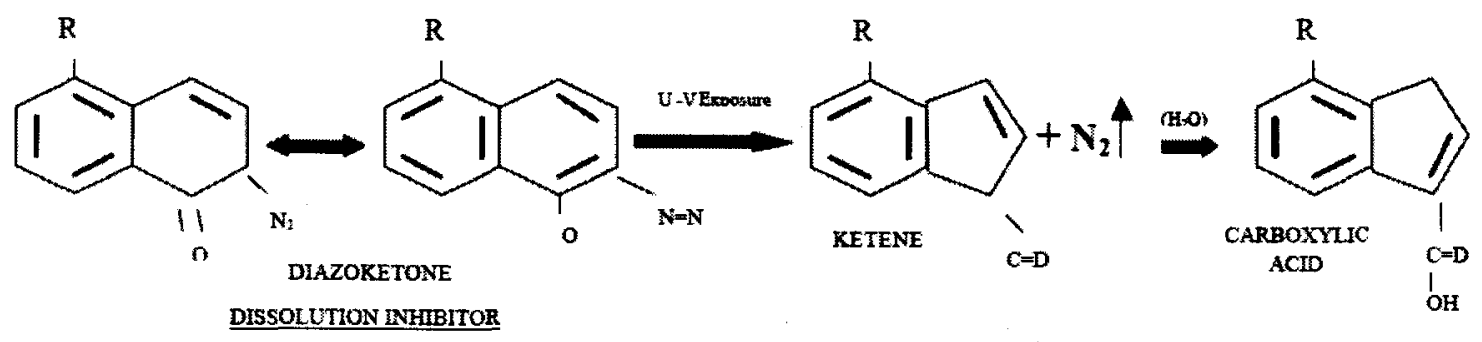

DISSOLUTION ENHANCER

Fig 3.5 Positive Photoresist Reaction.

The contact layer mask is exposed by aligning itself to the already exposed wafer with the same pattern. Then the wafer is put in the image reversal YES oven with the required parameters. During this reversal bake the exposed resist undergoes the reversal process, enhanced by triethanolamine vapors, the entire resist film receives its densification bake [4].

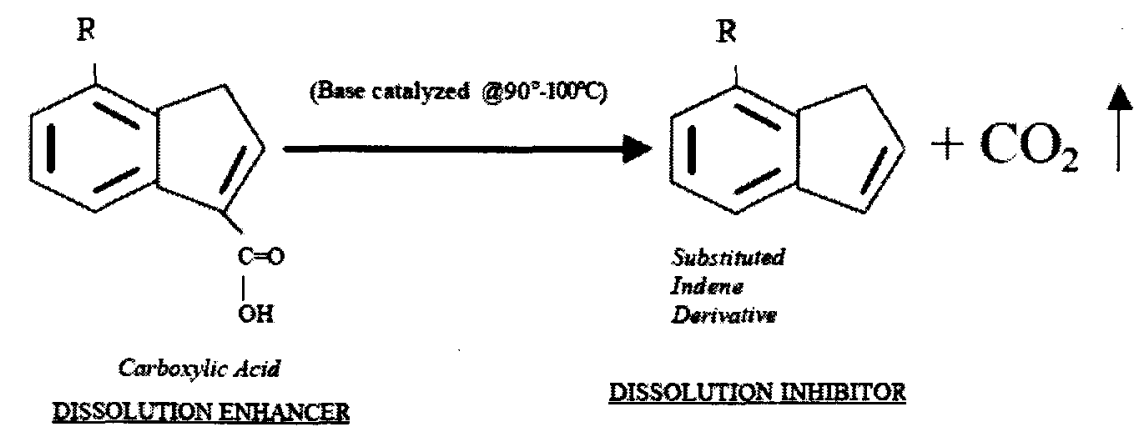

\section{Fig 3.6 Reaction during Reversal Bake.}

Any residual triethanolamine vapors are driven off. Then the wafer is flood exposed for 36 seconds and developed in MF319. The high dose required is due to the extended reversal bake which has reduced the sensitivity of the previously unexposed resist. The rest of the aluminum which is not covered by the photoresist is etched away in the aluminum etch at a temperature of $40 \mathrm{C}$. Then the photoresist covering the pads is stripped off. 


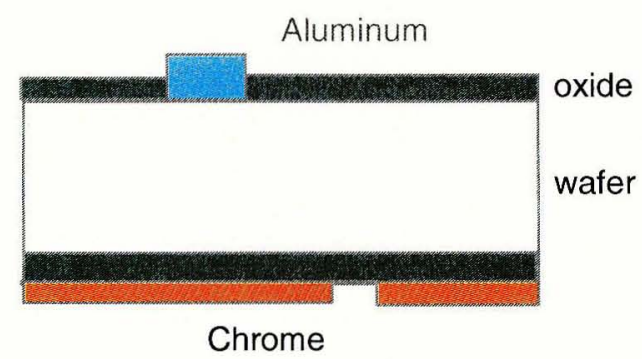

Fig 3.7 Chrome Layer Patterned.

After the aluminum contacts are made then with the help of backside alignment the chrome layer is patterned on the backside and chrome deposited where there are no apertures so that we get apertures of smaller features which is not possible in DRIE as the chrome will block the extra light coming through the apertures. $275 \mathrm{~nm}$ of chrome was deposited when sputtered for 5 minutes at 150 watts on the DC side.

\subsection{Sacrificial Layer}

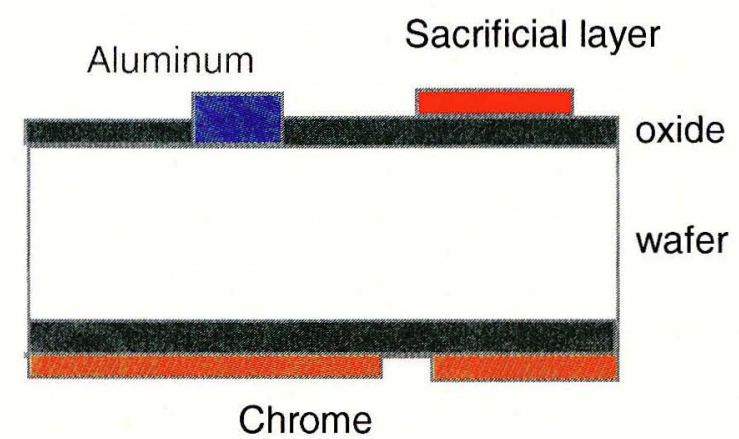

Fig 3.8 Sacrificial Layer Patterned.

MEMS fabrication requires the release of compliant mechanical structures. A sacrificial layer is typically used to provide as a structural layer on which device layers can be deposited and subsequently removed to leave a suspended or freestanding device. There are several sacrificial layers commonly used in MEMS fabrication such as $\mathrm{SiO}_{2}$, polysilicon, polyimide and photoresist. For this project the sacrificial layer is patterned with S-1827. An UV flood exposure is also performed so that the layer can be etched 
easily later on. The photoresist is baked for a long time to evaporate all the solvents so that it does not crack up the seed layer which will be sputtered on top of it later. It is baked for one hour at a temperature of $115 \mathrm{C}$.

\subsection{Seed Layer}

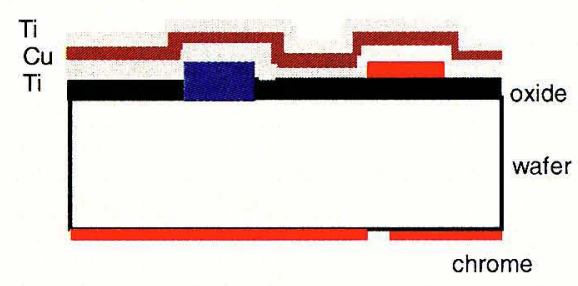

Fig 3.9 Seed Layer Deposited.

The baked wafer is then put in the sputter machine to sputter the seed layer of $\mathrm{Ti} / \mathrm{Cu} / \mathrm{Ti}$ with a thickness of $1000 \mathrm{~A} / 2500 \mathrm{~A} / 1000 \mathrm{~A}$. The top titanium layer will act as an adhesion layer for the mould photoresist. The copper layer underneath will be a good conducting layer with the actuator metal to the substrate. Titanium is sputtered on the RF side for 5 minutes at 315 watts and copper on the DC side for 5 minutes at 120 watts.

\subsection{Moulds for Electroplating}

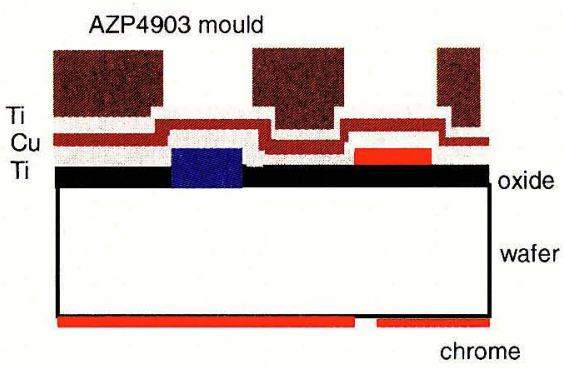

Fig 3.10 Mould Formed for Electroplating.

Once the seed layer is sputtered the next task is to form the moulds for the electroplating for which a thick photoresist AZP4903 is used as the actuators have significant height of around 15 microns. The thick photoresist is spun at a spread spin of 
$100 \mathrm{rpm}$ for 7 seconds and spin speed of $1000 \mathrm{rpm}$ for 25 seconds which gives a thickness of around 22 microns. The soft bake process is carried out at three different temperatures of $60 \mathrm{C}, 90 \mathrm{C}, 110 \mathrm{C}$ for three minutes each to reduce cracking and improve adhesion of the resist to the seed layer. During the process of softbake the edge bead remover is also spun to remove any possible edge bead effects as that can cause diffraction and increase feature size. Because of the high aspect ratio the Dektak profilometer was not able to measure the mould height of the combs so the thickness was measured with one of the larger structures. The wafer is not exposed within minimum thirty minutes after soft baking. The exposure times and development times played a crucial role for patterning the mould layer. A lot of trial and errors finally gave the appropriate value of UV exposure intensity as $7 \mathrm{~mW} / \mathrm{cm}^{2}$ for a time of 450 seconds and then a development time of 4 minutes in 1:4:: AZ400K: water. The problem was either it was underexposed which would result in incomplete development or overexposed which will broaden the feature size of the comb fingers. Also a steep wall as far as possible is aimed in this process and the slope measured was around 5 degrees which is pretty good for a thick resist. The development time also took a long time to figure out for this process as the developer was getting saturated after a certain time and the last bit of resist took some time to get developed which is difficult to predict at first. The major problem which was faced with the developing and exposing of the resist was that the metal would not plate over the resist even if there was a very thin layer of resist remaining that will prevent the metal to plate over the seed layer and if plated on just a few points will not adhere the metal well to the copper layer. After the resist was finally developed it was etched in the RIE with oxygen gas so as to remove any residual debris of the resist that 
could have been remaining after the development. The recipe for the dry etch is oxygen flow at a rate of $20 \% \mathrm{sccm}$, pressure of $200 \mathrm{mtorr}$, and power of 200 mwatts for one minute. Once the resist is completely developed and stripped from the places where the metal is to be plated, then the wafer is etched in 1:40 HF to remove the titanium from those places as nickel will not plate on titanium. Now the wafer is ready for electroplating.

\subsection{Electroplating}

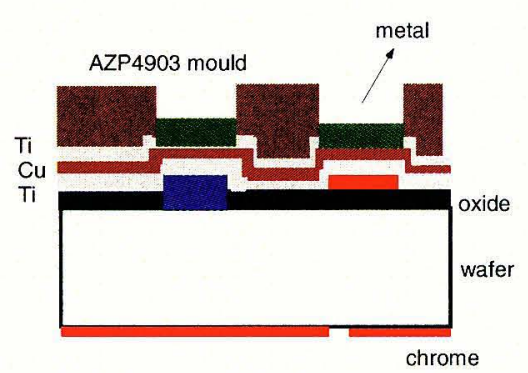

Fig 3.11 Nickel Electroplated over Copper.

The metal electroplated is nickel which has a density of $8.9 \mathrm{gm} / \mathrm{cc}$ at $300 \mathrm{~K}$. The amount of area to be plated is 24.8 square $\mathrm{cm}$ with a current density of $20 \mathrm{Amp} / \mathrm{ft}^{2}$ which is $21.52 \mathrm{~mA} / \mathrm{cm}^{2}$ and that result in a current of $533.88 \mathrm{~mA}$. Using Faradays Law of Electrolysis

$$
\text { Time }=\frac{t \rho F n}{J M}
$$

where $\mathrm{t}=$ Film Thickness in $\mu \mathrm{m}$

$\rho=$ Density of $\mathrm{Ni}=8.9 \mathrm{~g} / \mathrm{cm}^{3}$

$\mathrm{F}=$ Faraday constant $=96488 \mathrm{C} / \mathrm{mol}$

$\mathrm{n}=$ No. of electrons available in Nickel $=2$

$\mathrm{J}=$ Current Density in $\mathrm{mA} / \mathrm{cm}^{2}$

$\mathrm{M}=$ Molecular weight of Nickel Electroplating solution $=58.71 \mathrm{~g} / \mathrm{mol}$ 
Substituting the above values:

$$
\text { Time }=48.756217 \frac{t}{J}
$$

where Time $=$ Time measured in $\min$

The amount of time calculated is 45 minutes to plate a nickel layer of 15 microns.

The electroplating is carried out with a Technic nickel sulfamate solution whose $\mathrm{pH}$ is maintained at 4.0 and at $100 \mathrm{~F}$ throughout the experiment to minimize stress. To increase the $\mathrm{pH}$ the base nickel carbonate was added to the solution and to decrease the same an acid sulfamic acid was mixed in the solution. The $\mathrm{pH}$ meter monitored the $\mathrm{pH}$ before the experiment. Once the electroplating bath is ready then the wafer is dipped in a $5 \%$ $\mathrm{H}_{2} \mathrm{SO}_{4}$ solution so as to strip off any native copper oxide formed on the wafer which could stop the plating. The anode is formed by the platinum mesh and the cathode is the wafer itself in which the nickel from nickel sulfamate deposits. After the electroplating the photoresist mould is stripped off in acetone and observed under the microscope. The nickel structures measured were around $10 \mu \mathrm{m}$ in height. Now the metal seed layer which is not plated is etched, titanium and copper in 1:40 HF and Copper dip (7 gm of sodium perchlorate in 100 gm of DI water) respectively. The last titanium layer is then etched and the oxide is seen in those places.

\subsection{DRIE}

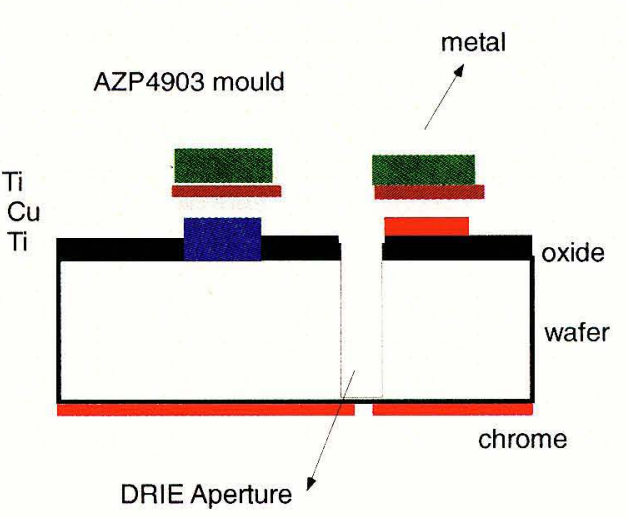


Deep Reactive Ion Etching (DRIE) is a means of etching deep, high aspect silicon structures. This is accomplished in part by using a switched gas scheme that includes both a passivation and etch step, otherwise known as Bosch Process. The DRIE system has an inductively coupled plasma (ICP) source to provide a high density plasma, and an independent substrate power bias to provide directional ion bombardment during the etch step. A protective layer of polymer is first deposited. $\mathrm{C}_{4} \mathrm{~F}_{8}$ (Octofluorocyclobutane) is the gas used for passivation step, and it deposits on the substrate in a conformal manner. This is followed by the Etch step where the gas $\mathrm{SF}_{6}$ (sulphur hexafluoride) is made to flow with the substrate bias on. During this step the sidewalls of the silicon trench are relatively protected by the $\mathrm{C}_{4} \mathrm{~F}_{8}$ induced polymer layer. The bottom of the trench being formed, although also coated with polymer, is pierced by the directional ion bombardment. The silicon is then etched by means of reaction. The iteration of these passivation /etch cycles allows the desired anisotropic features to be achieved. Based on the aspect ratio required the recipe of etch cycle, passivation cycle, power on platen, overrun etc are determined.

The sacrificial layer is not etched before the DRIE so that the movable actuator structure does not free itself and breaks in the process of lithography. Now for the DRIE lithography another thick resist SPR 220 is used. The wafer is coated with SPR 220 spun at $4000 \mathrm{rpm}$ for a resist thickness of $8 \mu \mathrm{m}$, but the edges of the metal are not covered fully so the resist is spun again as the metal layer should not be exposed inside the DRIE ICP plasma chamber since it will deposit the metal in the chamber. Then the wafer is soft baked at 90C and then the pattern exposed in KARL SUSS mask aligner for 145 seconds. The post exposure bake is performed at $50 \mathrm{C}$ after 30 minutes and then developed in 
MF319 for 2 minutes. The wafer is glued to a handle wafer because the etch will go through the full $300 \mu \mathrm{m}$. The etch should terminate at the oxide on the bottom surface of the wafer but still the precaution is taken to place it on a handle wafer to ensure that there is no helium leakage during the etching process. The etch aspect ratio is 20:1.

\subsection{Etching of Sacrificial Layer}

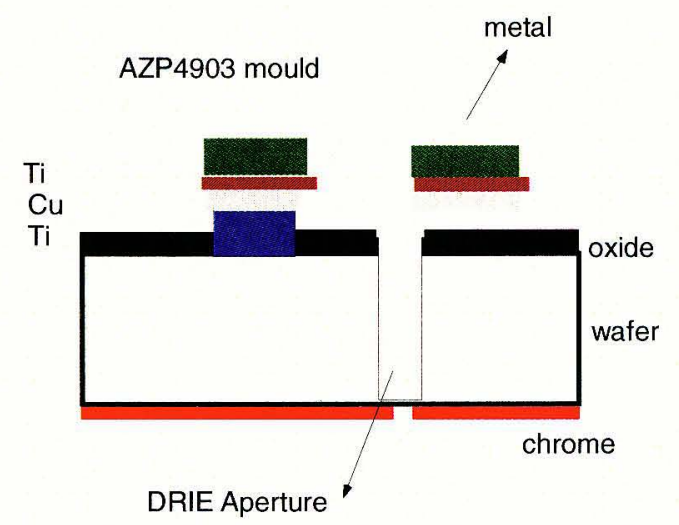

Fig 3.13 Sacrificial Layer Etched to Free the Structure.

After the apertures are etched the movable parts need to be freed from the sacrificial layer. To etch the sacrificial layer a dry etch is used as a wet etch may cause stiction problems [8]. The SPR 220 is etched in the RIE with an oxygen plasma and the sacrificial layer is etched inside a plasma asher at a forward power of 50 watts and pressure of 0.5 torr for approximately 8 hours as the photoresist was difficult to remove after the long hard bakes. The plasma asher is isotropic and thus helps remove the resist under the metal structures. The plasma asher is preferred over the RIE which is anisotropic and etches vertically more and laterally less. 


\section{CHAPTER 4}

\section{RESULTS}

\subsection{Contact Resistance Measurements}

Contact resistance is the resistance between the metal to the silicon substrate. This is very important because a high contact resistance indicates that the metal is not in proper contact with the substrate and the circuit may not perform as expected.

Contact resistance is very important. In a modern $90 \mathrm{~nm}$ process, the vias that contact the silicon have a contact area of about $1 \mu \mathrm{m}^{2}$, or $10^{-8} \mathrm{~cm}^{2}$. If the contact resistance is $10^{-5}$ $\Omega \mathrm{cm}^{2}$, that amounts to $1 \mathrm{k} \Omega$ resistor just to get into the silicon plus another to get out. A good contact resistance is on the order of $10^{-7} \Omega / \mathrm{cm}^{2}[25]$.

The measurements required to measure the contact resistance are performed at a probe station. A voltage is applied between pairs of adjacent pads in a row, and the current flow is measured. From this, the resistance is calculated between those two pads $\left(\mathrm{R}=\frac{V}{I}\right)$.

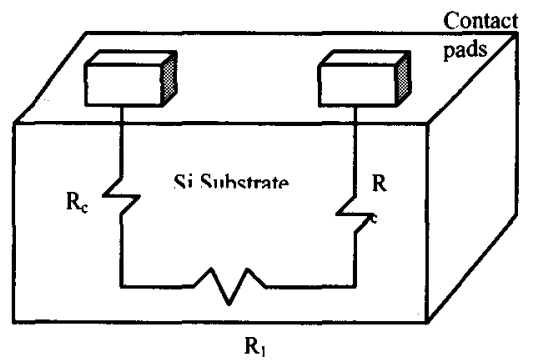

Fig 4.1 Schematic showing the current path between contact pads on the silicon substrate. There is a contact resistance per unit area $\left(R_{c}\right)$ between the pad and the substrate, and the substance has some resistance to it $\left(\mathrm{R}_{1}\right)$. 
As illustrated in Fig 4.1, the total resistance between any two pads is the series combination of 3 resistors: metal to semiconductor $\left(\mathrm{R}_{\mathrm{c}}\right)$, through the semiconductor $\left(\mathrm{R}_{1}\right)$, and back into metal $\left(\mathrm{R}_{\mathrm{c}}\right)$. Since ohmic contacts are the same for both polarities of current flow, the total resistance is $2 R_{c}+R_{1}$.

Figures $4.2-4.4$ show the voltage versus current measurement between different contact points separated by corresponding distances, in the parameter analyzer, and the reciprocal of the slope gives the resistance values.

Fig 4.2 I-V curve for pad spacing of 1500 $\mu \mathrm{m}$.

Resistance $=26.2 \mathrm{k} \Omega$ on the positive side

$=25.7 \mathrm{k} \Omega$ on the negative side
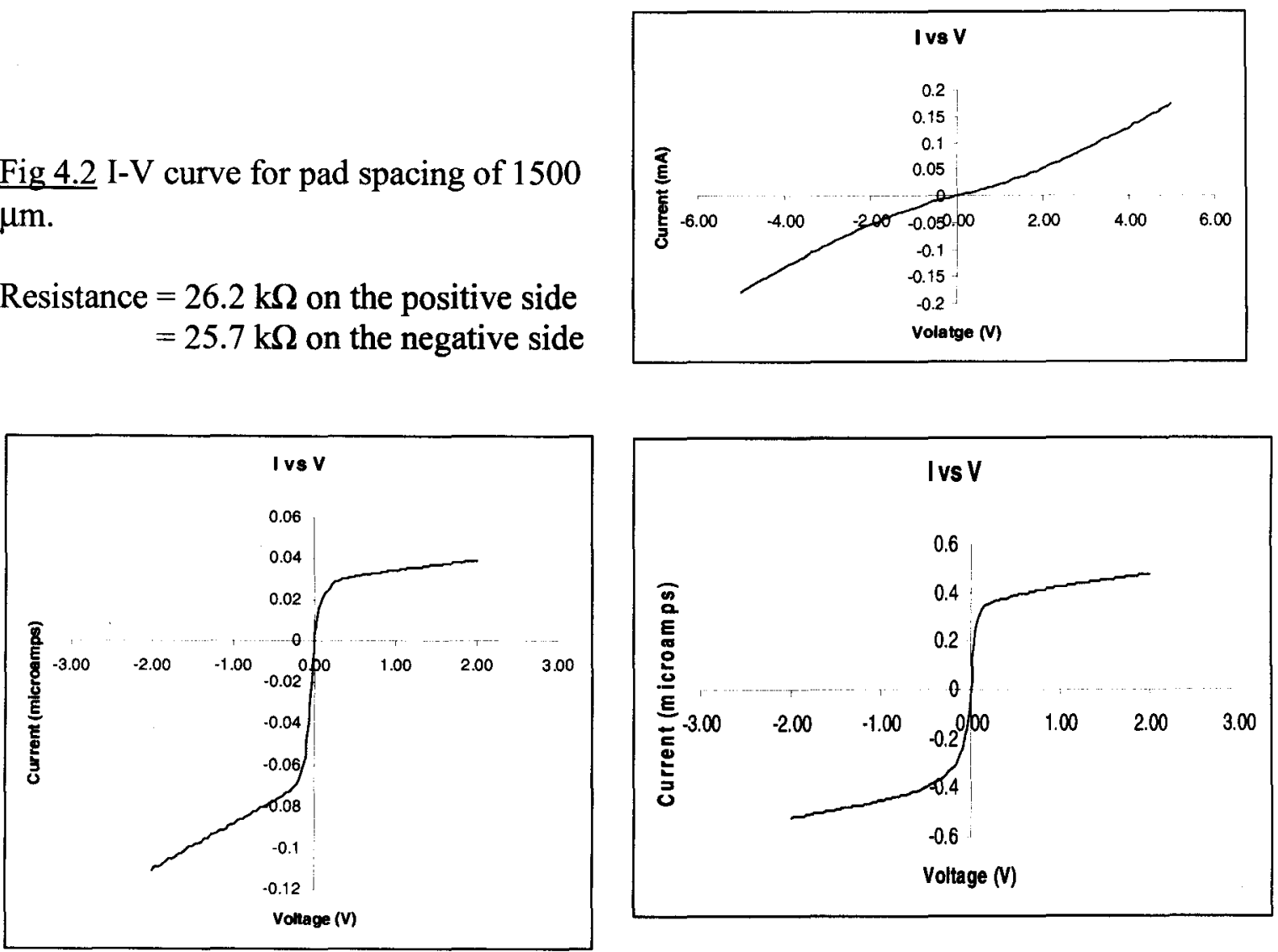

Fig 4.3 I-V curve for pad spacing of 6185 $\mu \mathrm{m}$

Fig 4.4 I-V curve for pad spacing of 4000 $\mu \mathrm{m}$

Resistance $=212.8 \mathrm{M} \Omega$ on the positive side Resistance $=18.5 \mathrm{M} \Omega$ on the positive side $=43.8 \mathrm{M} \Omega$ on the negative side $=14.9 \mathrm{M} \Omega$ on the negative side 


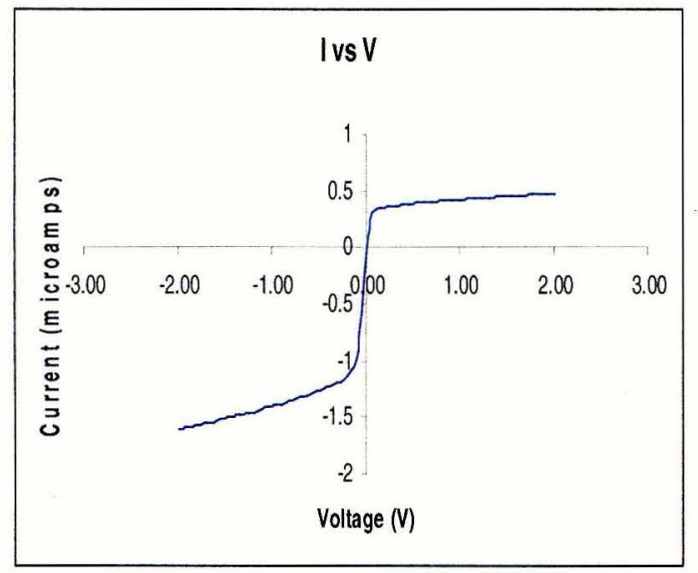

Fig 4.5 I-V curve for pad spacing of $5000 \mu \mathrm{m}$

Resistance $=4.76 \mathrm{M} \Omega$ on the positive side $=18.86 \mathrm{M} \Omega$ on the negative side

In the limit where the distance between the pads approaches $0, R_{1}$ goes to 0 and what is left is $2 R_{c}$. Now if the area of the pads is multiplied with $R_{c}$ to get the contact resistance of the pads.

The above figures $4.2-4.4$ show curves are not lines, showing that they are not ideal ohmic contacts and show evidence of a Schottky barrier. The asymmetric curves on either side of a shottky barrier and wide range of resistance values does not give the best data to plot the resistance versus distance curve and thus restricts the measurement of the contact resistance.

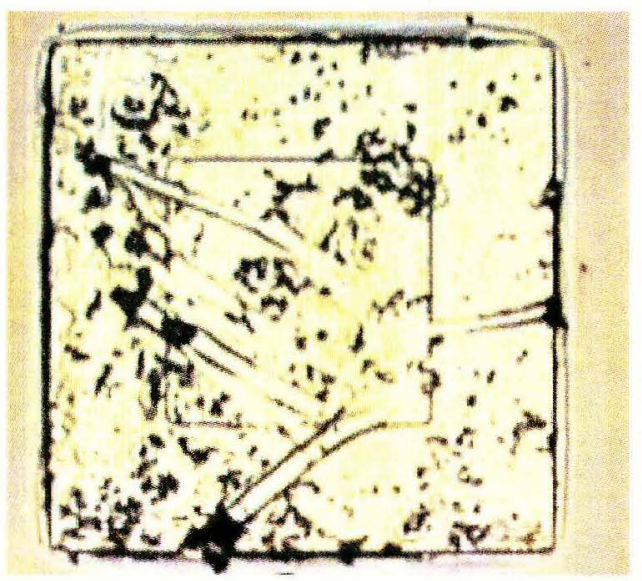

Fig 4.6 Test Structure Used to Measure the Contact Resistance. 
This resistance is high. Potential reasons for the high resistance include (1) the fact that the current wafer was not properly doped with boron forming a schottky barrier between the metal and silicon; (2) there could be some oxide remaining on the contact windows; (3) improper annealing and (4) the wafers may not have been properly cleaned prior to annealing.

\subsection{Resistivity of the Deposited Film}

In general, resistivity is calculated from the potential difference between electrodes on the sample when a known current flow between the same or other electrodes attached to the sample, with different mathematical formula for different boundary shapes of samples. Van der Pauw described a method of measuring electrical resistivity in flat samples which is independent of the current flow in the sample and is therefore applicable to boundaries of arbitrary shapes.

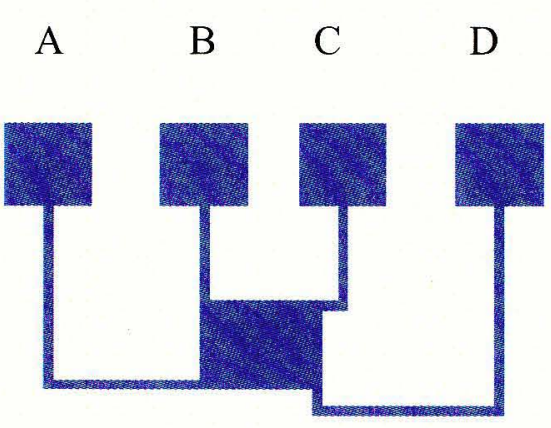

a)

b)

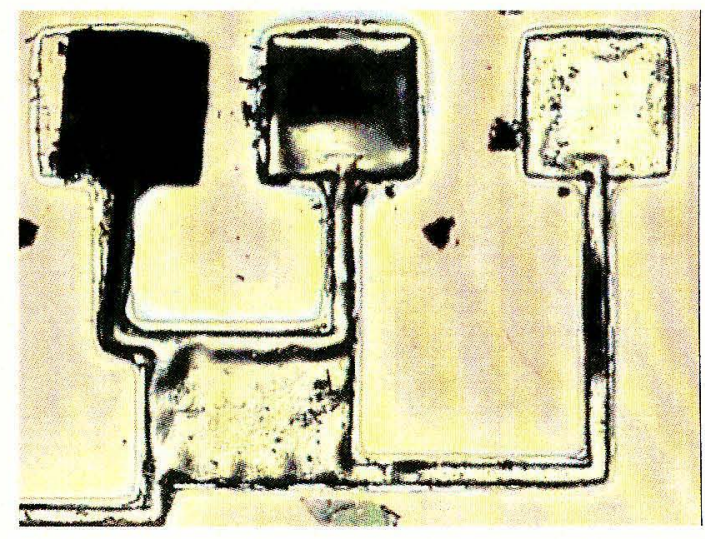

Fig 4.7 Van der Pauw Structure a) on Mask b) on Wafer. 
The Van der Pauw structure shown in Fig 4.6 (b) is made of uniform thickness and has no holes. It was used in the testing of this study to measure the resistivity of the electroplated nickel layer. Four points A,B,C,D are made at the periphery of the sample.

$$
\mathrm{R}_{\mathrm{AB}, \mathrm{CD}}=\left(\mathrm{V}_{\mathrm{D}}-\mathrm{V}_{\mathrm{C}}\right) / \mathrm{I}_{\mathrm{AB}}
$$

The resistance $R_{B C, D A}$ is defined in a similar way and the resistivity of the material ( $\rho$ ), assumed to be isotropic, is uniquely determined by the relation

$$
\exp \left(-\pi d R_{A B, C D} / \rho\right)+\exp \left(-\pi d R_{B C, D A} / \rho\right)=1
$$

where $d$ is the thickness of the sample. Once $R_{A B, C D}$ and $R_{B C, D A}$ are measured the value of $\rho$ can be found. The solution to Eq (4.1) is

$$
\rho=\frac{\pi d}{\ln 2} \frac{\left(R_{A B, C D}+R_{B C, D A)}\right.}{2} f \frac{R_{A B, C D}}{R_{B C, D A}}
$$

If $R_{B C, D A}$ and $R_{B C, D A}$ are almost equal then $f$ can be approximated as

$$
\mathrm{F} \sim 1-\frac{\left(R_{A B, C D}-R_{B C, D A}\right)^{2}}{\left(R_{A B, C D}+R_{B C, D A}\right)^{2}} \frac{\ln 2}{2}-\frac{\left(R_{A B, C D}-R_{B C, D A}\right)^{4}}{\left(R_{A B, C D}+R_{B C, D A}\right)^{4}}\left\{\frac{(\ln 2)^{2}}{4}-\frac{(\ln 2)^{3}}{12}\right\}
$$

Using $\mathrm{Eq}(4.1)$ to $\mathrm{Eq}(4.4)$ the calculated resistivity of electroplated nickel is $9.6 \mathrm{E}-08$ ohm-cm.

\subsection{Test Structures to Measure Stress}

Free standing flexible microstructures fabricated from deposited thin films become mechanically unstable when internal stresses exceed critical value. Excessive compressive or tensile strain fields result in cracking, splintering and adhesion problems of the film to the substrate.

Two major sources of internal stress or strain in films deposited on thick substrates are: 
(i) The first cause is due to differences in the thermal expansion coefficients between the film and the substrate for films deposited at elevated temperatures and measured at room temperatures.

(ii) The second reason is caused by a high growth rate and low surface mobility of added material which prevents the atoms from reaching low energy states, resulting in a 'freezing in' of the strain field.

Film stresses cause a slight bending or curvatures of the substrate which can be measured by a cantilever beam measurements or radius of curvature measurements.

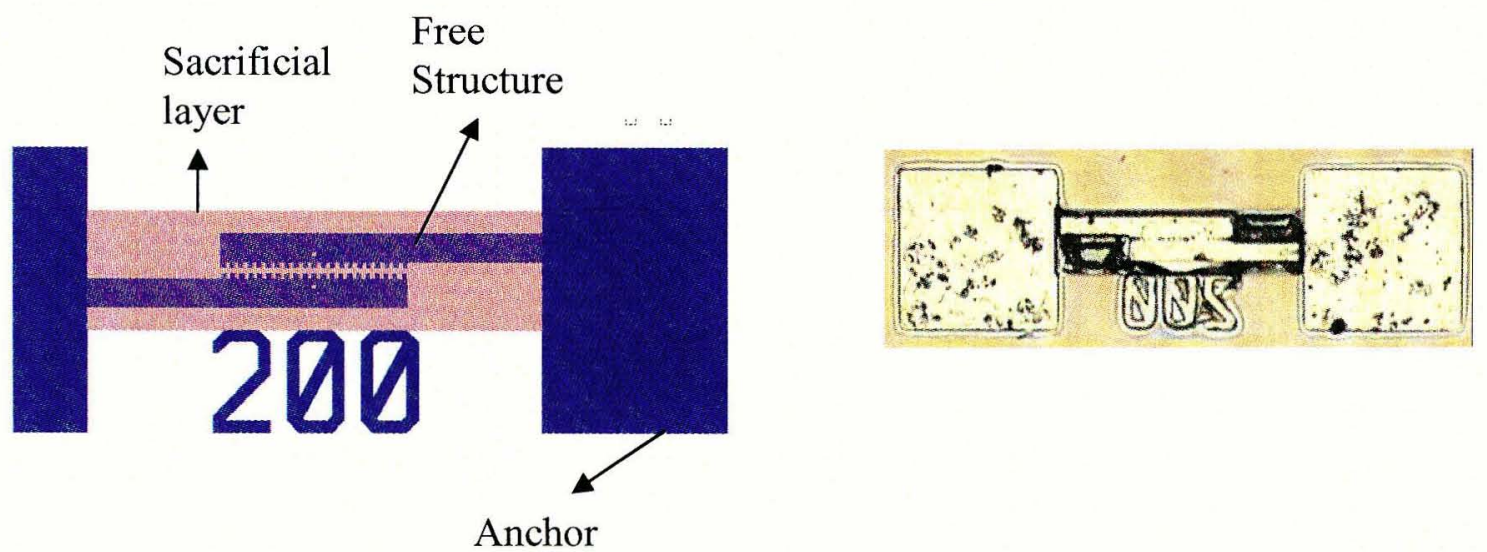

Fig 4.8 Stress test structures for measuring strain in electroplated nickel, the left diagram is from the mask and the right one is from the wafer.

Fig 4.8 is a beam strain sensor. Initially developed by Gianchandani and Najafi in 1996 [23] they are quite popular because they can measure both compressive and tensile stresses. The ends of the cantilevers contain a vernier scale. Upon release from the substrate, these structures expand or contract due to internal stresses. By measuring the displacement of the teeth of the vernier, stress measurements can be obtained either analytically or by FEA simulation. 
These structures are limited in resolution by the minimum feature size of a technology. Out of plane displacements caused by stress gradients and non uniform beam thickness can inhibit device sensitivity.

$$
\frac{\partial \sigma}{\partial t}=\frac{2 y E}{(1-v) l^{2}}
$$

$y=$ non planar deflection of the cantilever tip which is measured optically or with a SEM.

$t=$ thickness of the film

$1=$ length of the cantilever

$v=$ poisson's ratio

$\mathrm{E}=$ Young's Modulus

This test structures in this device didn't work because the verniers were physically connected during electroplating.

\subsection{Fabrication Results}

\subsubsection{Thick Photoresist as Electroplating Mould}

At the time of making the moulds for electroplating the major problem faced was that the nickel was not electroplating on the seed layer. The reason behind that was the thick photoresist AZP4903 was not removed entirely from the places where the metal had to be plated. This was not noticeable by bare eyes or even under the microscope but SEM images clearly depicts the mould structure, the slope and the residual resist as shown in Fig 4.9 and 4.10 . 


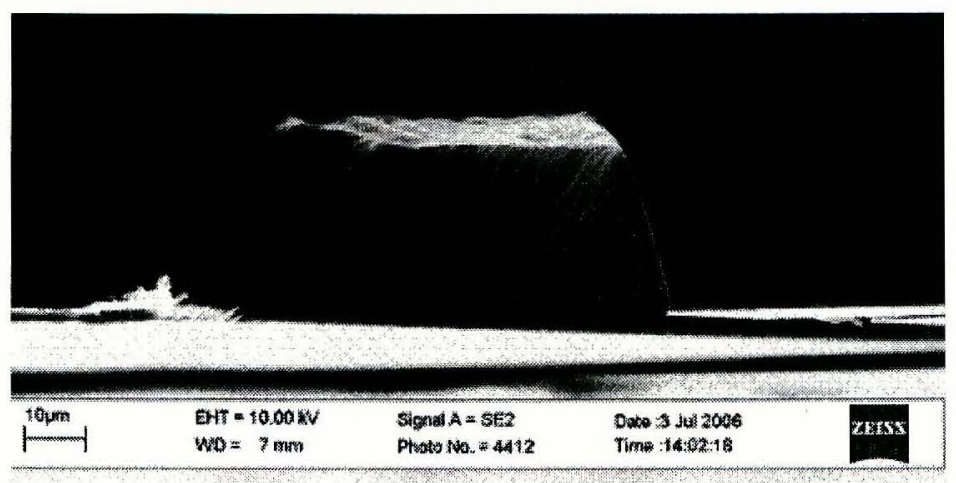

Fig 4.9 The spacing between the moulds of the comb fingers has a thin layer of photoresist layer remaining on the substrate.

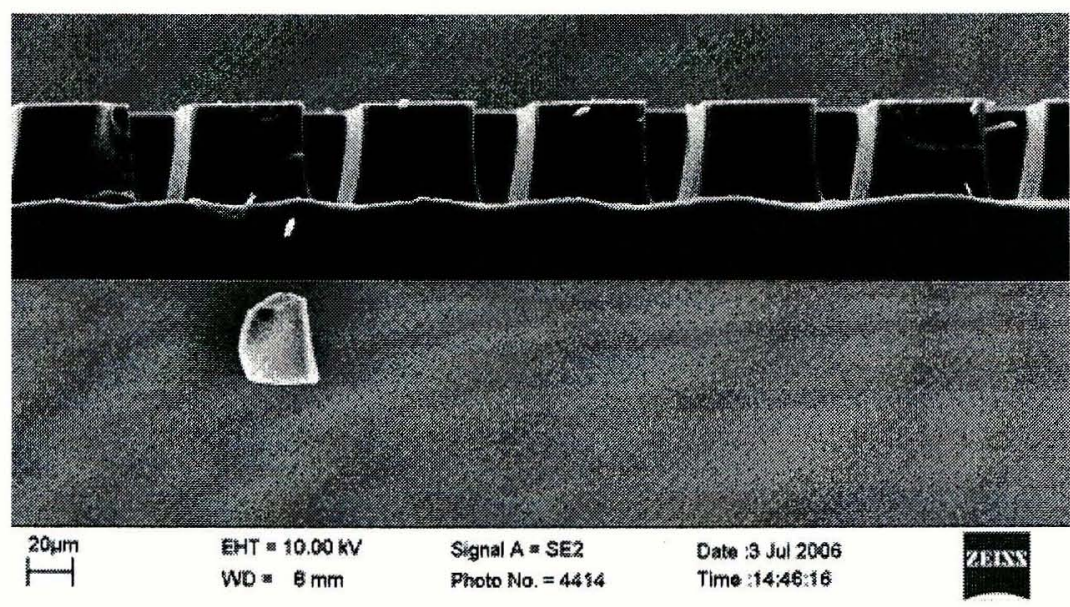

Fig 4.10 AZP4903 mould as seen under the SEM. The walls are almost vertical with a little slope of about 5 degrees. The photoresist is only half developed.

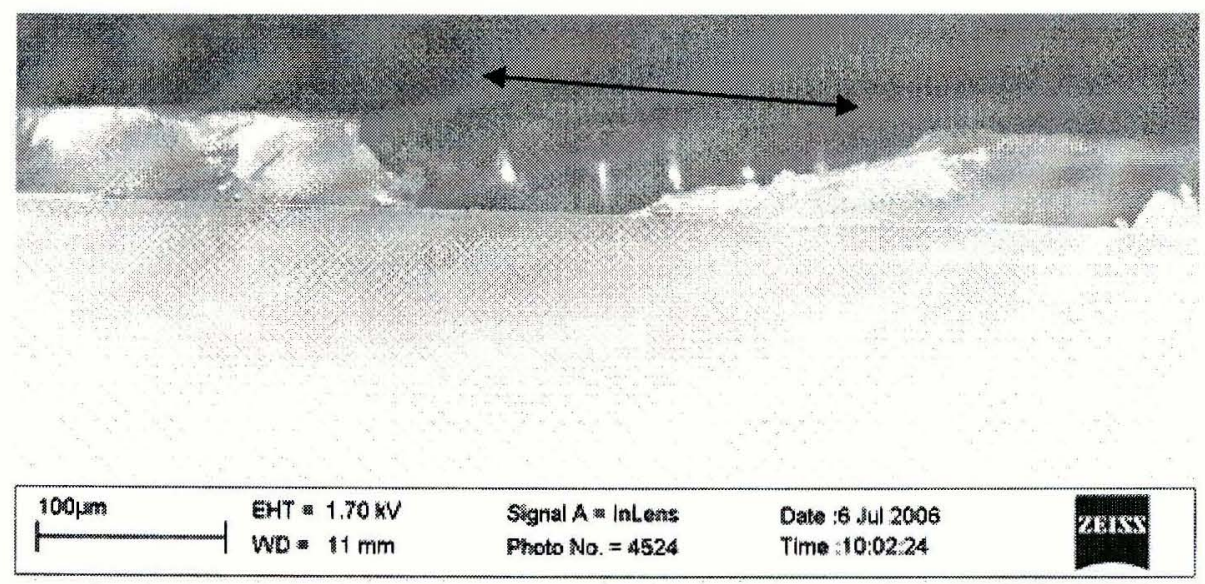

Fig 4.11 Side view of the Mould. 


\subsubsection{Electroplated Nickel Structures}

Once the above mentioned problem was fixed with proper exposure dose and development times then actuators were fabricated by electroplating nickel in the mould. The results are shown in Fig 4.11 through Fig 4.15

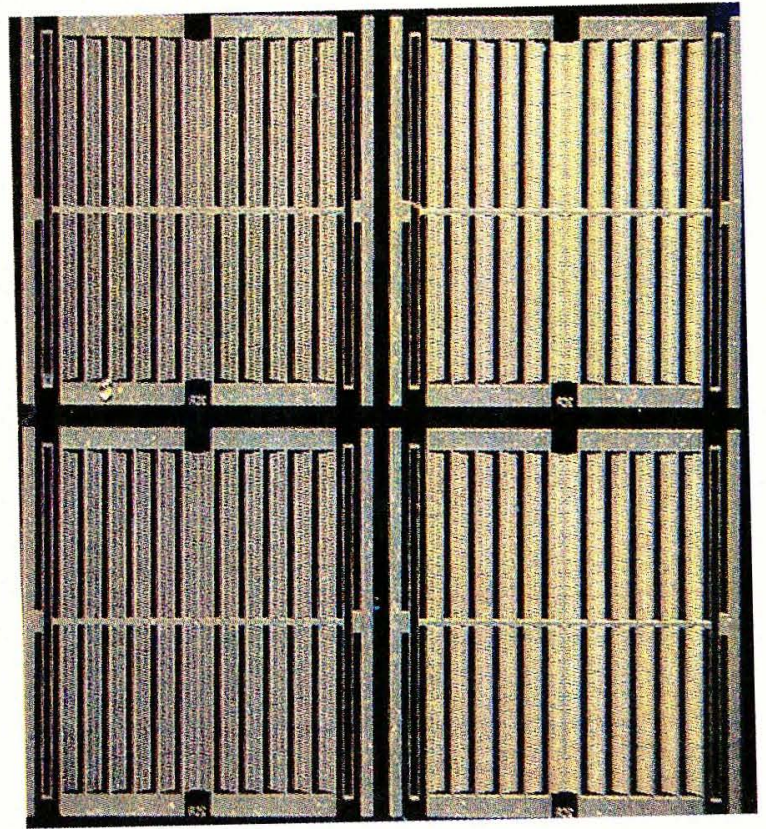

Fig 4.12 A Picture of Four Comb Drive Dies taken with a Microcamera.

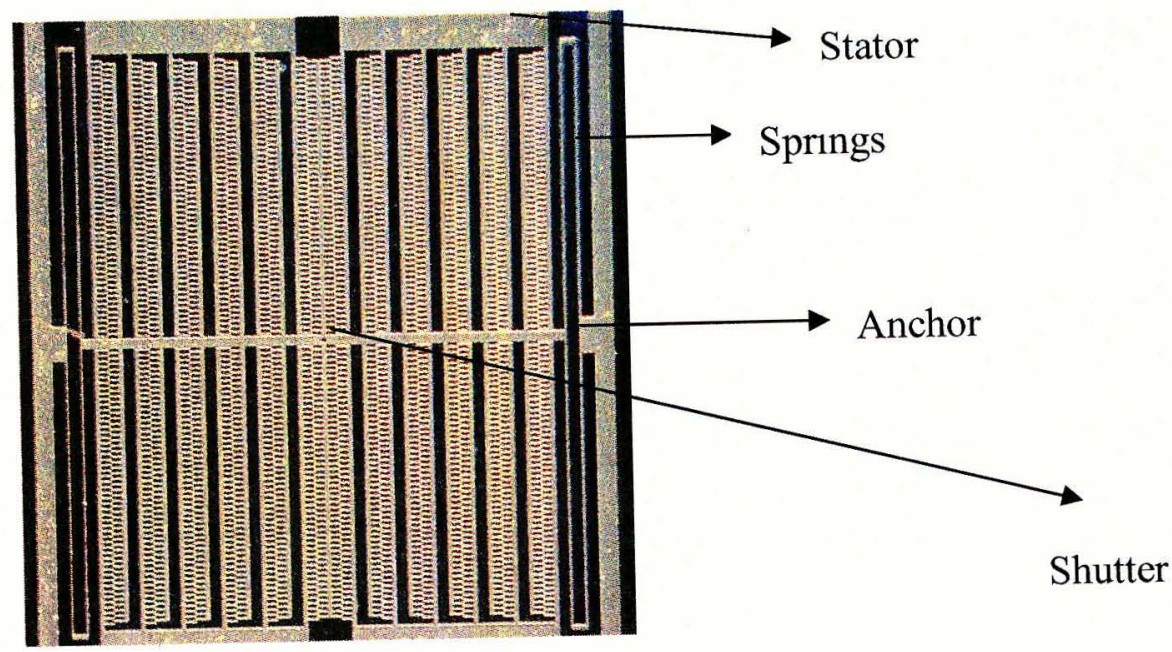

Fig 4.13 A Detailed Picture of a Comb Drive. 


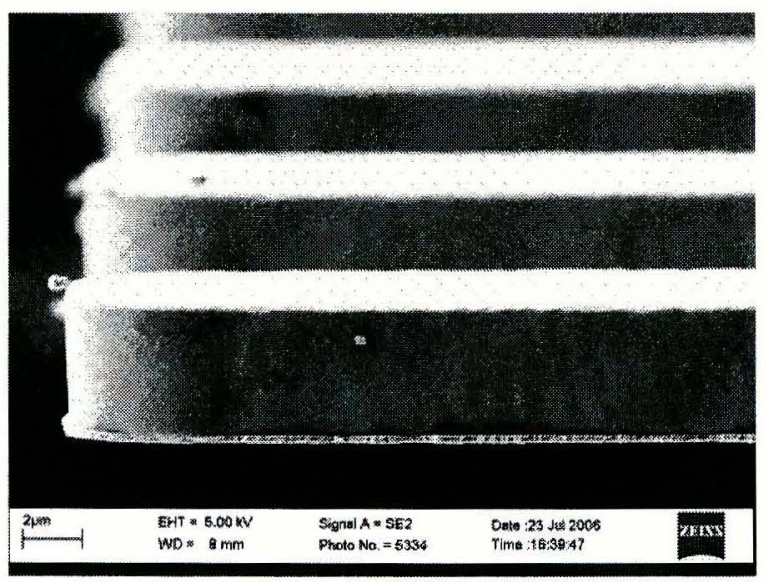

Fig 4.14 SEM Picture of the Comb Fingers Suspended in Air with the Seed Layer at the base.

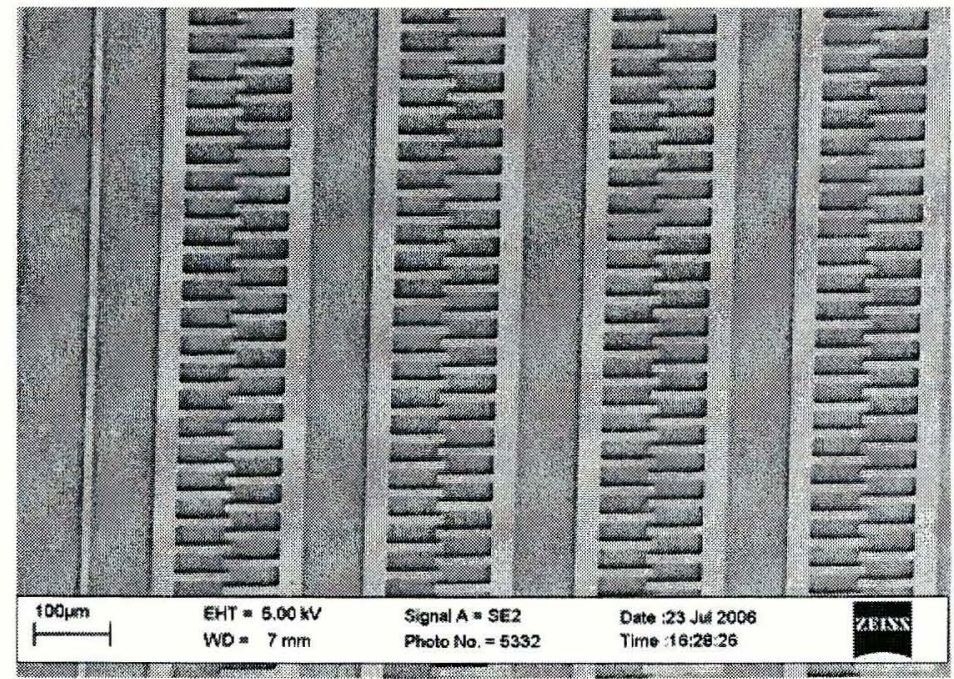

Fig 4.15 Top view of the Combs under SEM.

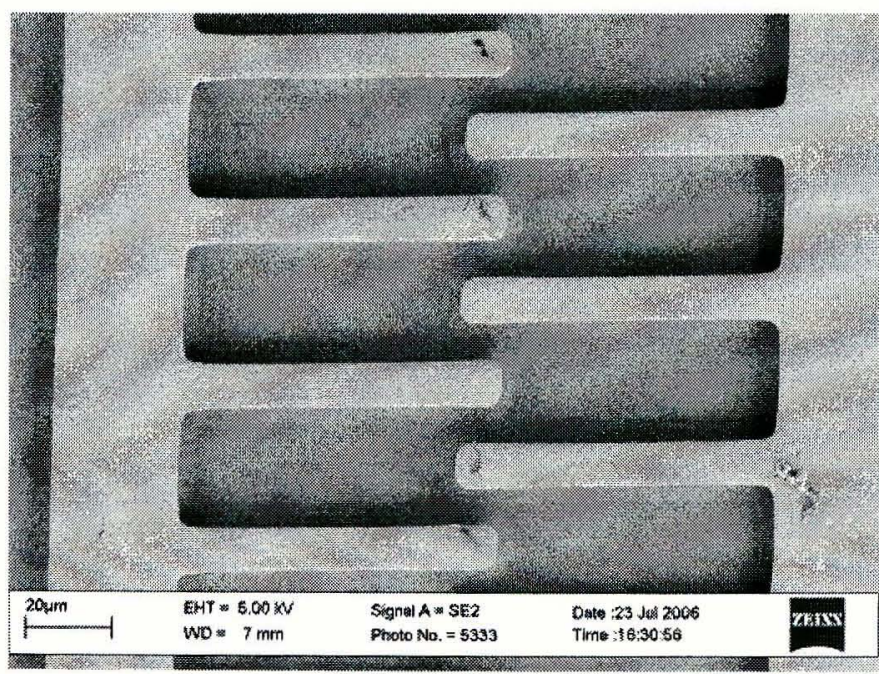

Fig 4.16 Picture showing Good Fabrication result. The Fingers Maintain their Edges. 


\subsubsection{DRIE of Apertures}

A test wafer was used to test the through-wafer DRIE etch step. $15 \mu \mathrm{m} \times 15 \mu \mathrm{m}$ apertures were successfully etched through the wafer with nearly vertical sidewalls. The $1,2,3,4,5$ and $10 \mu \mathrm{m}$ apertures did not etch through the wafer, although they were just designed to see if the chrome layer was not necessary.

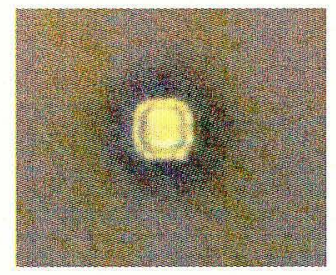

Fig 4.17 Top view of the $15 \mu \mathrm{m}$ Aperture when Illuminated from the Top and Bottom Sides Simultaneously. This Image was taken using a 20x Objective.

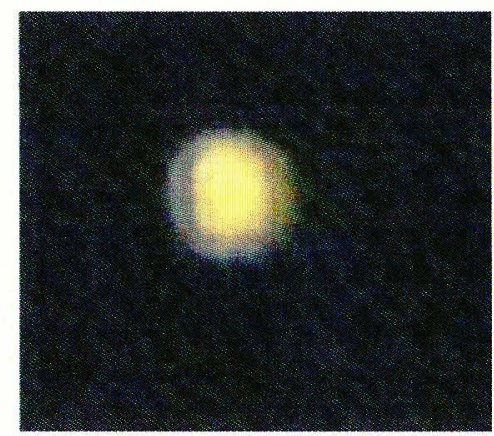

a)Top view of the 15 um aperture when illuminated from the back

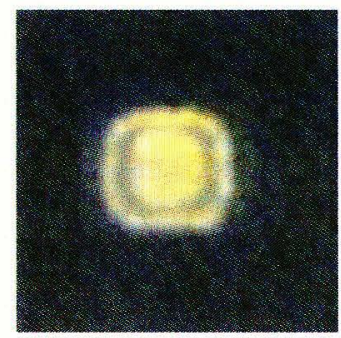

c) Top view of the 15 um aperture when illuminated from the back with a different objective.

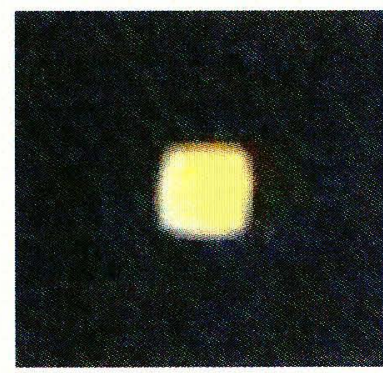

b) Top view of the 15 um aperture when illuminated from the back at different depth of focus

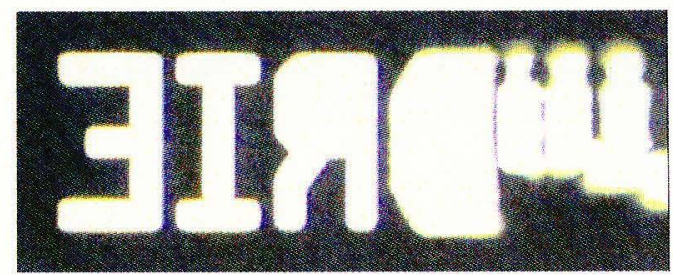

d) DRIE letters at $5 x$

Fig 4.18 Optical Images of the Light Transmitted Through the Programmable Mask at Various Resolutions. 


\subsubsection{Sacrificial Layer Etching}

The final step is to free the actuators by etching the sacrificial layer. Since the sacrificial layer photoresist got hardened by long hard bakes in the initial stages it took around 8 hours approximately to etch the same. During intervals of etching the wafer was inspected of the sacrificial layer resist. Once the parts started to free themselves a few of the comb fingers touched each other because of misbalance in the spring force as the entire structure was not free at that time. This was an indication that the sacrificial layer was getting etched in the plasma asher. As long as it had the dark background under the rotor fingers more etching was required. Looking at the color it was predicted that the photoresist was etched away only when the background turned to green from black in color. The final device can be seen in Figs.4.18- 4.22.

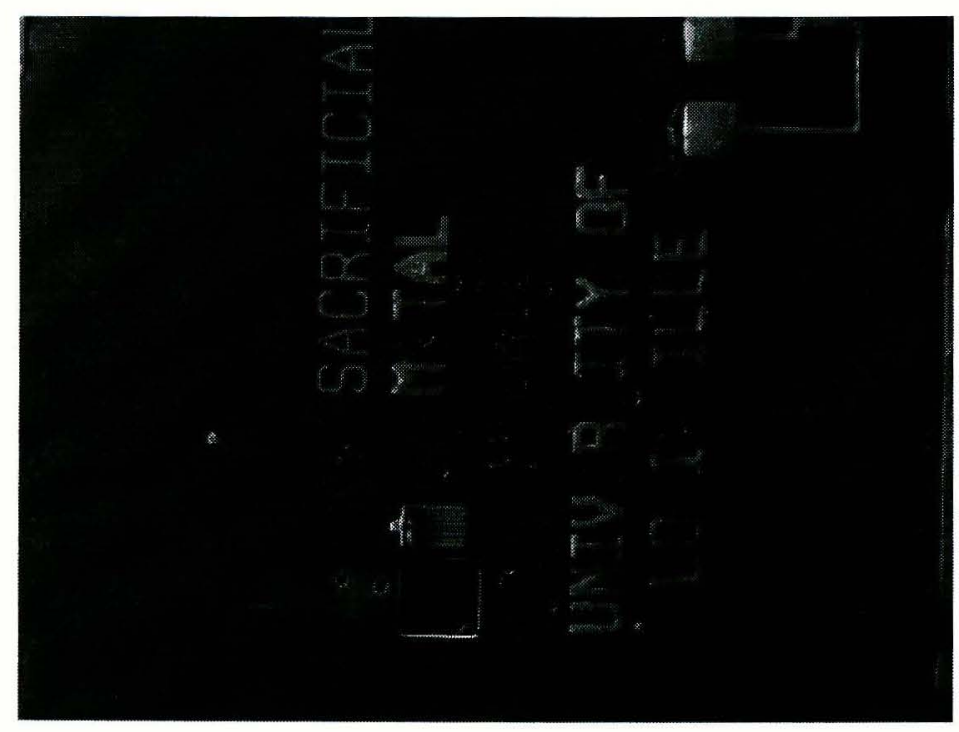

Fig 4.19 SEM picture of Alignment marks after Etching in Plasma Asher. Square hole is through wafer Etch. Missing letters of "UofL" shows Poor Adhesion of Nickel to Susbtrate. 


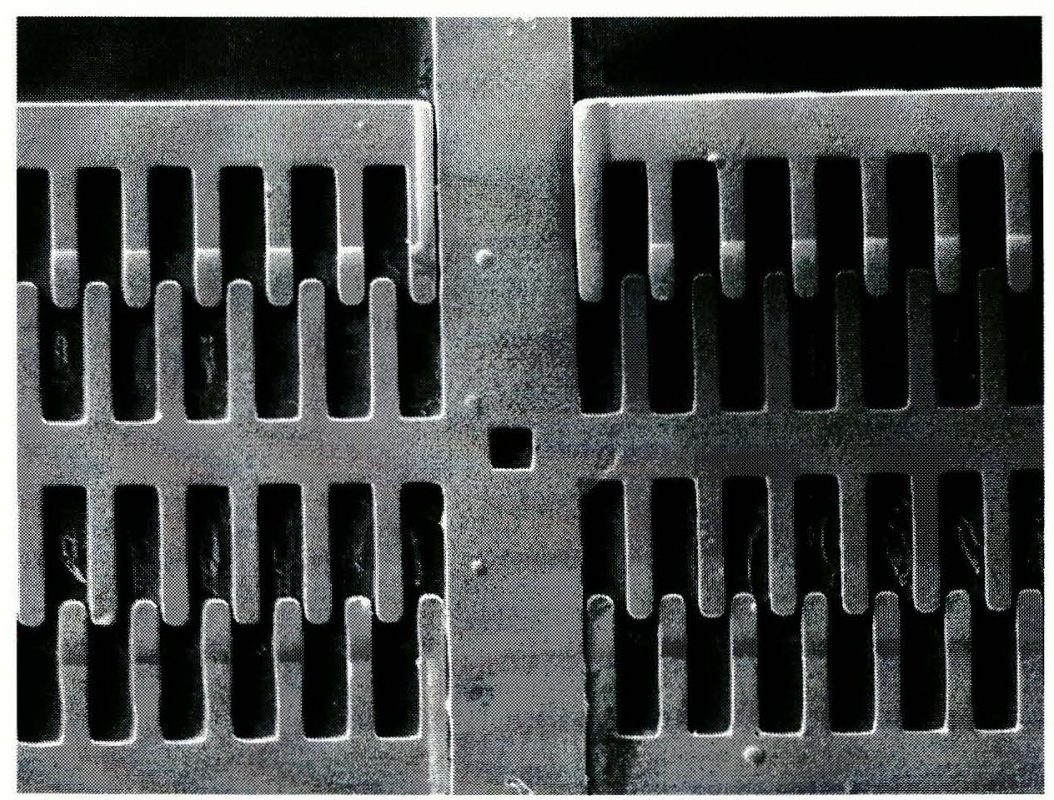

Fig 4.20 SEM picture of the Comb Fingers after Etching in Plasma Asher. Free Combs are touching the Fixed fingers showing Incomplete Etch and Poor Adhesion.

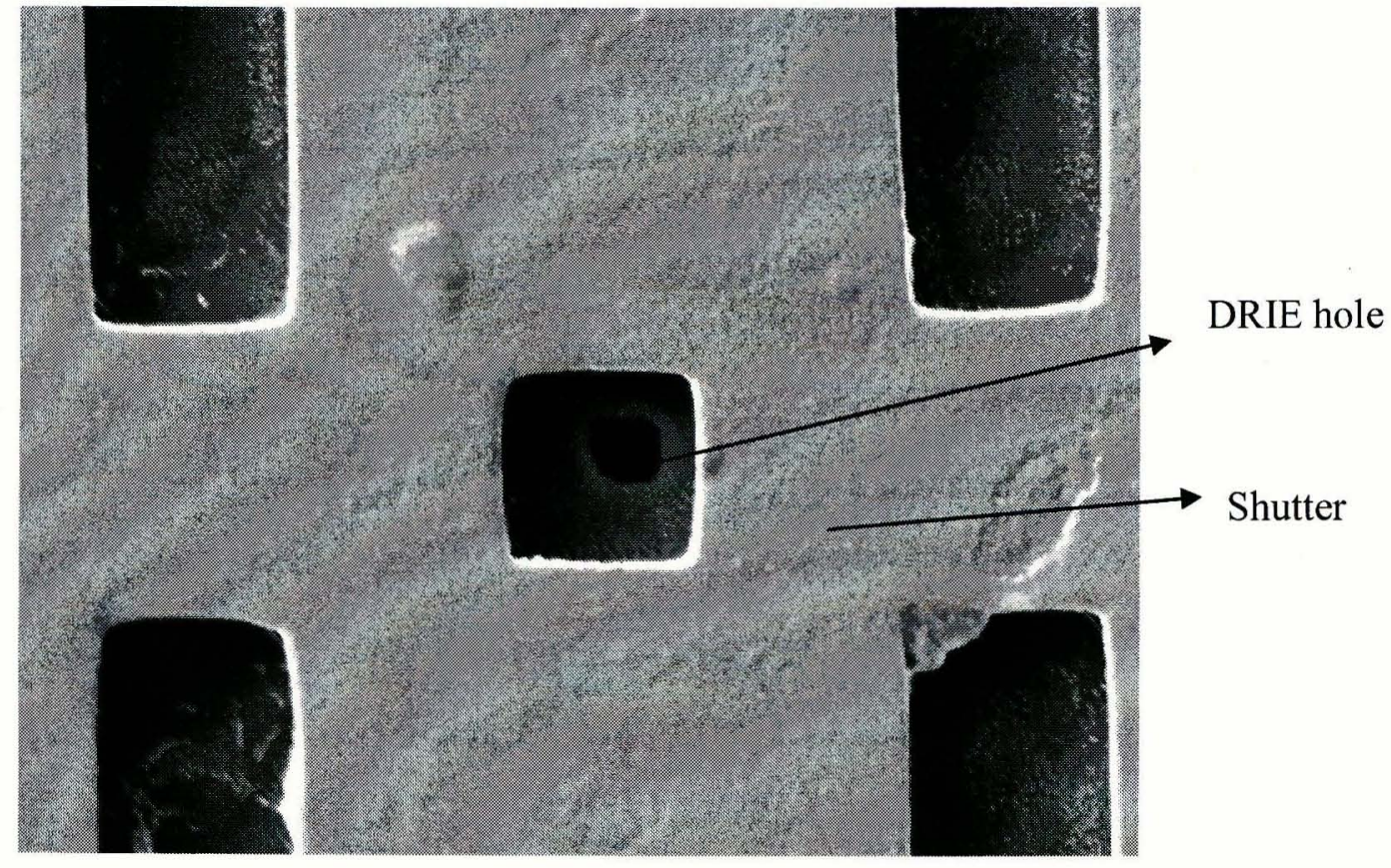

Fig 4.21 SEM picture of the Shutter showing the DRIE hole in the wafer after Etching in Plasma Asher. The shutter is $20 \mu \mathrm{m}$ wide. The DRIE hole did not go through the Substrate. 


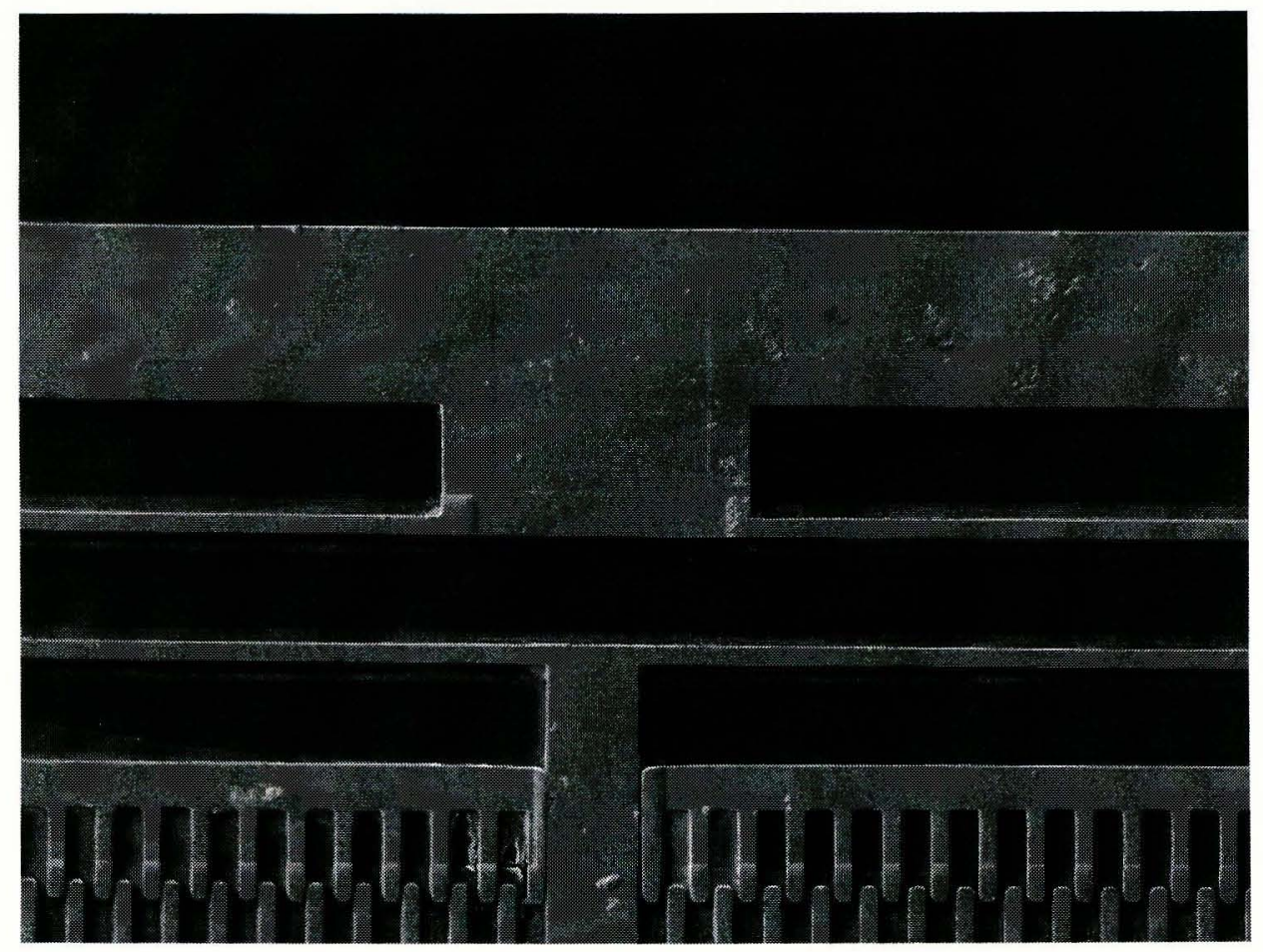

Fig 4.22 SEM picture of the Anchor with Springs after Etching in Plasma Asher.

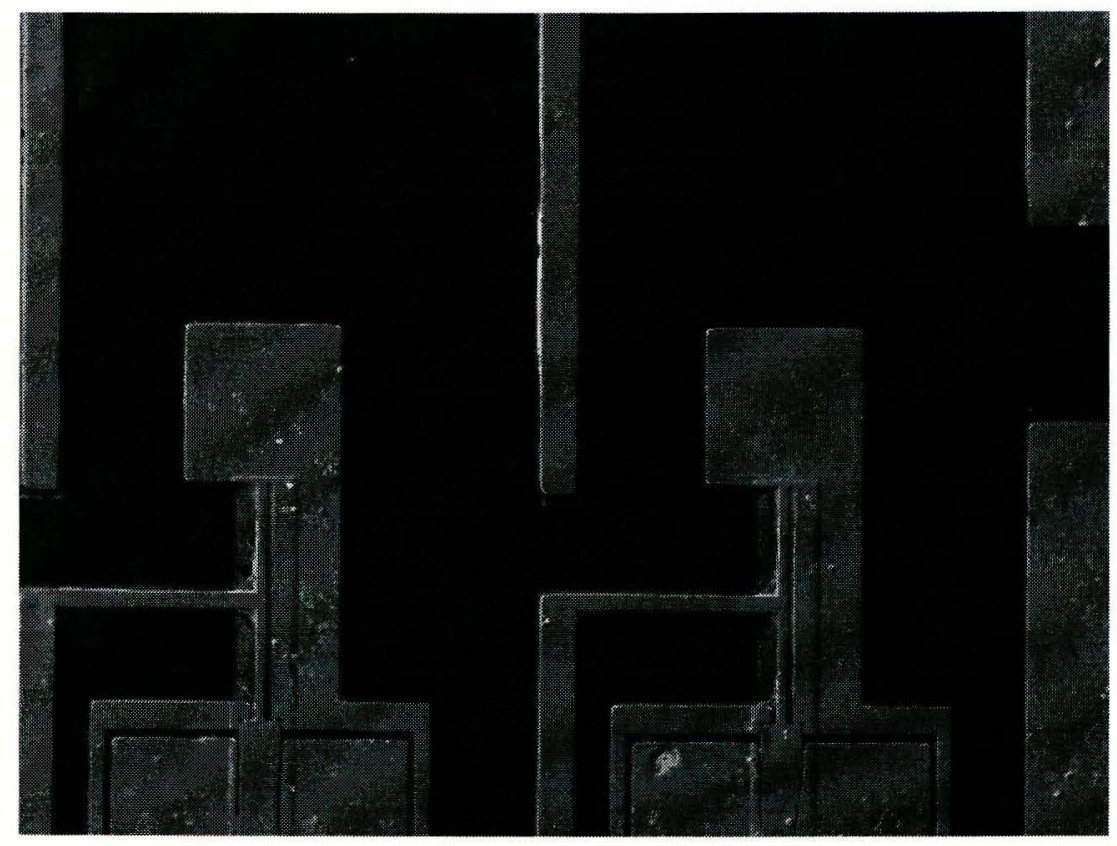

Fig 4.23 SEM picture of the Cantilever Beam Actuator along with the DRIE hole after Etching in Plasma Asher. 


\subsection{Test results for Comb Actuators}

The actuators were tested for short circuit before any voltage was applied. If there was a short circuit the nickel structures would melt when current flowed through it. Thus, each actuator structure was tested for a resistance between the fixed and movable part using a digital multimeter. The movable electrode is the anchor of the spring and there are four points for four electrodes on each quarter of the fixed fingers. Unfortunately, resistances were found in every measurement which showed that during fabrication the nickel structures shorted, which ruled out the further testing.

\subsection{Optical Image of Exposed Apertures}

As a proof of concept, the programmable mask was used to expose photoresist on a silicon wafer. Although the shutter did not work, this demonstrates the principle of operation and thus holds a great future for Direct Write lithography.

a)

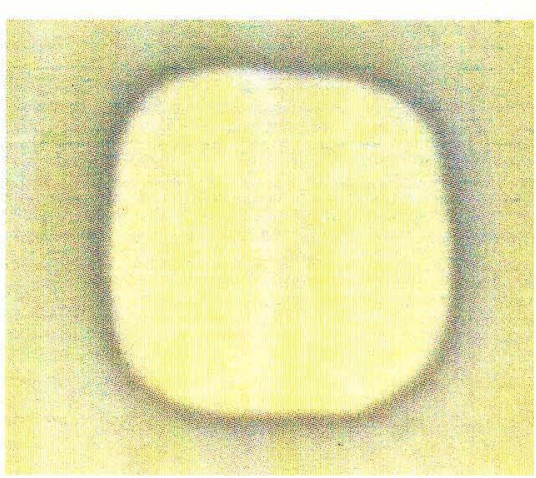

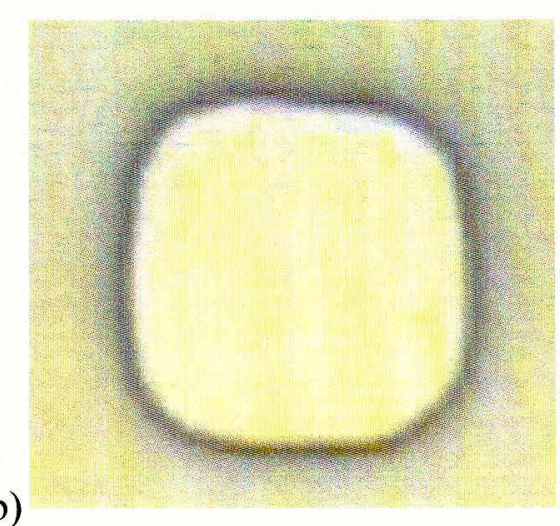

b)

Fig 4.24 Optical Image of Developed Photoresist that was Exposed through the a) $15 \mu \mathrm{m}$ Aperture at 1000x resolution; b) $15 \mu \mathrm{m}$ Aperture at 500x resolution. 


\section{CHAPTER 5}

\section{CONCLUSION AND FUTURE WORK}

In this project a detailed discussion about the theory of electrostatic actuators is presented along with their fabrication processes. The project tried to build a modern system of lithography using a very simple and practical approach. This project makes use of almost all the important microfabrication methods available at the University of Louisville's cleanroom. The design of the project was made in L-Edit using simple mathematical equations. Although MEMCAD simulation was not performed the design should work for the minimum displacement required from the comb actuators. All the individual processes related to fabrication were carried out successfully but at the end the integrated model did not work because the wafer in process got short circuited in the metal layer. A few areas which if considered may significantly improve the yield of the process.

The nickel did not stick to the copper seed layer in some of the places which could be either because of the copper oxide formed during the stop before plating or maybe because the nickel did not survive the copper etch after plating. In a couple of places, the DRIE did not etch through the entire wafer or it did not etch at all and that could be because of the underdevelopment of the double coated SPR220 photoresist. Still even with these shortcomings this process encourages trying and increasing the yield in the future which would yield more dies per wafer and result in a faster speed of actuation 
or shorter exposure time. For this to happen, the dimensions of the actuators would have to decrease while light intensity is increased.

This could be done in a couple of different ways.

(i) Modify the design of combs into cantilever beams with larger displacement. To reduce the imbalance in side electrostatic forces the comb fingers can be bent at a certain angle and also the fingers should be of different lengths to nullify the pull in effect.

(ii) Incorporate optical proximity correction techniques to improve the resolution of the programmable mask - To obtain the finest feature sizes, it is required to use subwavelength patterns on the programmable mask that are not imaged on the wafer, but their interference patterns adjust the imaged feature. With such a technique, the IC industry is now routinely patterning features that are 0.33 times the wavelength of light. The mask pattern to be used on the programmable mask is calculated using Fourier optics.

Using an i-line filter in the Nikon stepper to obtain light with a wavelength of 365 $\mathrm{nm}$, it will be possible to attain $120 \mathrm{~nm}$ feature sizes with this technique, which will be suitable for standard $130 \mathrm{~nm}$ lithography. The $130 \mathrm{~nm}$ lithography node is still used for a lot of IC fabrication, and $130 \mathrm{~nm}$ is suitable for the upper metallization layers on even the most advanced $65 \mathrm{~nm}$ process line. The optical proximity correction techniques will make the direct-write lithography competitive with conventional lithography.

(iii) Integrate micro-lenses to improve the light collection and focusing of the programmable mask - The micro-lenses are essential to improve the throughput of the system, and are the key to making direct-write lithography competitive with conventional photolithography. Without the micro-lens, most of the light striking the programmable 
mask will be lost. With the micro-lens, the collection of light is improved by orders of magnitude, reducing the total exposure time accordingly. High quality micro-lens arrays can be fabricated by bringing a polymer (such as photoresist) near the glass transition temperature and allowing the polymer to reflow.

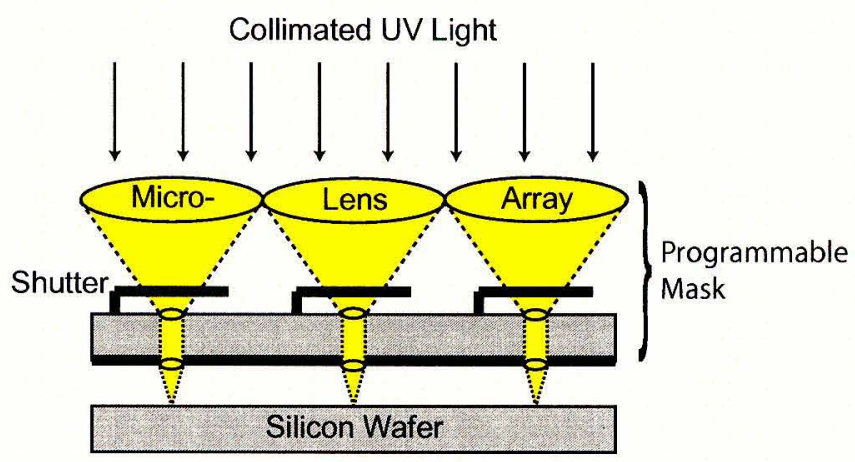

Fig. 5.1: A schematic of a Direct Write Lithographic system using an Array of Optical elements. The Micro-Lens array at the top Collects the light, and the micro-lens array at the bottom Focuses the Light onto the Silicon Wafer.

(iv) Use a different dielectric medium to reduce the dimensions. One upcoming field in this area is the immersion lithography. A metric commonly used to quantify resolution in photolitography is numerical aperture (N.A.).

$$
\mathrm{NA}=\mathrm{n} \sin \theta
$$

where $\mathrm{n}=$ the refractive index of refraction

$\theta=$ the maximum angle of propagation of light, relative to the surface. The numerical aperture has a maximum possible value equal to the refractive index. In an airbased optical system, the numerical aperture has a maximum value of 1.0. If NA increases the resolution enhances without changing the light source. The resolution 


$$
\mathrm{R}=\frac{k \lambda}{N A}
$$

where $\lambda=$ wavelength of light,

$$
\mathrm{K}=\text { lithographic factor. }
$$

The current maximum N.A. is 1.35 for water-based immersion. 


\section{REFERENCES}

[1] Walt Trybula, "Directions in Maskless lithography, 2005", Future Fab Issue 19.

[2] Ken Rygler, “ Photomask Costs: Damming the rising tide”, Future Fab Issue 17.

[3] J. Paufler, H. Kuck, R. Seltman, W. Doleschal, A. Gehner, G. Zimmer, "Highthroughput Optical direct write lithography", June 1997 Solid State Technology.

[4] Mary L. Long, Jeff Newman, "Image Reversal techniques with standard positive photoresists".

[5] H. Guckel, D. Burns, C. Rutigliano, E. Lovell , B. Choi, "Diagnostic microstructures for the measurement of intrinsic strain in thin films", J.Micromech.Microeng. 2 (1992).

[6] Matthew Wasilik, Ning Chen, "Deep Reactive Ion Etch Conditioning Recipe".

[7] M. Agarwal, R. A. Gunasekaran, P. Koane, K. Varahramyan "Polymer-based variable focal length microlens system. J.Micromech.microeng.14 (2004).

[8] In-hyouk Song, Pratul K. Ajmera "Use of a Photoresist Sacrificial layer with SU-8 electroplating mould in MEMS fabrication", J.Micromech.microeng.13 (2003).

[9] Till Kuendiger, G. Michael Howard, Pedram Mokrian, Majid Ahmadi, W. C. Miller, "Design and Analysis of Planar and lattice Electrostatic Comb Drive Actuators". 2005 IEEE.

[10] Emily Carr, Scot Oliver, Olav Solgaard, "Large-stroke Self-Aligned Vertical Comb Drive Actuators for Adaptive Optics Applications", Lawrence Livermore National Laboratory.

[11] L. J. Van Der Pauw, "A Method of Measuring Specific Resistivity And Hall Effect of Discs of Arbitrary Shape", Philips Research Reports, Vol 13 No.1.

[12] Peter Osterberg, Stephen Senturia , "M-TEST: A test Chip for MEMS Material Property Measurement Using Electrostatically Actuated Test Structures", Journal of MEMS Vol 6, No 2, June 1997. 
[13] Kristian Larsen, "Micro Electro Mechanical Devices for Controlling Light", $\mathrm{PhD}$ Thesis.

[14] Kraus, Baltzer, Obermeier, "A Micro Shutter For Applications in Optical and Thermal Detectors", Transducers' 97.

[15] "Fabrication of microshutter Arrays for Space Applications", NASA Goddard Space Flight Center.

[16] Zone plate Array lithography-MIT http://nanoweb.mit.edu/zpal/.

[17] A. S. Basu, S. McNamara, and Y. B. Gianchandani, "Scanning thermal lithography: Maskless, submicron thermochemical patterning of photoresist by ultracompliant probes", J. Vac. Scie. Technol. B 22(6), pg. 3217 (2004).

[18] G. Kovacs, "Micromachined Transducers Sourcebook" McGrawHill.

[19] Peter Van Zant, “ Microchip Fabrication- Third Edition-A Practical Guide to semiconductor Processing", McGrawHill.

[20] Stephen A. Campbell, "The Science and Engineering of Microelectronic Fabrication- $2^{\text {nd }}$ Edition", Oxford.

[21] Sheats \& Smith, "Microlithography", Dekker.

[22] Marc Madou, "Fundamentals of Microfabrication", CRC.

[23] Yogesh Gianchandani, Khalil Najafi, "Bent Beam Strain Sensors", JMEMS March 1996.

[24] Saleh and Teich, "Fundamentals of Photonics", Wiley series in Pure and Applied Optics.

[25] http://www.ee.byu.edu/cleanroom/contact_resistance.phtml. 


\section{APPENDIX A}

FABRICATION OUTLINE

\begin{tabular}{|c|c|c|c|c|}
\hline Step & Name & $\begin{array}{l}\text { Equipment/ } \\
\text { Chemicals used }\end{array}$ & Parameters & Notes \\
\hline 1 & RCA Clean & Wet Bench & & \\
\hline la & & & $\begin{array}{l}\mathrm{NH}_{4} \mathrm{OH}: \mathrm{H}_{2} \mathrm{O}_{2}: \mathrm{H}_{2} 01: 5: 5 \\
80 \mathrm{C}, 10 \mathrm{~min} \text {, Rinse } 5 \mathrm{~min}\end{array}$ & $\begin{array}{l}\mathrm{H}_{2} \mathrm{O}_{2} \text { is } 30 \% \\
\mathrm{CMOS} \text { electronic } \\
\text { grade. }\end{array}$ \\
\hline $1 b$ & & & $\begin{array}{l}\mathrm{HF}: \mathrm{H}_{2} \mathrm{O} \quad 100: 1 \\
30 \text { seconds } \\
\text { Rinse } 5 \mathrm{~min}\end{array}$ & \\
\hline $1 \mathrm{c}$ & & & $\begin{array}{l}\mathrm{HCl}: \mathrm{H}_{2} \mathrm{O}_{2}: \mathrm{H}_{2} \mathrm{O} \quad 1: 5: 5 \\
80 \mathrm{C}, 10 \mathrm{~min}, \text { Rinse } 5 \mathrm{~min}\end{array}$ & \\
\hline $2 a$ & Doping & Diffusion furnace & $\begin{array}{l}15 \text { minutes, } 925 \mathrm{C}, \\
\mathrm{N}_{2} 1 \mathrm{~L} / \mathrm{min}, \mathrm{O}_{2} 0.05 \mathrm{~L} / \mathrm{min}\end{array}$ & 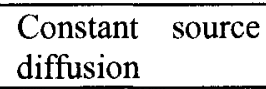 \\
\hline $2 b$ & $\mathrm{BOE}$ & $\begin{array}{l}\text { Wet Bench, } 6: 1 \\
\mathrm{NH}_{4} \mathrm{~F}: \mathrm{HF}\end{array}$ & lminute & \\
\hline $2 c$ & Doping & Diffusion Furnace & $\begin{array}{l}1000 \mathrm{C} \text { in } 1.0 \mathrm{~L} / \text { minute of } \\
\text { nitrogen for } 30 \text { minutes } \\
\text { and then } 1.0 \mathrm{~L} / \text { minute of } \\
\text { oxygen for another } 30 \\
\text { minutes }\end{array}$ & $\begin{array}{l}\text { Drive } \\
\text { diffusion }\end{array}$ \\
\hline 3 & $\begin{array}{l}\text { Oxidation } \\
\text { (wet) }\end{array}$ & Oxidation furnace & $\begin{array}{l}1050 \mathrm{C} \text { for } 45 \text { minutes, } \mathrm{O}_{2} \\
\text { and } \mathrm{N}_{2} \text { flow rate }= \\
1.0 \mathrm{~L} / \mathrm{min}, \text { ramp rate } \\
=20 \mathrm{C} / \mathrm{min}, \\
\text { temperature } 95 \mathrm{C}\end{array}$ & $\begin{array}{l}\text { Thickness of } \\
\text { around } 5000 \mathrm{~A}\end{array}$ \\
\hline 4 & Photolithography & & & \\
\hline $4 a$ & Apply HMDS & $\begin{array}{l}\text { Solitec } 5100 \text { Spinner, } \\
\text {, S1813 }\end{array}$ & $\begin{array}{l}\text { Spread } 500 \mathrm{rpm} \text { for } 2 \mathrm{sec}, \\
\text { spin } 4000 \mathrm{rpm} \text { for } 10 \mathrm{sec}\end{array}$ & \\
\hline $4 b$ & Resist spin & $\begin{array}{l}\text { Solitec } 5100 \text { Spinner, } \\
\text {, S1813 }\end{array}$ & $\begin{array}{l}\text { Spread } 500 \mathrm{rpm} \text { for } 2 \mathrm{sec}, \\
\text { spin } 4000 \mathrm{rpm} \text { for } 10 \mathrm{sec}\end{array}$ & \\
\hline $4 \mathrm{c}$ & Soft bake & Hot plate & $75 \mathrm{sec} @ 90 \mathrm{C}$ & \\
\hline $4 d$ & Exposure & $\begin{array}{ll}\text { KarlSuss } & \text { MA6, } \\
\text { Contact mask } & \\
\end{array}$ & $15.5 \mathrm{sec}(7 \mathrm{~mW} / \mathrm{cm} 2)$ & \\
\hline $4 \mathrm{e}$ & Development & MF 319 & $45 \mathrm{sec}$ & \\
\hline $4 \mathrm{f}$ & Hard bake & Hot plate & $90 \sec @ 115 \mathrm{C}$ & \\
\hline $4 \mathrm{~g}$ & Resist spin & Solitec 5100 Spinner & Spread $500 \mathrm{rpm}$ for $2 \mathrm{sec}$, & On the backside \\
\hline
\end{tabular}




\begin{tabular}{|c|c|c|c|c|}
\hline & & & spin $4000 \mathrm{rpm}$ for $10 \mathrm{sec}$ & of the wafer. \\
\hline $4 \mathrm{~g}$ & Soft bake & Hot plate & $75 \sec @ 90 \mathrm{C}$ & \\
\hline 5 & $\mathrm{BOE}$ & $\begin{array}{ll}\text { Wet Bench, } & 6: 1 \\
\mathrm{NH}_{4} \mathrm{~F}: \mathrm{HF} & \end{array}$ & $7 \mathrm{~min}$ & $\begin{array}{l}\text { Silicon is shiny } \\
\text { while oxide is } \\
\text { dull }\end{array}$ \\
\hline 6 & Resist Strip & Acetone & & \\
\hline 7 & Al deposition & $\begin{array}{l}\text { Technics } \\
\text { sputterer } \\
\text { Target (Al } 98.5 \%, \mathrm{Si} \\
1.0 \% \text { and cu } 0.5 \% \text { ) }\end{array}$ & $\begin{array}{l}20 \text { min at } 200 \text { Watts in } \\
\text { static mode in an argon } \\
\text { atmosphere of } 20 \text { mtorr in } \\
\text { DC side }\end{array}$ & 0.7 um thick film \\
\hline 8 & Annealing & Trash Furnace & $\begin{array}{l}480 \mathrm{C} \text { for } 30 \text { minutes, } 10 \% \\
\text { sccm of argon gas }\end{array}$ & \\
\hline $9 \mathrm{a}$ & Resist spin & Solitec 5100 Spinner & $\begin{array}{l}\text { Spread } 500 \mathrm{rpm} \text { for } 2 \mathrm{sec}, \\
\text { spin } 4000 \mathrm{rpm} \text { for } 10 \mathrm{sec}\end{array}$ & \\
\hline $9 b$ & Soft bake & Hot plate & $75 \mathrm{sec} @ 90 \mathrm{C}$ & \\
\hline $9 c$ & Exposure & $\begin{array}{ll}\text { KarlSuss } & \text { MA6, } \\
\text { Contact mask }\end{array}$ & $15.5 \mathrm{sec}(7 \mathrm{~mW} / \mathrm{cm} 2)$ & \\
\hline $9 d$ & Image Reversal & Yes oven, Ammonia & $\begin{array}{l}\text { Front zone } 90 \mathrm{C}, \text { Rear zone } \\
90 \mathrm{C}, \mathrm{Sp} 1600 \text { torr, Sp2 } \\
100 \text { torr, Sp3 } 1 \text { torr, Sp4 } \\
500 \text { torr } \\
\text { \# dehydration cycles } 3 \\
\text { \# exit cycle } 5 \\
\text { IR warm up delay } 10 \\
\text { Process Duration } 2700 \mathrm{sec}\end{array}$ & \\
\hline $9 \mathrm{e}$ & Flood Exposure & KarlSuss MA6 & $36 \mathrm{sec}$ & \\
\hline $9 f$ & Development & MF 319 & $2.5 \mathrm{~min}$ & \\
\hline 10 & $\mathrm{Al}$ etch & $\begin{array}{l}\mathrm{H}_{3} \mathrm{PO}_{4} \quad 80 \% \text { wt, } \\
\mathrm{CH}_{3} \mathrm{COOH} \quad 15 \% \text { wt, } \\
\mathrm{NHO}_{3} 3 \% \text { wt, } \mathrm{H}_{2} \mathrm{O} \\
2 \% \text { wt }\end{array}$ & $40 \mathrm{C}$ & \\
\hline 11 & Strip resist & Acetone & & \\
\hline 12 & Cr deposition & $\begin{array}{ll}\text { Technics } & 4604 \\
\text { sputterer } & \\
\text { Target }(\mathrm{Cr}) & \end{array}$ & $\begin{array}{l}5 \text { min at } 150 \text { Watts in } \\
\text { static mode in an argon } \\
\text { atmosphere of } 20 \text { mtorr in } \\
\text { DC side }\end{array}$ & $\begin{array}{l}275 \mathrm{~nm} \text { thick } \\
\text { film on the back } \\
\text { side of the wafer. }\end{array}$ \\
\hline $13 a$ & Resist spin & $\begin{array}{l}\text { Solitec } 5100 \text { Spinner, } \\
\text { S1827 }\end{array}$ & $\begin{array}{l}\text { Spread } 500 \mathrm{rpm} \text { for } 2 \mathrm{sec}, \\
\text { spin } 4000 \mathrm{rpm} \text { for } 10 \mathrm{sec}\end{array}$ & \\
\hline $13 b$ & Soft bake & Hot plate & $75 \mathrm{sec} @ 90 \mathrm{C}$ & \\
\hline $13 \mathrm{c}$ & Exposure & $\begin{array}{l}\text { KarlSuss MA6, } \\
\text { sacrificial mask }\end{array}$ & $15.5 \mathrm{sec}(7 \mathrm{~mW} / \mathrm{cm} 2)$ & \\
\hline $13 \mathrm{~d}$ & Development & MF 319 & $45 \mathrm{sec}$ & \\
\hline $13 \mathrm{e}$ & Hard bake & Hot plate & 1hour@115C & \\
\hline 14 & $\mathrm{Ti} / \mathrm{Cu} / \mathrm{Ti}$ deposition & $\begin{array}{ll}\text { Technics } & 4604 \\
\text { sputterer } & \\
\text { Target }(\mathrm{Ti}, \mathrm{Cu}) & \end{array}$ & $\begin{array}{l}\text { TI: } 5 \text { min at } 315 \text { Watts in } \\
\text { static mode in an argon } \\
\text { atmosphere of } 20 \text { mtorr in } \\
\mathrm{RF} \text { side } \\
\mathrm{Cu}: 5 \text { min at } 120 \text { Watts in } \\
\text { static mode in an argon } \\
\text { atmosphere of } 20 \text { mtorr in } \\
\mathrm{DC} \text { side for } \mathrm{Cu} \text {. }\end{array}$ & 0.7 um thick film \\
\hline $15 \mathrm{a}$ & Resist spin & $\begin{array}{l}\text { Solitec } 5100 \text { Spinner, } \\
\text { HMDS, AZP4903 }\end{array}$ & $\begin{array}{l}\text { Spread } 100 \mathrm{rpm} \text { for } 8 \mathrm{sec} \text {, } \\
\text { spin } 1000 \mathrm{rpm} \text { for } 25 \mathrm{sec}\end{array}$ & $\begin{array}{l}\text { Same parameters } \\
\text { for HMDS }\end{array}$ \\
\hline $15 b$ & $\begin{array}{ll}\text { Edge } & \text { Bead } \\
\text { Remover } & \end{array}$ & Solitec 5100 Spinner & Spin speed $2000 \mathrm{rpm}$ & \\
\hline
\end{tabular}




\begin{tabular}{|c|c|c|c|c|}
\hline $15 \mathrm{c}$ & Soft bake & Hot plate & $\begin{array}{l}3 \min @ 60 \mathrm{C} \\
3 \min @ 90 \mathrm{C} \\
3 \min @ 110 \mathrm{C}\end{array}$ & \\
\hline $15 \mathrm{~d}$ & Exposure & $\begin{array}{l}\text { KarlSuss MA6, metal } \\
\text { mask }\end{array}$ & $450 \mathrm{sec}(7 \mathrm{~mW} / \mathrm{cm} 2)$ & \\
\hline $15 \mathrm{e}$ & Development & $\begin{array}{l}\text { AZ400K } \\
\text { AZ400K:water })\end{array}$ & $4 \mathrm{~min}$ & $\begin{array}{ll}\text { Resist } & \text { doesn't } \\
\text { have a smooth } \\
\text { surface }\end{array}$ \\
\hline 16 & Dry etch & March RIE & $\begin{array}{l}\mathrm{O}_{2} \text { flow }=20 \% \mathrm{sccm}, \\
\text { pressure of } 200 \mathrm{mtorr} \text {, and } \\
\text { power of } 200 \text { watts for one } \\
\text { minute }\end{array}$ & $\begin{array}{l}\text { Etch till Ti layer } \\
\text { is seen clearly. }\end{array}$ \\
\hline 17 & Ti Etch & Wet bench & 1:40 (HF:water) & $\begin{array}{l}\text { Etch till copper is } \\
\text { visible }\end{array}$ \\
\hline 18 & Strip copper oxide & & $5 \% \mathrm{H}_{2} \mathrm{SO}_{4}$ for $30 \mathrm{sec}$ & \\
\hline 19 & Electroplate & $\begin{array}{l}\text { Electroplating Bath : } \\
\text { Technic nickel } \\
\text { sulfamate solution, } \\
\text { Nickel carbonate, } \\
\text { sulfamic acid, PH } \\
\text { meter, Thermometer, } \\
\text { magnetic stirrer. } \\
\end{array}$ & $\begin{array}{l}\text { PH } 4.0,100 F, 533 \mathrm{~mA} \text { for } \\
45 \mathrm{~min}\end{array}$ & $\begin{array}{l}15 \text { um nickel } \\
\text { layer plated }\end{array}$ \\
\hline 20 & Strip resist & Acetone & $\begin{array}{l}\text { Slowly spread the wafer } \\
\text { while spraying acetone }\end{array}$ & $\begin{array}{l}\text { Gently rinse and } \\
\text { dry without } \\
\text { damaging the } \\
\text { nickel structures. }\end{array}$ \\
\hline 21 & $\mathrm{Cu}$ Etch & Wet Bench & $\begin{array}{l}\mathrm{Cu} \operatorname{dip}(7 \mathrm{gm} \text { of sodium } \\
\text { perchlorate in } 100 \mathrm{gm} \text { of } \\
\text { DI water) }\end{array}$ & $\begin{array}{l}\text { Etch till titanium } \\
\text { is seen }\end{array}$ \\
\hline 22 & Ti Etch & Wet bench & 1:40 (HF:water) & $\begin{array}{l}\text { Etch till } \\
\text { sacrificial layer is } \\
\text { visible }\end{array}$ \\
\hline 23 & Resist spin & $\begin{array}{l}\text { Solitec } 5100 \text { Spinner, } \\
\text { HMDS, SPR } 220\end{array}$ & $\begin{array}{l}\text { Spread } 500 \mathrm{rpm} \text { for } 2 \mathrm{sec}, \\
\text { spin } 4000 \mathrm{rpm} \text { for } 20 \mathrm{sec}\end{array}$ & $\begin{array}{l}\text { Same parameters } \\
\text { for HMDS, coat } \\
\text { the resist twice. }\end{array}$ \\
\hline 24 & Soft bake & Hot plate & $75 \sec @ 90 \mathrm{C}$ & \\
\hline 25 & Exposure & $\begin{array}{l}\text { KarlSuss MA6, DRIE } \\
\text { mask }\end{array}$ & $84 \sec (7 \mathrm{~mW} / \mathrm{cm} 2)$ & \\
\hline 26 & Post exposure bake & Hot Plate & $50 \mathrm{C}$ for $30 \mathrm{sec}$ & \\
\hline 27 & Development & MF 319 & $1 \mathrm{~min}$ & $\begin{array}{ll}\text { Make sure the } \\
\text { apertures } & \text { are } \\
\text { clear off the } \\
\text { resist. }\end{array}$ \\
\hline 28 & Hard bake & Hot plate & $90 \mathrm{sec} @ 115 \mathrm{C}$ & \\
\hline 29 & Dry etch & March RIE & $\begin{array}{l}\mathrm{O}_{2} \text { flow }=20 \% \text { sccm, } \\
\text { pressure of } 200 \text { mtorr, and } \\
\text { power of } 200 \text { watts for one } \\
\text { minute }\end{array}$ & \\
\hline 30 & Handle wafer & Glue, Hot Plate & & \\
\hline 31 & DRIE & STS DRIE & See DRIE Appendix & \\
\hline 32 & $\begin{array}{l}\text { Etch } \\
\text { layer }\end{array}$ & Plasma Asher & $\begin{array}{l}\text { Forward Power }=50 \text { Watts } \\
\text { Pressure }=0.5 \text { torr Time }= \\
\text { approximately } 8 \text { hours }\end{array}$ & \\
\hline
\end{tabular}




\section{APPENDIX B}

\section{DRIE RECIPE}

\begin{tabular}{|c|c|c|c|c|c|}
\hline Step & Time & $\begin{array}{l}\text { Etch/Pas } \\
\text { sivate }\end{array}$ & Power & Flow & Other parameters \\
\hline $\begin{array}{l}\text { O2 } \\
\text { Plasm } \\
\text { a } \\
\text { Clean }\end{array}$ & $10 \mathrm{sec}$ & & & & $\begin{array}{l}\text { Pump down } 20 \mathrm{sec} \\
\text { Gas Stabilization } 10 \mathrm{sec}\end{array}$ \\
\hline $\begin{array}{l}100 \\
\text { micro } \\
n\end{array}$ & $\begin{array}{l}1 \mathrm{hr} 29 \\
\min \end{array}$ & $9.5 / 7 \mathrm{sec}$ & $\begin{array}{l}\text { Coil : } \\
550 \mathrm{~W}(\text { Etch) } / 500 \\
\text { W(passivate) } \\
50 \% \text { tolerance } \\
\text { Platen : } 17 \\
\text { W(Etch) } / 0 \\
\text { (passivate) } \\
95 \% \text { tolerance }\end{array}$ & $\begin{array}{l}\mathrm{C}_{4} \mathrm{~F}_{8} 75 \\
\mathrm{sccm} \\
\mathrm{SF}_{6} 160 \\
\mathrm{sccm} \\
\mathrm{O}_{2} 13 \\
\mathrm{sccm}\end{array}$ & $\begin{array}{l}\text { Overrun } 1 / 1 \\
\text { Base pressure } 0.2 \text { mtorr } \\
\text { Pressure tip } 94 \text { mtorr } \\
\text { Position } 82 \% \\
\text { Helium: } \\
\text { Pressure } 9.8 \text { torr } \\
25 \% \text { tolerance } \\
\text { Max } 40 \\
\text { Min } 10\end{array}$ \\
\hline $\begin{array}{l}100 \\
\text { micro } \\
\text { n } 2\end{array}$ & $\begin{array}{l}1 \mathrm{hr} 15 \\
\min 10 \\
\mathrm{sec}\end{array}$ & $9.5 / 6 \mathrm{sec}$ & $\begin{array}{l}\text { Coil : } \\
550 \mathrm{~W}(\text { Etch) } / 500 \\
\text { W(passivate) } \\
50 \% \text { tolerance } \\
\text { Platen : } 17 \\
\text { W(Etch) } / 0 \\
\text { (passivate) } \\
95 \% \text { tolerance }\end{array}$ & $\begin{array}{l}\mathrm{C}_{4} \mathrm{~F}_{8} 75 \\
\mathrm{sccm} \\
\mathrm{SF}_{6} 160 \\
\mathrm{sccm} \\
\mathrm{O}_{2} 13 \\
\mathrm{sccm}\end{array}$ & $\begin{array}{l}\text { Overrun } 1 / 1 \\
\text { Base pressure } 0.2 \text { mtorr } \\
\text { Pressure tip } 94 \text { mtorr } \\
\text { Position } 82 \%\end{array}$ \\
\hline $\begin{array}{l}+100 \\
\text { micro } \\
\text { n } 2\end{array}$ & $\begin{array}{l}59 \mathrm{~min} \\
56 \mathrm{sec}\end{array}$ & $9.5 / 6 \mathrm{sec}$ & $\begin{array}{l}\text { Coil : } \\
550 \mathrm{~W}(\text { Etch }) / 500 \\
\text { W(passivate) } \\
50 \% \text { tolerance } \\
\text { Platen : } 19 \\
\text { W(Etch) } / 0 \\
\text { (passivate) }\end{array}$ & $\begin{array}{l}\mathrm{C}_{4} \mathrm{~F}_{8} 75 \\
\mathrm{sccm} \\
\mathrm{SF}_{6} 160 \\
\mathrm{sccm} \\
\mathrm{O}_{2} 13 \\
\mathrm{sccm}\end{array}$ & $\begin{array}{l}\text { Overrun } 1 / 1 \\
\text { Base pressure } 0.2 \text { mtorr } \\
\text { Pressure tip } 94 \text { mtorr } \\
\text { Position } 82 \%\end{array}$ \\
\hline
\end{tabular}




\section{APPENDIX C}

\section{L-EDIT DESIGN FOR EACH MASKING LAYER}

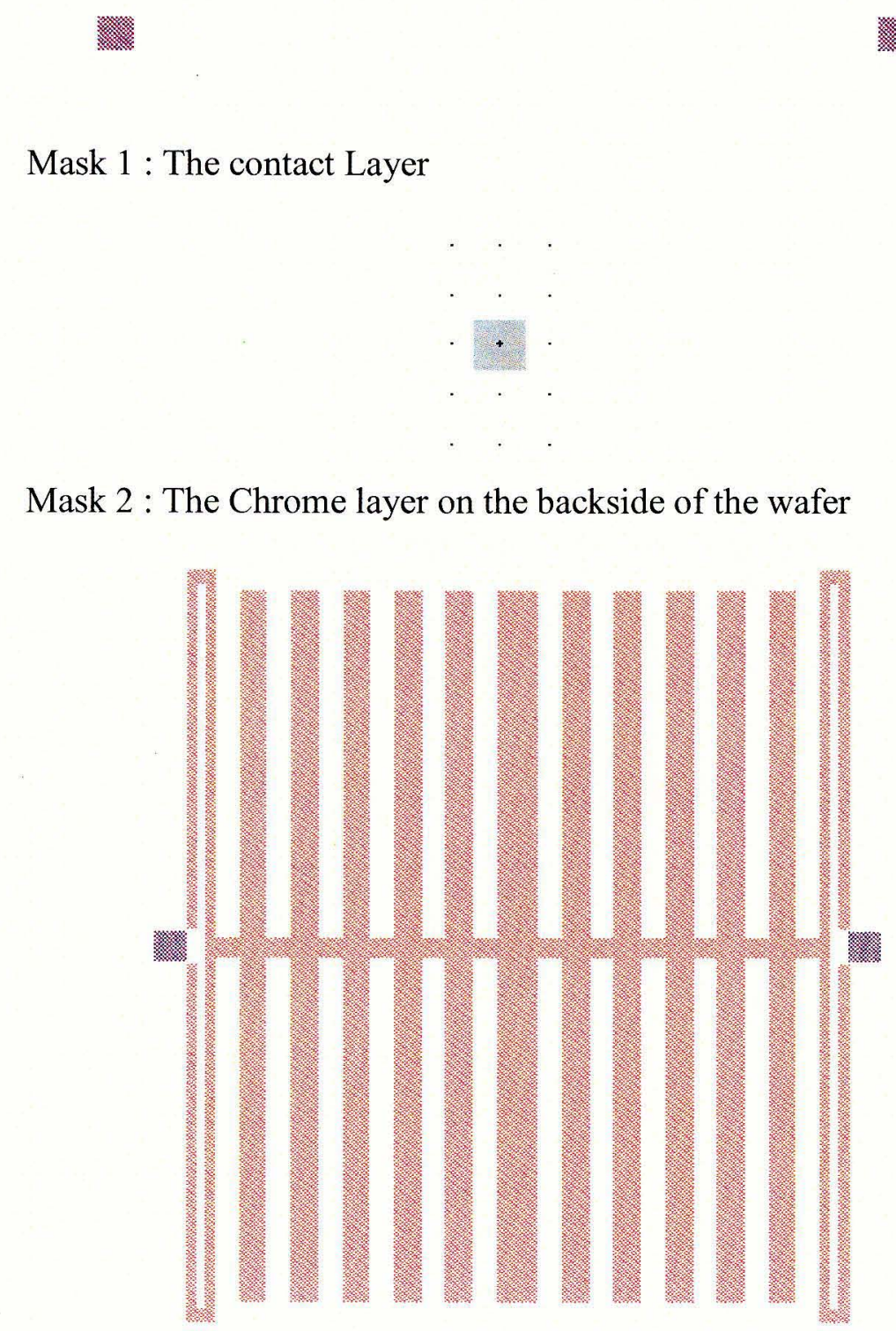

Mask 1 \& 3 : The sacrificial layer over the contact layer 


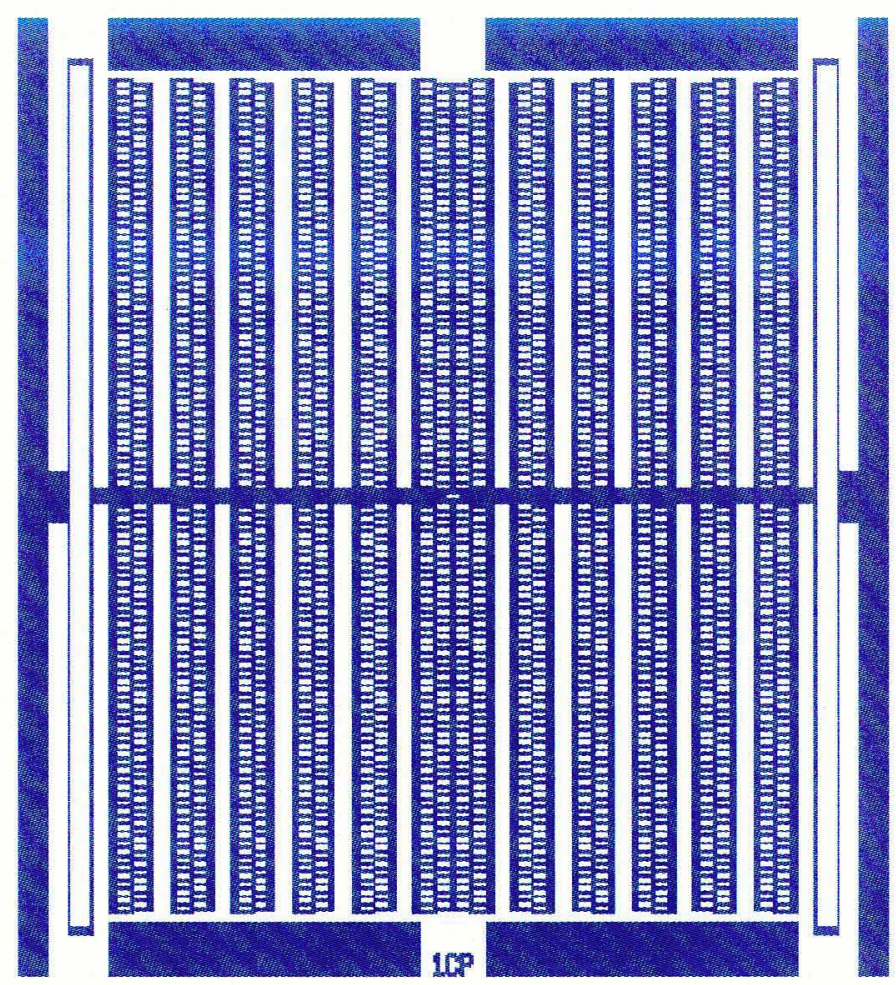

Mask 4 : The Metal mask

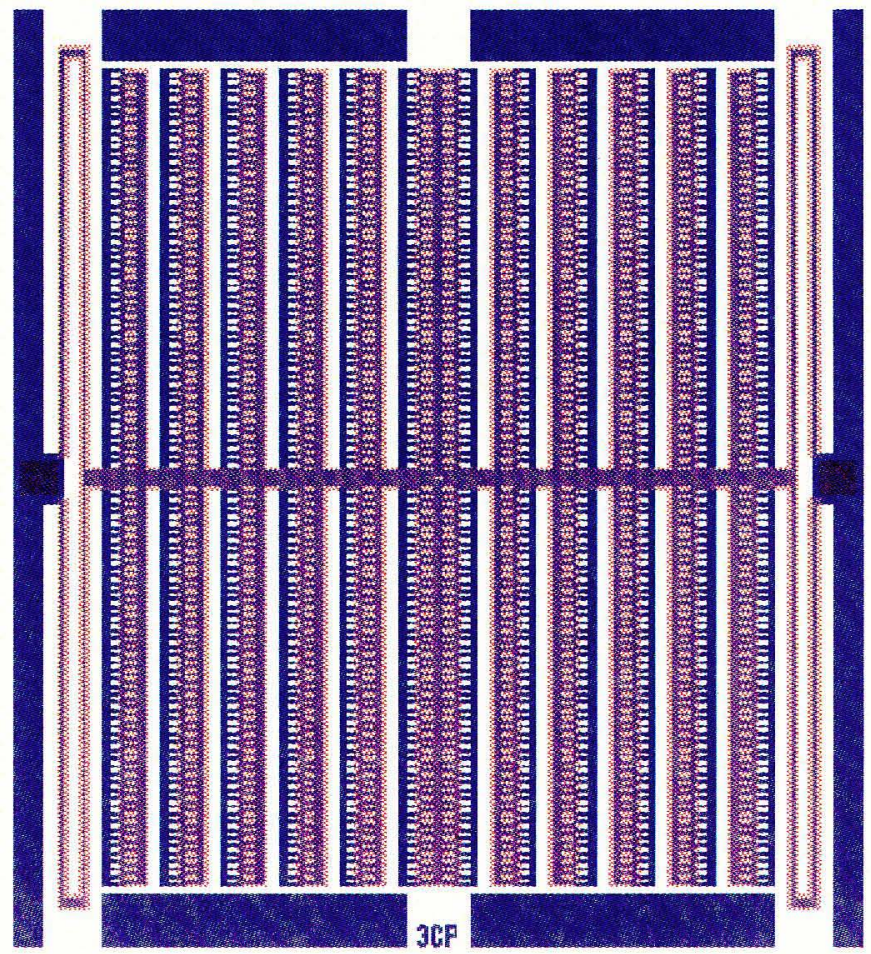

Mask 1,3 \& 4 : The metal layer over the sacrificial layer 


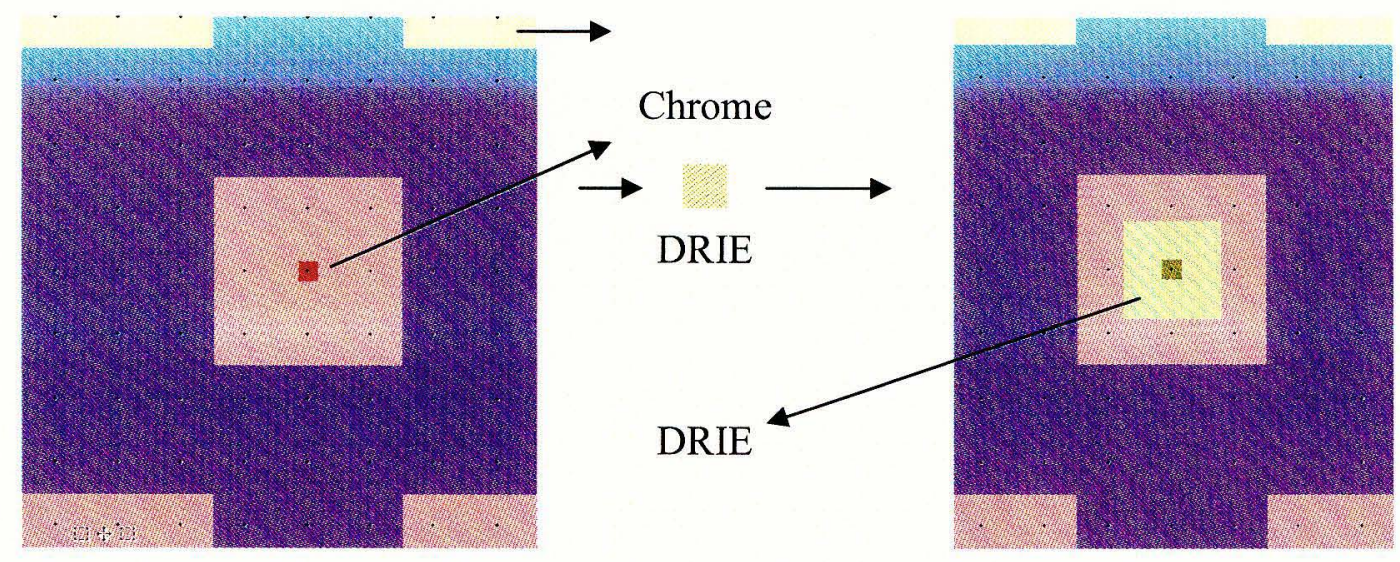

a)

b)

c)

The figures depict the shutter view before and after adding the DRIE mask

a) Without the DRIE mask

b) The DRIE mask

c) After the DRIE mask

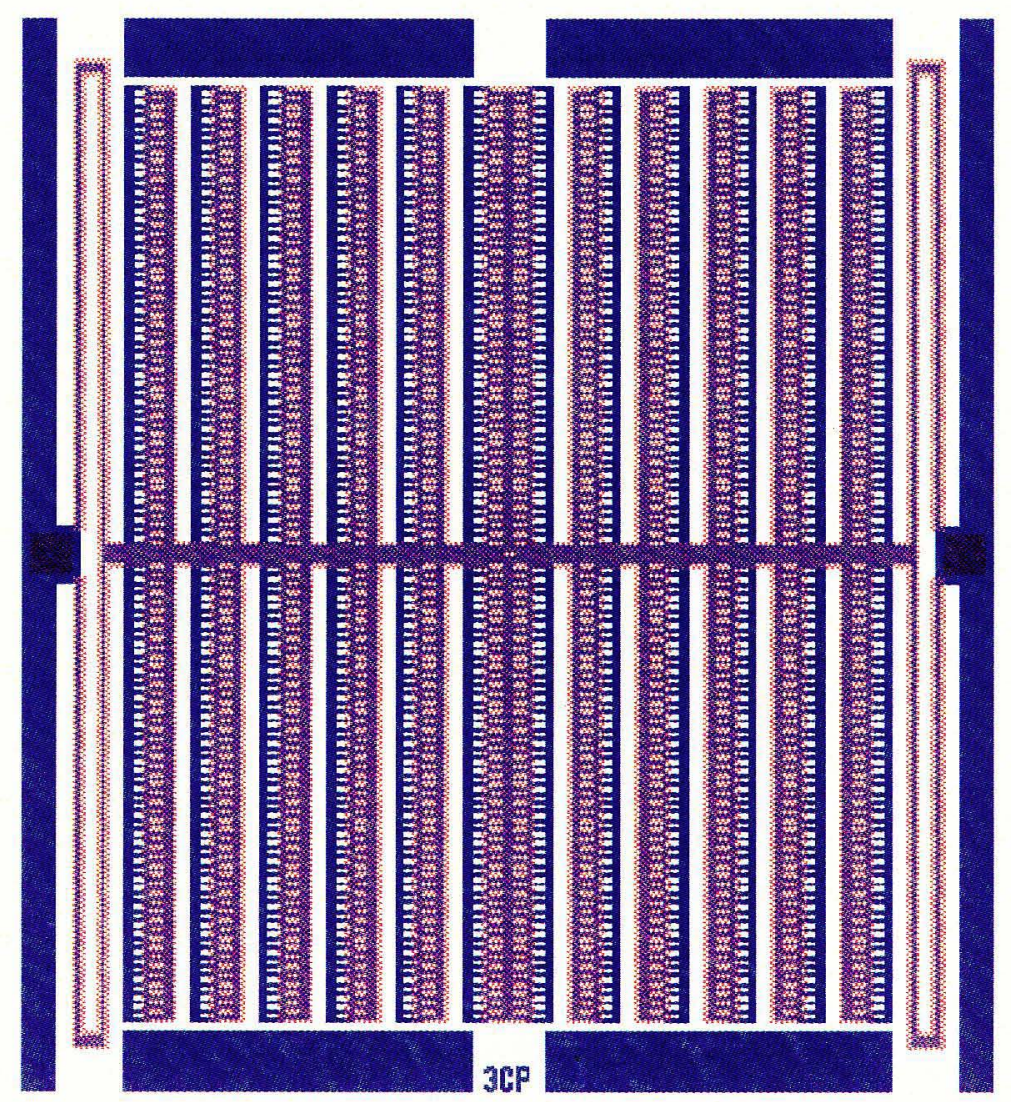

The final design after the five mask process 


\section{CURRICULUM VITAE}

Date of Birth : August 5, 1979

Place of Birth: Kolkata, India.

\section{Education}

High School - Graduated in 1998 from K.V. Khamaria with 84\% marks.

B.E (Bachelor of Engineering) in Electrical Engineering from Engineering College

Bilaspur, India with First Division

August 1998-July 2002.

MS in Electrical Engineering from University of Louisville, Kentucky with

GPA 3.454/4.000 August 2004-December 2006.

\section{WORK EXPERIENCE}

- Research assistant at MEMS Lab in University of Louisville Cleanroom, (Aug 05 - Till Date).

i) Photolithography of 1 micron features, characterizing photoresist AZP4903, electroplating nickel, deep reactive ion etching with aspect ratio of $20: 1$, oxidation, doping of silicon wafers.

ii) Designed masks in L-EDIT.

iii)Developed the process flow for microactuated shutters.

- Teaching Assistant for Undergraduate Electronic Circuits Design Laboratory,

Fall 2006.

- Graduate Assistant -REACH - University of Louisville August 2005-May 2006

Conduct Tutoring Classes, supervise tutors and maintain the database software, organize seminars.

- Teaching Assistant -Dept of Chemistry -University of Louisville

Fall 2004 